ROBERTO NICOLAS DE JARDIN JÚNIOR

\title{
MODELAGEM MATEMÁTICA DE UM PROCESSO INDUSTRIAL DE PRODUÇÃO DE CLORO E SODA POR ELETRÓLISE DE SALMOURA VISANDO SUA OTIMIZAÇÃO
}

Dissertação apresentada à Escola Politécnica da Universidade de São Paulo para obtenção do título de Mestre em Engenharia

São Paulo 2006 


\title{
ROBERTO NICOLAS DE JARDIN JÚNIOR
}

\section{MODELAGEM MATEMÁTICA DE UM PROCESSO INDUSTRIAL DE PRODUÇÃO DE CLORO E SODA POR ELETRÓLISE DE SALMOURA VISANDO SUA OTIMIZAÇÃO}

\author{
Dissertação apresentada à Escola \\ Politécnica da Universidade de São \\ Paulo para obtenção do título de Mestre \\ em Engenharia \\ Área de Concentração: \\ Engenharia Química \\ Orientador: \\ Prof. Dr. Roberto Guardani
}

São Paulo 2006 
Este exemplar foi revisado e alterado em relação à versão original, sob responsabilidade única do autor e com a anuência de seu orientador.

São Paulo, 05 de outubro de 2006.

Assinatura do autor

Assinatura do orientador

De Jardin Junior, Roberto Nicolas

Modelagem matemática de um processo industrial de produção de cloro e soda por eletrólise de salmoura visando sua otimização. São Paulo, 2006.

Dissertação de Mestrado - Escola Politécnica da Universidade de São Paulo. Departamento de Engenharia Química.

1.Redes neurais 2.Modelagem e simulação de processo 3.Otimização de processo I. Universidade de São Paulo. Escola Politécnica. Departamento de Engenharia Química. II. t. 
A Deus pela vida.

A meus pais Roberto Nicolas (em memória) e Maria Célia pelo esforço e dedicação voltados a minha formação.

A minha esposa Mônica e minha filha Stephanie pelo amor e felicidade encontrados dentro do meu lar. 


\section{AGRADECIMENTOS}

Ao Prof. Dr. Roberto Guardani pelo apoio, incentivo e orientação sempre presentes que através de idéias, discussões e diretrizes possibilitou a realização deste trabalho.

À Carbocloro S.A. Indústrias Químicas, empresa em que trabalho, pela oportunidade e suporte dados, disponibilizando tempo e informações sem as quais este trabalho não seria possível.

Aos meus amigos de trabalho Airton, Eliezer, Hilton, Marcílio, Priscila e Tanja pela colaboração e contribuição realizadas neste trabalho, além dos que indiretamente me apoiaram em outras atividades o que permitiu que eu me dedicasse a este estudo. Nesse sentido agradeço à Ana Maria, ao Apolinário e à Sonia.

Ao Departamento de Engenharia Química da Escola Politécnica da Universidade de São Paulo em disponibilizar conhecimento científico o qual tornou possível a realização deste trabalho. 


\section{SUMÁRIO}

RESUMO

ABSTRACTS

LISTA DE FIGURAS

LISTA DE TABELAS

NOMENCLATURA

1. INTRODUÇÃO

2. DESCRIÇÃO DO PROCESSO 4

3. FUNDAMENTOS DO PROCESSO 6

3.1. Eletrólise

3.1.1. Eficiência de corrente 6

3.1.2. Diafragma da célula 11

3.1.3. Efeito da densidade de corrente 12

3.1.4. Voltagem 13

3.1.5. Efeito da temperatura 20

3.1.6. Efeito das bolhas de gás na condutividade da solução 20

3.1.7. Efeito do $\mathrm{pH}$

3.1.8. Efeito da vazão de salmoura 21

3.2. Evaporação 22

4. OBJETIVO 26

5. REVISÃO BIBLIOGRÁFICA 27

5.1. Modelagem de processos químicos por redes neurais (RN) 27

5.1.1. Introdução 27

5.1.2. Treinamento 31

5.2. Metodologia para otimização via redes neurais 33

5.3. Analise das correlações entre as variáveis de processo 35

5.4. Analise discriminante 38

6. BASE DE DADOS

6.1. Sala de células diafragma $\quad 40$ 
7. RESULTADOS DAS ANÁLISES DE DADOS 45

$\begin{array}{ll}\text { 7.1. Sala de células diafragma } & 45\end{array}$

7.1.1. Identificação de grupos distintos 45

7.1.1.1. Dados do grupo I 45

7.1.1.2. Dados do grupo II 48

7.1.2. Análise de componentes principais (PCA) 49

7.1.2.1. Dados do grupo I 49

7.1.2.2. Dados do grupo II 52

7.1.3. Análise de correlação $\quad 54$

7.2. Evaporação $\quad 55$

7.2.1. Análise de componentes principais $\quad 55$

$\begin{array}{ll}\text { 7.2.2. Análise de correlação } & 57\end{array}$

8. RESULTADOS DO AJUSTE DE MODELOS DE REDES NEURAIS 59

8.1. Sala de células diafragma $\quad 59$

$\begin{array}{ll}\text { 8.2. Evaporação } & 81\end{array}$

9. SIMULAÇÃO COM OS MODELOS DE REDES NEURAIS 88

9.1. Sala de células diafragma $\quad 88$

9.1.1. Concentração de $\mathrm{NaOH}$ e eficiência de corrente 88

9.1.2. Voltagem 90

9.2. Evaporação 93

10. OTIMIZAÇÃO

$\begin{array}{lll}10.1 & \text { Função objetivo } & 94\end{array}$

$\begin{array}{lll}10.2 & \text { Resultados da otimização } & 98\end{array}$

$\begin{array}{ll}\text { 11. CONCLUSÃO } & 103\end{array}$

$\begin{array}{ll}\text { 12. BIBLIOGRAFIA } & 106\end{array}$

ANEXO I - MODELO FENOMENOLÓGICO PARA UNIDADE DE EVAPORAÇÃO 111

ANEXO II - RESULTADOS DE OTIMIZAÇÃO 119 


\section{RESUMO}

O presente trabalho envolve a elaboração de um modelo matemático para um processo industrial de produção de cloro e soda a partir de salmoura, visando sua otimização em termos de eficiência de produção e dos custos dos consumos de energia elétrica e vapor. $\mathrm{O}$ estudo contemplou duas etapas do processo: eletrólise e concentração de licor de $\mathrm{NaOH}$ por evaporação.

Para a unidade de eletrólise não foram encontrados na literatura modelos fenomenológicos adequados à simulação do processo. Por essa razão, foram desenvolvidos modelos empíricos baseados em redes neurais tipo "feedforward" constituídas por três camadas, a partir de dados da operação industrial.

Para a unidade de evaporação foi elaborado um balanço de energia adequado à estimativa do consumo de vapor. Porém, devido à falta de modelos para previsão das relações de equilíbrio para o sistema, o modelo fenomenológico foi substituído por um modelo de redes neurais tipo "feedforward" de três camadas também para essa unidade.

Para ajuste dos modelos, uma base de dados foi montada a partir de dados de operação do processo da Carbocloro S.A. Indústrias Químicas, localizada em Cubatão-SP, analisados por meio de técnicas estatísticas multivariadas, visando detectar e eliminar erros grosseiros e dados anômalos, além de identificar correlações entre variáveis e diferentes regimes operacionais da planta de produção de cloro e soda.

Os modelos ajustados para os diferentes circuitos de células de eletrólise, bem como para a etapa de evaporação, apresentaram boa concordância com os dados operacionais. Isto possibilitou sua utilização para simular a operação das unidades de células eletrolíticas e evaporação no processo industrial de produção de cloro-soda, com células tipo diafragma.

O modelo matemático baseado em redes neurais foi utilizado em estudos de otimização do processo, de modo a maximizar o ganho financeiro na unidade industrial, para uma dada condição de operação. 


\begin{abstract}
The present work consists on the development of a mathematical model on an industrial chlorine and sodium hydroxide production plant, aiming at the optimization of production efficiency and costs saving concerning electrical energy and vapor consumption. Two process steps were considered in the study: electrolysis and $\mathrm{NaOH}$-liquor concentration by evaporation.

Since there are no adequate models reported in the literature for simulating electrolysis-based processes like the one considered, empirical models for the different types of electrolysis cells were developed based on the fitting of neural networks to operational data from industrial operation. In this case, feedforward neural networks containing three neuron layers were fitted to the data. The raw data obtained from industrial operation at Carbocloro plant, in Cubatão - SP, were first treated by means of multivariate statistical techniques, with the purpose of detecting and eliminating data containing gross errors and outliers, as well as to identify correlations among variables and different operational regimes of the industrial plant.

Although material and energy balances for the evaporation step have been initially adopted, this approach could not be used in simulations due to the lack of valid models to predict liquid - vapor equilibria for the specific system. Thus, a neural network model was also fitted to data from operation of the evaporation step.

Fitting of the neural network models resulted in good agreement between model predictions and measured values of the model output variables, and this enabled their use in simulation studies for the electrolysis and evaporation process steps.
\end{abstract}

The neural network-based mathematical model was utilized in process optimization studies aiming at the best financial gain under given operational conditions. 


\section{LISTA DE FIGURAS}

Figura 2.1 Fluxograma simplificado de uma planta de cloro-soda por tecnologia diafragma (Hine, 1985)

5

Figura 3.1 Condutividade das soluções de HCl (Hine, 1985) 16

Figura 3.2 Condutividade das soluções de $\mathrm{NaOH}$ (Hine, 1985) 17

$\begin{array}{llll}\text { Figura 3.3 Variação de voltagem da célula diafragma (Hine, 1985) } & 18\end{array}$

Figura 3.4 Diagrama de entalpia para solução aquosa de $\mathrm{NaOH}$ em função da concentração (McCabe; Smith, 1976)

Figura 3.5 Variação do ponto de ebulição de solução de $\mathrm{NaOH}$ com a pressão (Kern, 1950)

Figura 5.1 Rede de múltiplas camadas com sentido único ("multilayer feedforward network")

Figura 5.2 Rede recursiva ("recurrent network")

Figura 5.3 Representação de um neurônio $j$ da estrutura da rede

Figura 6.1 Modelo de célula eletrolítica tipo diafragma

Figura 6.2 Modelo de unidade de eletrólise diafragma contendo dois circuitos de 46 células cada um

Figura 7.1 Coeficientes das variáveis de processo para o $1^{\circ}$ componente principal, dados grupo I, eletrólise diafragma

Figura 7.2 Coeficientes das variáveis de processo para o $2^{\circ}$ componente principal, dados grupo I, eletrólise diafragma

Figura 7.3 Coeficientes das variáveis de processo para $01^{\circ}$ componente principal para dados do grupo II

Figura 7.4 Coeficientes das variáveis de processo para $01^{\circ}$ componente principal, evaporação

Figura 7.5 Coeficientes das variáveis de processo para o $2^{\circ}$ componente principal, evaporação

Figura 8.1 a Erro quadrático em função do número de apresentações para eficiência de corrente, dados do grupo I sem interpolação, células I. II e III e $\mathrm{NH}=4$ 
Figura 8.1 b Comparação entre valores calculados de eficiência de corrente pela $\mathrm{RN}$ com dados de processo do grupo I, células I, II e III e $\mathrm{NH}=4$

Figura 8.2 a Função distância entre valores calculados de eficiência pela $\mathrm{RN}$ e dados de processo para célula $\mathrm{I}, \mathrm{NH}=4$

Figura 8.2 b Função distância entre valores calculados de eficiência pela $\mathrm{RN}$ e dados de processo para célula $\mathrm{II}, \mathrm{NH}=4$

Figura 8.2 c Função distância entre valores calculados de eficiência de $\mathrm{RN}$ e dados de processo para célula III, $\mathrm{NH}=4$

Figura 8.3 a Erro quadrático em função do número de apresentações para voltagem, dados do grupo I sem interpolação, células I, II e III e $\mathrm{NH}=4$

Figura 8.3 b Comparação entre valores calculados de voltagem pela RN com dados de processo do grupo I sem interpolação, células I, II e III e $\mathrm{NH}=4$

Figura 8.4 a Função distância entre valores calculados de voltagem pela $\mathrm{RN}$ e dados de processo para célula $\mathrm{I}, \mathrm{NH}=4$

Figura 8.4 b Função distância entre valores calculados de voltagem pela $\mathrm{RN}$ e dados de processo para célula II, $\mathrm{NH}=4$

Figura 8.4 c Função distância entre valores calculados de voltagem pela $\mathrm{RN}$ e dados de processo para célula III, $\mathrm{NH}=4$

Figura 8.5 a Erro quadrático em função do número de apresentações para concentração de $\mathrm{NaOH}$, voltagem e eficiência, dados do grupo $\mathrm{I}$, e $\mathrm{NH}=6$

Figura 8.5 b Comparação entre valores calculados de concentração de $\mathrm{NaOH}$ pela $\mathrm{RN}$ com dados de processo do grupo $\mathrm{I}$, e $\mathrm{NH}=6$

Figura 8.5 c Comparação entre valores calculados de voltagem pela $\mathrm{RN}$ com dados de processo do grupo I, e $\mathrm{NH}=6$

Figura 8.5 d Comparação entre valores calculados de eficiência pela RN com dados de processo do grupo I, e $\mathbf{N H}=6$

Figura 8.6 a Erro quadrático em função do número de apresentações para concentração de $\mathrm{NaOH}$, voltagem e eficiência, dados do grupo I, e $\mathrm{NH}=6$

Figura 8.6 b Comparação entre valores calculados de concentração de $\mathrm{NaOH}$ pela $\mathrm{RN}$ com dados de processo do grupo $\mathrm{I}$, e $\mathrm{NH}=6$ 
Figura 8.6 c Comparação entre valores calculados de voltagem pela $\mathrm{RN}$ com dados de processo do grupo I, e $\mathrm{NH}=6$

Figura 8.6 d Comparação entre valores calculados de eficiência pela $\mathrm{RN}$ com dados de processo do grupo I, e $\mathrm{NH}=6$

Figura 8.7 a Erro quadrático em função do número de apresentações para concentração de $\mathrm{NaOH}$, voltagem e eficiência, dados do grupo I, e $\mathrm{NH}=6$

Figura 8.7 b Comparação entre valores calculados de concentração de $\mathrm{NaOH}$ pela $\mathrm{RN}$ com dados de processo do grupo $\mathrm{I}$, e $\mathrm{NH}=6$

Figura 8.7 c Comparação entre valores calculados de voltagem pela RN com dados de processo do grupo I, e $N H=6$

Figura 8.7 d Comparação entre valores calculados de eficiência pela $\mathrm{RN}$ com dados de processo do grupo I, e $\mathrm{NH}=6$

Figura 8.8 a Função distância entre valores calculados de concentração de $\mathrm{NaOH}$ pela $\mathrm{RN}$ e dados de processo para célula $\mathrm{I}, \mathrm{NH}=6$

Figura 8.8 b Função distância entre valores calculados de voltagem pela $\mathrm{RN}$ e dados de processo para célula $\mathrm{I}, \mathrm{NH}=6$

Figura 8.8 c Função distância entre valores calculados de eficiência pela $\mathrm{RN}$ e dados de processo para célula $\mathrm{I}, \mathrm{NH}=6$

Figura 8.9 a Função distância entre valores calculados de concentração de $\mathrm{NaOH}$ pela $\mathrm{RN}$ e dados de processo para célula $\mathrm{II}, \mathrm{NH}=6$

Figura 8.9 b Função distância entre valores calculados de voltagem pela $\mathrm{RN}$ e dados de processo para célula $\mathrm{II}, \mathrm{NH}=6$

Figura 8.9 c Função distância entre valores calculados de eficiência pela $\mathrm{RN}$ e dados de processo para célula $\mathrm{II}, \mathrm{NH}=6$

Figura 8.10 a Função distância entre valores calculados de concentração de $\mathrm{NaOH}$ pela $\mathrm{RN}$ e dados de processo para célula III, $\mathrm{NH}=6$

Figura 8.10 b Função distância entre valores calculados de voltagem pela $\mathrm{RN}$ e dados de processo para célula III, $\mathrm{NH}=6$

Figura 8.10 c Função distância entre valores calculados de eficiência pela $\mathrm{RN}$ e dados de processo para célula III, $\mathrm{NH}=6$

Figura 8.11 Erro quadrático em função do número de apresentações para dados do Grupo II, circuito I e II, para $\mathrm{NH}=4$ e 6 
Figura 8.12 Comparação entre os valores de processo e os valores calculados pela RN para dados do Grupo II, circuitos I e II, $\operatorname{com} \mathrm{NH}=4$ e 6

Figura 8.13 Comparação entre os valores de processo e os valores calculados pela RN para dados do Grupo II, consumo de energia até $580 \mathrm{MWh}$, circuitos I e II e $\operatorname{com} \mathrm{NH}=4$ e 6

Figura 8.14 Comparação entre os valores de processo e os valores calculados pela RN para dados do Grupo II, consumo de energia maior do que $580 \mathrm{MWh}$, circuitos I e II, $\operatorname{com} \mathrm{NH}=4$ e 6

Figura 8.15 Erro quadrático em função do número de apresentações, evaporação, para $\mathrm{NH}=6$

Figura 8.16 Comparação entre os valores de processo e os valores calculados pela RN para dados de treinamento, evaporação, para $N H=6$

Figura 8.17 Comparação entre os valores de processo e os valores calculados pela $\mathrm{RN}$ para dados de teste, evaporação, para $N H=6$

Figura 8.18 Distribuição de diferenças entre dados de processo e valores calculados pela $\mathrm{RN}$ para os conjuntos de dados de treinamento e teste, evaporação, para $\mathrm{NH}=6$

Figura 9.1 Dados de processo normalizados, concentração de $\mathrm{NaOH}$ em função da vazão de salmoura

Figura 9.2 Valores calculados normalizados a partir dos modelos de RH com NH=6, concentração de $\mathrm{NaOH}$ em função da vazão de salmoura

Figura 9.3 Dados de processo normalizados, eficiência de corrente em função da vazão de salmoura

Figura 9.4 Valores calculados normalizados a partir dos modelos de RN com $\mathrm{NH}=6$, eficiência de corrente em função da vazão de salmoura

Figura 9.5 Dados de processo normalizados, voltagem em função da intensidade de corrente

Figura 9.6 Valores calculados a partir dos modelos de $\mathrm{RN}$ com $\mathbf{N H = 6}$, voltagem em função da intensidade de corrente 
Figura 9.7 Resultados de simulações normalizados: consumo de vapor em função das variáveis de entrada para o modelo da evaporação, para $\mathrm{NH}=6$

Figura 10.1 Fluxograma proposto para otimização das unidades de eletrólise e evaporação

96

Figura 10.2 Ganho financeiro em função da vazão média de salmoura

101

Figura 10.3 Ganho financeiro em função da concentração de $\mathrm{NaOH}$ na evaporação

102

Figura 10.4 Ganho financeiro em função da intensidade de corrente

102

Anexo I

Figura 1 - Fluxograma do processo de evaporação para obtenção de soda líquida a $50 \%$ em peso 


\section{LISTA DE TABELAS}

Tabela 3.1 Condutância equivalente dos íons em solução à diluição infinita (Hine, 1985)

Tabela 3.2 Condição de operação e balanço de voltagem da célula diafragma tipo "Hooker H4" (Hine, 1985)

Tabela 6.1 Variáveis de processo contempladas nos grupos de dados I e II da eletrólise

Tabela 6.2 Variáveis do processo de evaporação

Tabela 7.1 A função discriminante resultante para cada um dos dois tipos de células considerando dez variáveis de processo

Tabela 7.2 Análise discriminante, número de observações e porcentagem de classificação nos anos dentro de cada classe, utilizando 10 variáveis de processo

Tabela 7.3 Análise discriminante, número de observações e porcentagem de classificação

Tabela 7.4 Análise discriminante, número de observações e porcentagem de classificação nos anos dentro de cada classe, utilizando 12 variáveis de processo

Tabela 7.5 Autovalores, porcentagem de variância e proporção da variância acumulada obtidos na análise dos componentes principais

Tabela 7.6 Análise do componente principal. Autovetores correspondentes aos 7 primeiros componentes principais e a seus respectivos autovetores.

Tabela 7.7 Análise dos componentes principais, proporção da variância e proporção da variância acumulada

Tabela 7.8 Análise dos componentes principais, autovalores, proporção de variância e proporção da variância acumulada

Tabela 7.9 Componentes principais e seus respectivos vetores

Tabela 7.10 Análise de correlação, coeficientes de correção entre variáveis 58

Tabela 8.1 Abordagens para as RN testadas

Tabela 8.2 Resultados do ajuste dos modelos de RN com três saídas para as células I, II e III 
Tabela 8.3 Teste ANOVA para hipótese de variâncias estatisticamente iguais entre os valores calculados pela $\mathrm{RN}$ e dados

de processo

Tabela 8.4 Teste ANOVA para hipótese de médias estatisticamente iguais entre os valores valvulados pela $R N$ e dados de processo

Tabela 8.5 Teste Análise de Regressão para hipótese de correlação entre os valores calculados pela $R N$ e dados de processo

Tabela 8.6 Abordagens para as RN testadas

Anexo II

Tabela A - Ganho financeiro versus vazão total de salmoura

Tabela B - Ganho financeiro versus concentração de $\mathrm{NaOH}$

Tabela C - Ganho financeiro versus intensidade de corrente 


\section{NOMENCLATURA}

\begin{tabular}{|c|c|c|}
\hline$a$ & Atividade & \\
\hline$A$ & Área & $\mathrm{cm}^{2}$ \\
\hline$c$ & Calor específico & $\mathrm{kcal} / \mathrm{kg}$ \\
\hline$C$ & Concentração & $\frac{g}{L}$ \\
\hline$C_{C a}$ & Concentração de cálcio na salmoura & $\frac{m g}{L}$ \\
\hline$C E$ & Consumo de energia elétrica & $\mathrm{MWh}$ \\
\hline$C_{F e}$ & Concentração de ferro na salmoura & $\frac{m g}{L}$ \\
\hline$C_{M g}$ & Concentração de magnésio na salmoura & $\frac{m g}{L}$ \\
\hline$C_{\mathrm{NaCl}}$ & Concentração de $\mathrm{NaCl}$ na salmoura & $\frac{g}{L}$ \\
\hline$C_{\mathrm{NaCl}-}$ & Concentração de $\mathrm{NaCl}$ no licor (saída eletrólise) & $\frac{g}{L}$ \\
\hline $\mathrm{C}_{\mathrm{NaOH}-\mathrm{I}}$ & Concentração de $\mathrm{NaOH}$ no licor (saída eletrólise) & $\frac{g}{L}$ \\
\hline $\mathrm{C}_{\mathrm{NaOH}-2}$ & Concentração de $\mathrm{NaOH}$ no licor (entrada $3^{\circ}$ efeito) & $\frac{g}{L}$ \\
\hline$C F E$ & Custo de energia elétrica & $\mathrm{R} \$$ \\
\hline$C V E$ & Custo de vapor & $\mathrm{R} \$$ \\
\hline$d$ & Espaçamento entre eletrodos & $\mathrm{cm}$ \\
\hline$D O L$ & Tempo de operação da célula & dia \\
\hline$E$ & Voltagem de decomposição & Volt \\
\hline$E_{f}$ & Força eletromotriz & Volt \\
\hline$E R$ & Erro quadrático & \\
\hline$F$ & Número de Faraday & \\
\hline$G$ & Energia Livre de Gibbs & $\frac{k c a l}{m o l}$ \\
\hline
\end{tabular}




\begin{tabular}{|c|c|c|}
\hline$G F$ & Ganho financeiro & $\mathrm{R} \$$ \\
\hline$G P$ & Ganho em produção & $\mathrm{R} \$$ \\
\hline$I$ & Corrente elétrica & $A$ \\
\hline$i$ & densidade de corrente elétrica & $\frac{k A}{m^{2}}$ \\
\hline $\mathrm{H}$ & Entalpia & kcal \\
\hline $\mathrm{H}^{\prime}$ & Entalpia Molar & kcal \\
\hline $\mathrm{k}$ & Condutividade & $\underline{m b o}$ \\
\hline $\mathrm{K}$ & Calor latente de condensação & $\frac{k c a l}{m o l}$ \\
\hline$L$ & Nível de salmoura na célula & $\mathrm{cm}$ \\
\hline$M$ & Massa molecular & $\frac{g}{m o l}$ \\
\hline$m$ & Número de interações & \\
\hline$n$ & Número de elétrons & \\
\hline$N H$ & Número de neurônios na camada oculta & \\
\hline$O_{j}$ & \multicolumn{2}{|c|}{$\begin{array}{l}\text { Valor de saída calculado para a função de transferência } \\
\text { aplicada ao neurônio } j \text { da camada interna }\end{array}$} \\
\hline$O_{k}$ & \multicolumn{2}{|c|}{$\begin{array}{l}\text { Valor de saída calculado para a função de transferência } \\
\text { aplicada ao neurônio } k \text { da camada saída. }\end{array}$} \\
\hline$p$ & Número de saídas da rede neural & \\
\hline$P_{1}$ & Pressão no evaporador do primeiro efeito & $m m H_{\xi}$ \\
\hline$P_{2}$ & Pressão no evaporador do segundo efeito & $m m H g$ \\
\hline$P_{3}$ & Pressão no evaporador do terceiro efeito & $m m H g$ \\
\hline$p H$ & Potencial hidrogeniônico & \\
\hline$P P$ & Taxa de produção & $\mathrm{t} / \mathrm{h}$ \\
\hline$P R$ & Preço do vapor & $\frac{R \$}{t}$ \\
\hline$P V$ & Preço de venda & $\mathrm{R} \$$ \\
\hline q & Calor & kcal \\
\hline$Q$ & Vazão de salmoura & $\frac{m^{3}}{h}$ \\
\hline
\end{tabular}




\begin{tabular}{|c|c|c|}
\hline$R$ & Constante dos gases ideais & $\frac{k c a l}{m o l . h}$ \\
\hline$S_{j}$ & \multicolumn{2}{|l|}{$\begin{array}{l}\text { Soma ponderada dos sinais interconectados da camada } \\
\text { anterior para o j-ésimo neurônio da camada interna. }\end{array}$} \\
\hline$S_{k}$ & \multicolumn{2}{|l|}{$\begin{array}{l}\text { Soma ponderada dos sinais interconectados da camada } \\
\text { anterior para o } k \text {-ésimo neurônio da camada de saída. }\end{array}$} \\
\hline$T$ & Temperatura & ${ }^{\circ} \mathrm{C}$ \\
\hline$T_{\text {licor }}$ & Temperatura do licor de célula (saída eletrólise) & ${ }^{\circ} \mathrm{C}$ \\
\hline$T_{\text {licor-3 }}$ & Temperatura do licor na entrada do $3^{\circ}$ efeito & ${ }^{\circ} \mathrm{C}$ \\
\hline$T_{\text {sal }}$ & Temperatura da salmoura (alimentação) & ${ }^{\circ} \mathrm{C}$ \\
\hline$T R$ & Tarifa de energia elétrica & $\frac{R \$}{M W h}$ \\
\hline$V$ & Voltagem & Volt \\
\hline$W_{i, j}$ & \multicolumn{2}{|l|}{$\begin{array}{l}\text { Peso da conexão entre o neurônio } i \text { da camada de } \\
\text { entrada e o neurônio } j \text { da camada interna. }\end{array}$} \\
\hline$W_{j, k}$ & \multicolumn{2}{|l|}{$\begin{array}{l}\text { Peso da conexão entre o neurônio } j \text { da camada interna } \\
\text { e o neurônio } k \text { da camada de saída. }\end{array}$} \\
\hline$W_{n+1, j}$ & \multicolumn{2}{|l|}{$\begin{array}{l}\text { Peso da conexão entre o bias da camada de entrada } \\
\text { e o neurônio } j \text { da camada de interna. }\end{array}$} \\
\hline$W T$ & Massa de produto gerado na eletrólise & $\mathrm{kg}$ \\
\hline$W T_{\mathrm{NaOH}}$ & Massa de $\mathrm{NaOH}$ processada na evaporação & $\mathrm{t} / \mathrm{h}$ \\
\hline$W T_{\text {vapor }}$ & Consumo de vapor na evaporação & $\mathrm{t} / \mathrm{h}$ \\
\hline$W T_{d i a}$ & Massa do diafragma & $\mathrm{kg}$ \\
\hline$X_{i}$ & \multicolumn{2}{|l|}{ Variável de entrada do $i$-ésimo elemento } \\
\hline$Y_{k, c a l c}$ & \multicolumn{2}{|l|}{ Valor calculado da variável do $k$-ésimo elemento } \\
\hline$Y_{k, \exp }$ & \multicolumn{2}{|l|}{ Valor experimental da variável do $k$-ésimo elemento } \\
\hline
\end{tabular}




\section{Letras gregas}

$\begin{array}{lll}\gamma_{ \pm} & \text {Coeficiente de atividade } & \\ \delta & \text { Número de registros experimentais } & \% \\ \varepsilon & \text { Eficiência de corrente } & \\ \zeta & \text { Resistividade } & \\ \eta & \text { Taxa de aprendizado } & h \\ \theta & \text { Tempo } & \end{array}$

$\varphi \quad$ Fração de gás na solução eletrolítica 


\section{INTRODUÇÃO}

\section{Importância da indústria de cloro e soda}

A cadeia de cloro, soda e seus derivados constitui uma das mais importantes atividades econômicas do mundo. Expressa uma extensa rede de produção, tendo como principais consumidores os seguintes setores da economia: Papel e Celulose, Química e Petroquímica, Alumínio, Construção Civil, Sabões e Detergentes, Têxtil, Metalúrgica, Eletrônica, Alimentos, Defensivos Agrícolas, Bebidas, Tintas, Tratamento de água e Embalagens.

As aplicações do cloro são muito variadas, o que lhe dá o título de reagente mais empregado na indústria química, participando direta ou indiretamente em mais de $50 \%$ da produção química mundial.

O mercado mundial de cloro está segmentado principalmente entre os vinílicos $(33 \%)$ e produtos orgânicos $(19 \%)$, e o mercado da soda está segmentado principalmente entre produtos orgânicos (18\%), papel e celulose $(16 \%)$ e produtos inorgânicos (15\%).

A capacidade mundial de produção de cloro e soda, em 2002, era da ordem de 53 e 60 milhões de toneladas respectivamente, distribuída principalmente na América do Norte, na Ásia e na Europa.

Atualmente no Brasil, tem-se um a produção da ordem de 1.099 mil toneladas de cloro e de 1.212 mil toneladas de soda (base 2003) (Hine, 2004).

Para a produção de cloro e soda existem três tecnologias: diafragma, mercúrio e membrana. O processo diafragma é o mais utilizado no mundo (46\%), seguido pelos processos membrana (32\%) e mercúrio $(22 \%)$.

No Brasil a participação da tecnologia no processo produtivo ocorre da seguinte maneira: diafragma com $71 \%$, mercúrio com $25 \%$ e membrana com apenas $4 \%$.

A célula diafragma foi criada na Inglaterra em 1851 e sugeria a produção de cloro, soda e hipoclorito de sódio a partir da eletrólise de salmoura. Com o 
surgimento dos geradores de eletricidade e de várias invenções em torno dos mesmos, teve início a evolução e o desenvolvimento da indústria do cloro.

A tecnologia de diafragma foi se desenvolvendo ao longo do tempo, principalmente quanto ao material de construção, que inicialmente era feito de madeira, depois passou para concreto, aço, polímeros e finalmente titânio. Os anodos passaram de carbono para grafite, e mais tarde para titânio revestido. Os catodos tiveram poucas modificações em termos de material, mantendo-se em aço, mas evoluíram no aspecto energético. Os diafragmas podem ser feitos a partir de fibras de amianto e de fibras sintéticas com nomes comerciais tais como Poliramix e Tephram (Lopes, 2003).

O presente trabalho consiste em modelar, simular e otimizar a operação das unidades de eletrólise e evaporação numa planta de produção de cloro-soda com tecnologia diafragma, utilizando redes neurais. A base de dados utilizada foi obtida do histórico de operação das duas unidades pertencentes à Carbocloro Indústrias Químicas.

No Capítulo 2 é apresentada a descrição do processo produtivo para plantas de cloro-soda com tecnologia diafragma.

No Capítulo 3 são apresentados os fundamentos dos processos de eletrólise tipo diafragma e evaporação.

No Capítulo 4 é apresentado o objetivo deste trabalho.

No Capítulo 5 é apresentada a revisão bibliográfica das técnicas de modelagem e otimização via redes neurais. Neste capítulo também são apresentadas as técnicas de estatística multivariada, análise de componentes principais e análise discriminante.

No Capítulo 6 são apresentadas as bases de dados utilizadas para ajuste dos modelos via redes neurais nos processos de eletrólise e evaporação.

No Capítulo 7 são apresentados os resultados das análises dos dados utilizando técnicas de estatística multivariada.

No Capítulo 8 são apresentados os resultados dos ajustes de rede neural para os modelos das unidades de eletrólise e evaporação.

No Capítulo 9 são apresentadas simulações com os modelos de redes neurais para as unidades de eletrólise e evaporação. 
No Capítulo 10 são apresentados os resultados do estudo de otimização via redes neurais.

No Capítulo 11 são apresentadas as conclusões deste trabalho.

No Capítulo 12 está a lista de referências bibliográficas. 


\section{DESCRIÇÃO DO PROCESSO INDUSTRIAL DE PRODUÇÃO DE CLORO-SODA UTILIZANDO CÉLULAS DIAFRAGMA}

De acordo com Hine (1985), o processo de produção industrial de cloro-soda consiste de uma unidade de tratamento de salmoura, da sala de eletrólise, da unidade de evaporação e dos sistemas de processamento de gás para o cloro e hidrogênio.

O sal é dissolvido em água até uma concentração de $320 \mathrm{~g} / \mathrm{L}$ de $\mathrm{NaCl}$. A solução aquosa de $\mathrm{NaCl}$, conhecida como salmoura, é encaminhada para tratamento com $\mathrm{NaOH}$. Em seguida a salmoura é filtrada para eliminação de impurezas, para então ser aquecida e alimentada na eletrólise.

$\mathrm{Na}$ eletrólise, a salmoura entra pelo lado anódico das células, ao mesmo tempo em que a energia elétrica é alimentada, possibilitando o fluxo de elétrons do anodo para o catodo. Os íons de cloro se dissociam da molécula de $\mathrm{NaCl}$, formando moléculas de gás na superfície do anodo. A salmoura atravessa o diafragma na direção do lado catódico, onde ocorre a eletrólise da água, com o íon $\mathrm{H}^{+}$se associando a outro na superfície do catodo formando gás $\mathrm{H}_{2}$, e a hidroxila $\mathrm{OH}^{-}$unese ao íon $\mathrm{Na}^{+}$formando $\mathrm{NaOH}$. O fluxo de salmoura é contínuo e mantido através do diafragma devido à diferença de nível entre o anólito, salmoura, e o católito, licor da célula. A solução aquosa efluente do catodo composta por $\mathrm{NaCl}$ (15\% em massa) e $\mathrm{NaOH}$ (12\% em massa) forma o licor de célula, que é encaminhado para a unidade de evaporação.

$\mathrm{Na}$ unidade de evaporação, composta por um evaporador de três efeitos, o fluxo do vapor é aplicado em contra-corrente ao do licor, onde, à medida em que ocorre a evaporação da água contida no licor, o $\mathrm{NaCl}$ é cristalizado e separado da solução. No fim deste processo tem-se uma solução aquosa de soda contendo $50 \%$ em massa de $\mathrm{NaOH}$ e $1 \%$ em massa de $\mathrm{NaCl}$, em condições de comercialização. O sal proveniente da cristalização é enviado para saturadores que irão alimentar outra unidade de eletrólise.

O gás cloro produzido no anodo é comprimido, secado e liquefeito, transformando-se em cloro líquido para venda. 
O gás hidrogênio é comprimido e posteriormente enviado para a unidade de ácido clorídrico e para combustão em caldeiras.

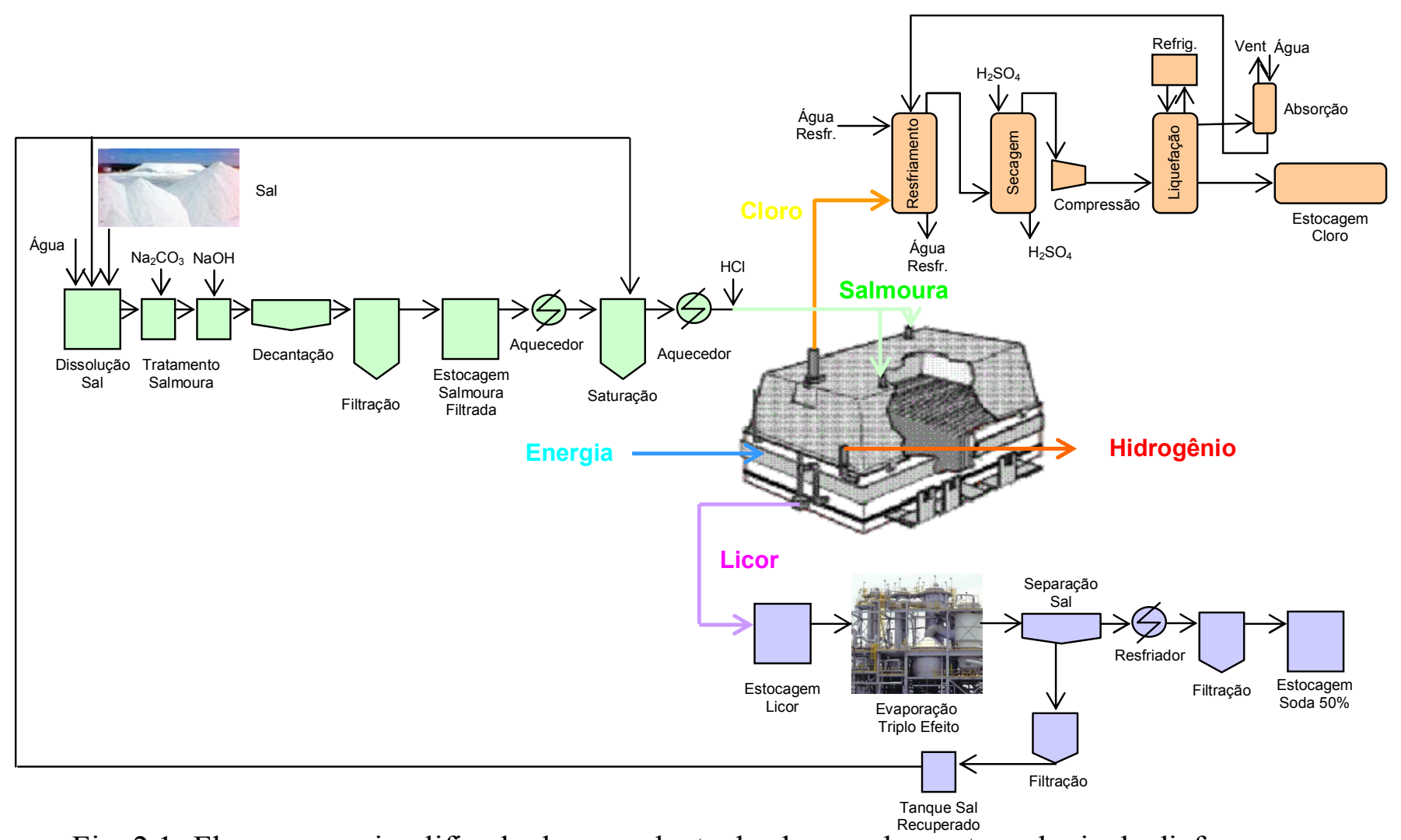

Fig. 2.1- Fluxograma simplificado de uma planta de cloro-soda por tecnologia de diafragma. (Hine, 1985)

Há um compromisso entre a eficiência de produção, o consumo de energia elétrica e de vapor nas etapas de eletrólise e evaporação, associado à concentração de $\mathrm{NaOH}$ e à temperatura no licor de célula. $\mathrm{O}$ incremento na concentração de $\mathrm{NaOH}$ no licor diminui a massa de água a ser separada da soda devido à menor vazão de salmoura na eletrólise, reduzindo o consumo de vapor na evaporação mas com perda de eficiência na eletrólise e vice-versa. O mesmo ocorre para a temperatura: enviando o licor para evaporação com uma temperatura mais elevada, consome-se menos vapor. Entretanto, temperaturas mais elevadas nas células tendem a aumentar o consumo de energia elétrica. 


\section{FUNDAMENTOS DO PROCESSO}

\subsection{Eletrólise}

A célula eletrolítica converte energia elétrica em energia química. A reação química não ocorre espontaneamente e sim quando aplicada uma corrente elétrica externa. A finalidade desta aplicação pode ser, por exemplo, armazenamento de energia elétrica em forma de energia química, como nas baterias, ou também para decompor ou sintetizar novos produtos químicos, como a eletrólise do cloreto de sódio em solução aquosa formando cloro, soda e hidrogênio.

De acordo com Knowlton (1941), o funcionamento de uma célula eletrolítica se baseia nas $1^{\mathrm{a}}$ e $2^{\mathrm{a}}$ leis de Faraday. A $1^{\mathrm{a}}$ lei estabelece que as quantidades de material liberadas no anodo e no catodo são diretamente proporcionais à quantidade de energia elétrica utilizada. A $2^{a}$ lei define que, para uma mesma quantidade de energia elétrica, as quantidades de materiais liberados no anodo e catodo são proporcionais às massas equivalentes das substâncias formadas, sendo a massa equivalente definida como a massa dividida pela valência.

Para um processo industrial de produção de cloro e soda, o rendimento da unidade eletrolítica está voltado para as variáveis de produtividade (eficiência de corrente) e eficiência energética (consumo específico de energia elétrica).

A seguir serão discutidos os efeitos dessas variáveis como também as causas de suas alterações.

\subsubsection{Eficiência de corrente}

Esta variável está associada à conversão eletroquímica, ou seja, a relação da quantidade de produto gerado e a quantidade de produto que se produz teoricamente considerando a massa molecular $(M)$ da espécie química formada, a corrente elétrica (I) aplicada na célula, o número de elétrons $(n)$ envolvidos na transferência entre 
anodo e catodo, a constante de Faraday $(F)$ e o tempo da eletrólise $(\theta)$. A quantidade teórica de produto formado pode ser representada pela Equação 3-1:

$$
W=\frac{M}{n F} I \theta
$$

A constante de Faraday $(F)$ estabelece a quantidade de energia elétrica para depositar $0,0011180 \mathrm{~g}$ de prata, que possui peso atômico de $107,880 \mathrm{~g}$ e valência 1 , ou seja, equivale a 96485,3 Coulombs por equivalente grama.

A eficiência de corrente é calculada pela equação:

$$
\varepsilon=\frac{W^{\prime}}{W} \times 100
$$

Em que $W^{\prime}$ é a quantidade de produto formado no processo. Os desvios de eficiência em relação a 100\% estão associados a fatores químicos como as reações que podem ocorrer na célula eletrolítica (reações secundárias) como também a fatores físicos como problemas de mistura, convecção e difusão.

A seguir são listadas as principais reações químicas que podem ocorrer na célula eletrolítica e os seus impactos sobre a eficiência de corrente de acordo com Eltech (1982).

A reação geral da eletrólise da solução de salmoura é representada pela equação com a formação de hidróxido de sódio, cloro e hidrogênio gasoso:

$2 \mathrm{NaCl}+2 \mathrm{H}_{2} \mathrm{O} \rightarrow \mathrm{Cl}_{2}+\mathrm{H}_{2}+2 \mathrm{NaOH}$

Porém, paralelamente a esta reação, ocorrem reações secundárias tanto no compartimento anódico como no catódico. 


\section{Reações no Anodo}

Formação de cloro:

A principal reação no anodo é a formação do cloro, em que átomos de cloro livre combinam-se para formar molécula de gás cloro.

$$
\begin{aligned}
& \mathrm{Cl}^{-} \rightarrow \mathrm{Cl}^{0}+\mathrm{e}^{-} \\
& \mathrm{Cl}^{0} \rightarrow \mathrm{Cl}_{2}+\mathrm{e}^{-}
\end{aligned}
$$

Essa reação representa cerca de $97 \%$ de todo o produto formado no anodo para células em boas condições de operação.

Formação de Oxigênio

Outros íons podem competir com o íon cloro na descarga do anodo. Isto ocorre com o íon hidroxila, de acordo com a reação

$4 \mathrm{OH}^{-} \rightarrow \mathrm{O}_{2}+2 \mathrm{H}_{2} \mathrm{O}+4 \mathrm{e}^{-}$

sendo essa considerada a mais importante reação competitiva do íon cloro.

Outras reações que prejudicam a eficiência da eletrólise podem ocorrer, tendo importância devido à influência que têm sobre o tempo de vida do anodo, tempo de vida do diafragma e a pureza dos produtos.

Hidrólise da água:

Hidrólise da água ocorre segundo a reação

$2 \mathrm{H}_{2} \mathrm{O} \rightleftarrows \mathrm{H}_{3} \mathrm{O}^{+}+\mathrm{OH}^{-}$ 
$\underline{\text { Reação de cloro com íon hidroxila: }}$

O cloro se forma na reação principal e se dissolve no anólito até que ocorra a saturação, reagindo com íon hidroxila, sendo estabelecido um equilíbrio de acordo com a seguinte reação:

$\mathrm{Cl}_{2}+\mathrm{OH}^{-} \rightleftarrows \mathrm{Cl}^{-}+\mathrm{HOCl}$

Essa reação representa perda de eficiência de corrente, pois parte do cloro produzido está sendo consumida em reações não desejadas. Essa reação também contribui para aumento do teor de clorato no licor de célula.

$\underline{\text { Reação de cloro com a água: }}$

O cloro formado reage com a água formando ácido hipocloroso

$\mathrm{Cl}_{2}+2 \mathrm{H}_{2} \mathrm{O} \rightleftarrows \mathrm{H}_{3} \mathrm{O}^{+}+\mathrm{Cl}^{-}+\mathrm{HOCl}$

O ácido hipocloroso formado na reação anterior sofre hidrólise, formando íons hipoclorito

$\mathrm{HClO}+\mathrm{H}_{2} \mathrm{O} \rightleftarrows \mathrm{H}_{3} \mathrm{O}^{+}+\mathrm{ClO}^{-}$

Formação de clorato:

O ácido hipocloroso reage com hipoclorito formando cloratos de acordo com a reação

$\mathrm{ClO}^{-}+2 \mathrm{HClO} \rightleftarrows 2 \mathrm{H}^{+}+\mathrm{ClO}_{3}^{-}+\mathrm{Cl}^{-}$

Outra reação que pode ocorrer formando cloratos é o íon hipoclorito reagir com a água para formar clorato e oxigênio. Entretanto esta reação não é muito representativa para o processo. 
$6 \mathrm{ClO}^{-}+3 \mathrm{H}_{2} \mathrm{O} \rightarrow 2 \mathrm{ClO}_{3}^{-}+4 \mathrm{Cl}^{-}+6 \mathrm{H}^{+}+\frac{3}{2} \mathrm{O}_{2}+6 \mathrm{e}^{-}$

\section{Formação de Gás Carbônico:}

No caso de eletrodos de grafite pode ocorrer a formação de gás carbônico a partir da reação do íon hidroxila com o carbono do eletrodo.

Outros íons como $\mathrm{HSO}_{4}{ }^{-}$, clorato, hipoclorito podem também formar oxigênio e dióxido de carbono. Porém, devido às quantidades muito reduzidas, não têm influência no total formado desses produtos.

\section{Reações no Catodo}

Formação de Hidrogênio:

A formação de hidrogênio envolve as sequintes reações:

$$
\begin{aligned}
& \mathrm{H}_{3} \mathrm{O}^{+}+\mathrm{e}^{-} \rightarrow 2 \mathrm{H}^{+}+\mathrm{ClO}_{3}^{-}+\mathrm{Cl}^{-} \\
& \mathrm{H}_{2} \mathrm{O}+\mathbf{e}^{-} \rightarrow \mathrm{H}^{0}+\mathrm{OH}^{-} \\
& 2 \mathrm{H}^{+} \rightarrow \mathrm{H}_{2}
\end{aligned}
$$

Formação do íon cloreto :

Os íons hipoclorito e cloratos gerados no anólito e que passaram para o católito podem ser descarregados no catodo formando íons cloreto. Entretanto esta reação não é muito representativa para o processo.

$$
\begin{aligned}
& \mathrm{ClO}^{-}+2 \mathrm{H}_{3} \mathrm{O}^{+}+\mathrm{e}^{-} \rightarrow \mathrm{Cl}^{-}+3 \mathrm{H}_{2} \mathrm{O} \\
& \mathrm{ClO}_{3}^{-}+6 \mathrm{H}_{3} \mathrm{O}^{+}+6 \mathrm{e}^{-} \rightarrow \mathrm{Cl}^{-}+9 \mathrm{H}_{2} \mathrm{O}
\end{aligned}
$$


Parte do cloro dissolvido no anólito pode passar através do diafragma indo para o católito sendo convertido primeiramente em hipoclorito e posteriormente em clorato:

$$
\mathrm{Cl}_{2}+2 \mathrm{OH}^{-} \rightarrow \mathrm{Cl}^{-}+\mathrm{OCl}^{-}+\mathrm{H}_{2} \mathrm{O}
$$

$\mathrm{Cl}_{2}+\mathrm{OH}^{-} \rightarrow \mathrm{Cl}^{-}+\mathrm{HOCl}$

$$
\mathrm{OH}^{-}+\mathrm{HOCl} \rightarrow \mathrm{CO}^{-}+\mathrm{H}_{2} \mathrm{O}
$$

$\mathrm{OH}^{-}+\mathrm{H}_{3} \mathrm{O}^{+} \rightarrow 2 \mathrm{H}_{2} \mathrm{O}$

$3 \mathrm{ClO}^{-} \rightarrow \mathrm{COO}_{3}^{-}+2 \mathrm{Cl}^{-}$

A formação de clorato no católito representa perda de eficiência de corrente, pois parte do produto cloro está sendo consumida em reações não desejadas.

Duas outras reações com o cloro gás dissolvido podem ocorrer tanto no anólito como no católito formando clorato:

$$
\begin{aligned}
& 3 \mathrm{Cl}_{2}+6 \mathrm{OH}^{-} \rightarrow \mathrm{CO}_{3}^{-}+5 \mathrm{Cl}^{-}+3 \mathrm{H}_{2} \mathrm{O} \\
& 3 \mathrm{Cl}_{2}+3 \mathrm{H}_{2} \mathrm{O} \rightleftarrows \mathrm{ClO}_{3}^{-}+6 \mathrm{H}^{+}+5 \mathrm{Cl}^{-}
\end{aligned}
$$

Em ambos os casos essas reações representam perda de eficiência de produção, acumulando clorato no católito.

\subsubsection{Diafragma da célula}

O diafragma é uma camada formada por uma mistura de amianto e teflon utilizada para separar o compartimento anódico do compartimento catódico. Atua 
como um filtro permitindo a difusão ou condutividade do solvente ou do eletrólito de um compartimento para outro. O fluxo de salmoura e a migração de íons podem ser estimados quando se conhece o número e o diâmetro médio dos poros.

A mistura de amianto e teflon é sensível ao $\mathrm{pH}$ e com tendência a se dissolver. A freqüência de recuperação depende da intensidade do fluxo de salmoura, teor e característica do sal e pH (Sconce, 1962).

Os diafragmas podem interferir no processo de eletrólise da célula de acordo com o tamanho dos poros, porosidade, tortuosidade do trajeto capilar, permeabilidade e condutividade superficial. Reduzindo a permeabilidade de íons $\mathrm{OH}$ através do diafragma do lado catódico para o anódico, melhora-se a eficiência de corrente na eletrólise.

Desta forma, de acordo com a característica do diafragma, constata-se influência na voltagem e eficiência da célula.

\subsubsection{Efeito da densidade de corrente}

Densidade de corrente, ou seja amperes por unidade de área, é diretamente proporcional à quantidade de produto gerado na eletrólise, quando associado com o suprimento de cátions e ânions necessários para atender a $1^{\mathrm{a}}$ e $2^{\mathrm{a}}$ leis de Faraday conforme citado anteriormente.

Desta forma a quantidade produzida em escala industrial em uma célula eletrolítica é definida pela equação 3-1.

A relação entre a densidade de corrente e o consumo de energia é associada à voltagem da célula eletrolítica, sendo representada por uma relação linear, (Hine, 1985),

$V=a+b i$

Em que $a$ é o valor da voltagem quando $i$ é igual a zero e é chamada voltagem de decomposição superficial e $b$ é a inclinação da curva da voltagem versus corrente. 


\subsubsection{Voltagem}

A voltagem aplicada em uma célula eletrolítica é a composição das voltagens necessárias para vencer cada uma das resistências internas e possibilitar a formação do produto desejado.

Hine (1985) considera a voltagem geral da célula diafragma como sendo a somatória das voltagens do potencial reversível dos eletrodos, da voltagem de decomposição, das sobrevoltagens do anodo e catodo, e da queda de voltagem dos eletrólitos, do diafragma e do metal. A seguir serão abordadas cada uma dessas parcelas que compõem a voltagem total da célula.

Potencial reversível anodo/catodo: é a voltagem teórica requerida para suprir a força eletromotriz da célula eletrolítica, ou seja, é a diferença de potencial necessária para a ocorrência das reações inversas no anodo e no catodo.

O potencial reversível está associado à energia livre de Gibbs, diferença entre o potencial de dois estados de um processo, que ocorre a pressão e temperatura constantes, indicando o quanto e em que direção o processo ocorre de modo espontâneo.

Para o processo de eletrólise em diafragma, admitindo-se que as reações ocorrem a pressão e temperatura constantes, o cálculo de energia livre de acordo com Hine (1985) é o seguinte:

\begin{tabular}{lll}
\hline Anodo: $\mathrm{Cl}^{-}=\frac{1}{2} \mathrm{Cl}_{2}+\mathrm{e}^{-}$ & & $\frac{\Delta G^{\mathrm{o}}, \mathrm{Kcal} / \mathrm{mol}}{31}$ \\
\hline Catodo: $\mathrm{OH}^{-}+\frac{1}{2} \mathrm{H}_{2}=\mathrm{H}_{2} \mathrm{O}+\mathrm{e}^{-}$ & & -19 \\
& & 50 \\
\hline
\end{tabular}


O potencial reversível é dado pela equação :

$-\Delta G=n F E_{f}$

em que $\Delta G$ é a energia livre de Gibbs, $E_{f}$ é a força eletromotriz para a reação eletroquímica em questão, $n$ é o número de cargas transferidas, $F$ a constante de Faraday .

Para a reação em questão,

$E_{f}=\frac{-50}{1 \times 23,06}=2,17 \mathrm{~V}$

ou seja, necessita-se de 2,17 volts para vencer a força eletromotriz da célula em questão.

Como a energia livre de Gibbs e o potencial reversível podem variar com a concentração da solução e com a temperatura, a equação pode ser utilizada para determinadas condições:

Para o anodo, a voltagem de decomposição $E_{A}$ é definida pela equação,

$$
E_{A}=E_{A}^{0}+\frac{R T}{n F} \ln \left[\frac{\left(p_{C_{2}}\right)^{1 / 2}}{\left(a_{C l^{-}}\right)}\right]
$$

Para o catodo, a voltagem de decomposição $E_{C}$ é definida pela equação,

$$
E_{C}=E_{C}^{0}+\frac{R T}{n F} \ln \left[\frac{\left(p_{H_{2}}\right)^{1 / 2}}{\left(a_{\mathrm{H}_{2} \mathrm{O}}\right)}\right]
$$

Logo a voltagem de decomposição $E$ é definida pela equação

$E=E_{A}-E_{C}$

em que $E_{A}, E_{C}$ são os potenciais eletroquímicos de reação a $25^{\circ} \mathrm{C}, R$ é a constante dos gases, $n$ é o número de elétrons transferidos para as reações da 
célula (1 para ambas as reações), $F$ a constante de Faraday, $a_{\mathrm{Cl}^{-}}$e $a_{\mathrm{H}_{2} \mathrm{O}}$ as atividades do íon cloro e da água respectivamente.

A atividade pode ser calculada pelo produto da concentração $C$ pelo coeficiente de atividade $\gamma_{ \pm} \ldots$

$a_{H^{+}}=C_{H^{+}} \times \gamma_{ \pm}$

Segundo Perry (1950), o coeficiente de atividade tende a aumentar com o incremento de temperatura, e pode ser obtido da equação

$\frac{2.3 d \log \gamma_{1}}{d T}=-\frac{H_{1}^{\prime}}{R T^{2}}$

Em que $H_{1}^{\prime}$ é a entalpia parcial molar do componente 1 na solução menos a entalpia do líquido puro à mesma temperatura, $T$ é a temperatura absoluta e $R$ a constante dos gases.

Desta forma verifica-se que o potencial reversível da célula está associado com a temperatura, concentração e pressão.

$>$ Sobrevoltagem do anodo: componente da voltagem quando ocorre a formação de gás nos eletrodos. A resistência provocada pelo filme de gás sobre a superfície do eletrodo e pelo efeito das bolhas de gás que estão próximas do anodo são os componentes mais representativos dessa parcela da voltagem da célula. Nas células eletrolíticas em questão o gás formado no anodo é o cloro.

Sobrevoltagem do catodo: ocorre o mesmo efeito já citado no anodo. Porém o gás gerado é o hidrogênio.

> Sobrevoltagem no eletrólito: voltagem necessária para suprimir as resistências do eletrólito (condutividade), influenciada pela concentração e temperatura da solução e pelo efeito de formação de bolhas, e pode ser definida pela lei de Ohm: 
em que $I$ é a corrente elétrica, $i$ a densidade de corrente, $d$ o espaçamento entre os eletrodos em $\mathrm{cm}, A$ área da seção transversal $\mathrm{em}^{\mathrm{cm}^{2}} \mathrm{e} k$ a condutividade e mhos $/ \mathrm{cm}$.

Verifica-se que a condutividade da solução, $k$, sofre influência da concentração e temperatura. Temperaturas mais elevadas, para uma mesma concentração, apresentam maiores condutividades, como por exemplo para as soluções de $\mathrm{HCl}$ e $\mathrm{NaOH}$. Entretanto, para uma mesma temperatura, pode ocorrer um incremento ou decréscimo na condutividade conforme a faixa de concentração em que se trabalha.

Os gráficos das Figuras 3.1 e 3.2 ilustram a condutividade de soluções de $\mathrm{HCl}$ e $\mathrm{NaOH}$ e retratam o efeito de concentração e temperatura sobre a condutividade $k$ destas soluções.

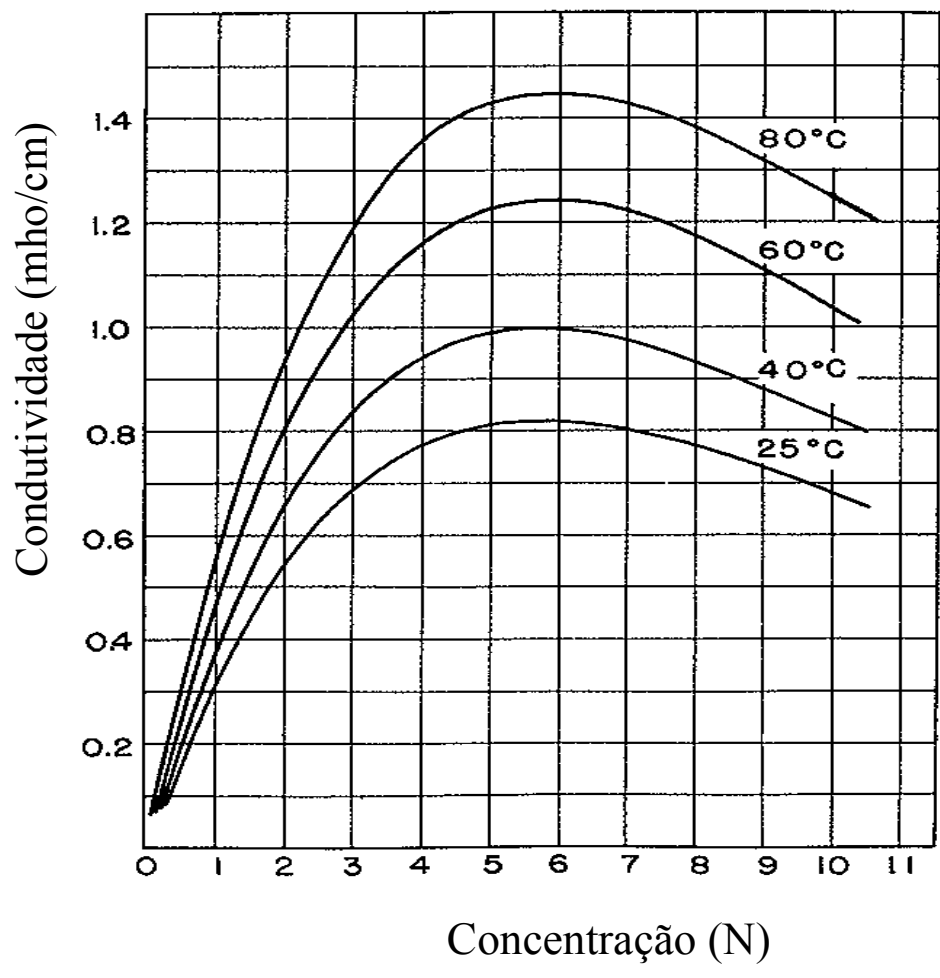

Figura 3.1 - Condutividade das soluções de HCl. (Hine, 1985) 


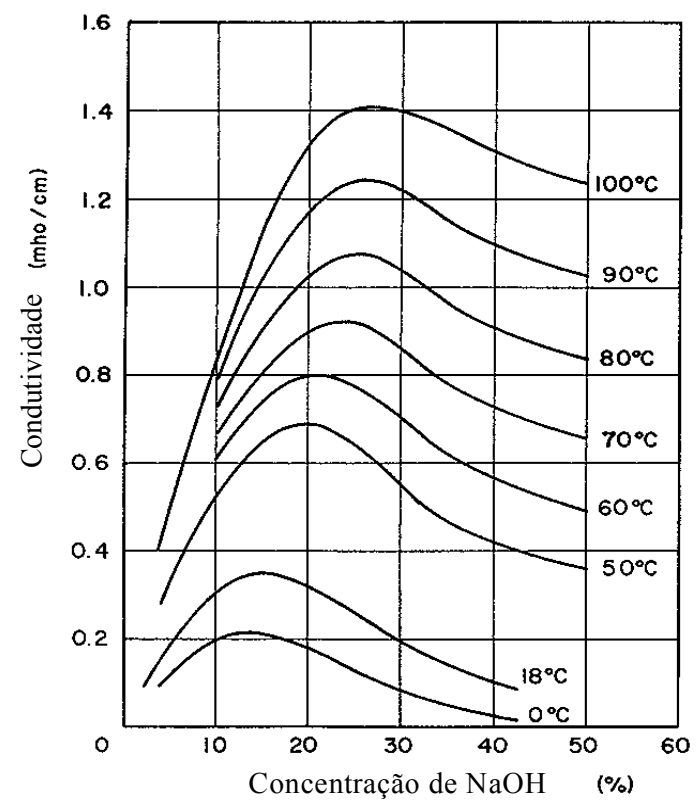

Figura 3.2 Condutividade das soluções de $\mathrm{NaOH}$ (Hine, 1985)

A Tabela 3.1 mostra a condutância de íons em soluções de diluição infinita para as temperaturas $0^{\circ} \mathrm{C}, 25^{\circ} \mathrm{C}$ e $100^{\circ} \mathrm{C}$.

Tabela 3.1 Condutância equivalente dos íons em solução a diluição infinita (Hine, 1985)

\begin{tabular}{lccc|llll}
\multicolumn{1}{c}{ Cations } & $0^{\circ} \mathrm{C}$ & $25^{\circ} \mathrm{C}$ & $100^{\circ} \mathrm{C}$ & \multicolumn{1}{c}{ Anions } & $0^{\circ} \mathrm{C}$ & $25^{\circ} \mathrm{C}$ & $100^{\circ} \mathrm{C}$ \\
\hline $\mathrm{H}^{+}\left(\mathrm{H}_{2} \mathrm{O}\right)$ & 225 & 349.7 & 637 & $\mathrm{OH}^{-}$ & 105 & 200 & 446 \\
$\mathrm{Li}^{+}$ & 19.1 & 38.68 & 120 & $\mathrm{~F}^{-}$ & & 55.4 & \\
$\mathrm{Na}^{+}$ & 25.85 & 50.10 & 150 & $\mathrm{Cl}^{-}$ & 41.4 & 76.32 & 207 \\
$\mathrm{~K}^{+}$ & 40.3 & 73.50 & 200 & $\mathrm{ClO}_{3}^{-}$ & 36 & 64 & 172 \\
$\mathrm{Rb}^{+}$ & 43.5 & 76.4 & & $\mathrm{ClO}_{4}^{-}$ & 37.3 & 68 & 179 \\
$\mathrm{Cs}^{+}$ & 44 & 76.8 & 200 & $\mathrm{Br}^{-}$ & 43.1 & 78.3 & \\
$\mathrm{NH}_{4}^{+}$ & 40.3 & 73.7 & 184.3 & $\mathrm{BrO}_{3}^{-}$ & 31 & 56 & 155 \\
$\frac{1}{2} \mathrm{Mg}^{2+}$ & 28.5 & 53.06 & 170 & $\mathrm{I}^{-}$ & 42.0 & 76.8 & \\
$\frac{1}{2} \mathrm{Ca}^{2+}$ & 30.8 & 59.50 & 187 & $1 \mathrm{O}_{3}^{-}$ & 21 & 41.0 & 127 \\
$\frac{1}{2} \mathrm{Ba}^{2+}$ & 33.6 & 63.7 & 200 & $10_{4}^{-}$ & & 55.6 & \\
$\frac{1}{3} \mathrm{Ce}^{3+}$ & & 67 & & $\frac{1}{2} \mathrm{SO}_{4}^{2-}$ & 41 & 79.8 & 256 \\
$\frac{1}{3} \mathrm{Cr}^{3+}$ & & 67 & & $\mathrm{NO}_{3}^{-}$ & 40.2 & 71.42 & 189 \\
$\frac{1}{2} \mathrm{Mn}^{2+}$ & 27 & 53.5 & & $\mathrm{H}_{2} \mathrm{PO}_{4}^{-}$ & & 36 & \\
$\frac{1}{2} \mathrm{Fe}^{2+}$ & 28 & 53.5 & & $\frac{1}{2} \mathrm{HPO}_{4}^{2-}$ & & 57 & \\
$\frac{1}{3} \mathrm{Fe}^{3+}$ & & 68 & & $\mathrm{HCO}_{3}^{-}$ & & 44.5 & \\
$\frac{1}{2} \mathrm{Co}^{2+}$ & 28 & 54 & & $\frac{1}{2} \mathrm{CO}_{3}^{2-}$ & 36 & 72 & \\
$\frac{1}{2} \mathrm{Ni}^{2+}$ & 28 & 54 & & $\mathrm{CN}^{-}$ & & 78 & \\
$\frac{1}{2} \mathrm{Cu}^{2+}$ & 28 & 56 & & $\frac{1}{2} \mathrm{CrO}_{4}^{2-}$ & 42 & 85 & \\
$\mathrm{Ag}^{+}$ & 33 & 61.9 & 180 & $\frac{1}{2} \mathrm{MoO}_{4}^{2-}$ & & 74.5 & \\
$\frac{1}{2} \mathrm{Zn}^{2+}$ & 28 & 53.5 & & $\mathrm{MnO}_{4}^{--}$ & 36 & 62.8 & \\
$\frac{1}{2} \mathrm{Cd}^{2+}$ & 28 & 54 & & $\mathrm{CH}_{3} \mathrm{COO}^{-}$ & 20 & 41 & 130 \\
$\mathrm{Tl}^{+}$ & 43.3 & 74.9 & & $\mathrm{HCOO}^{-}$ & & 47 at $18^{\circ} \mathrm{C}$ \\
$\frac{1}{2} \mathrm{~Pb}^{2+}$ & 37.5 & 70 & & $\frac{1}{2}\left(\mathrm{C}_{2} \mathrm{O}_{4}\right)^{2-}$ & & 63 at $18^{\circ} \mathrm{C}$ \\
\hline
\end{tabular}


Outro fator que contribui para alteração da condutividade da solução ocorre quando nos eletrodos há produção de gás como cloro e hidrogênio. As bolhas de gás dissolvidas na solução podem incrementar fortemente a queda de voltagem no anólito e no católito.

Voltagem do diafragma: uma das parcelas que compõem a voltagem da célula está associada à resistência ou obstrução imposta pelo diafragma, que são dependentes do nível de porosidade do diafragma, que é função do tipo e tamanho das fibras do material utilizado, das condições de deposição sobre o catodo (concentração de fibras na solução, pressão), da quantidade de partículas de grafite, da quantidade de precipitados de cálcio e magnésio provenientes da salmoura e do tempo de operação da célula, conforme mostrado na Figura 3.3.

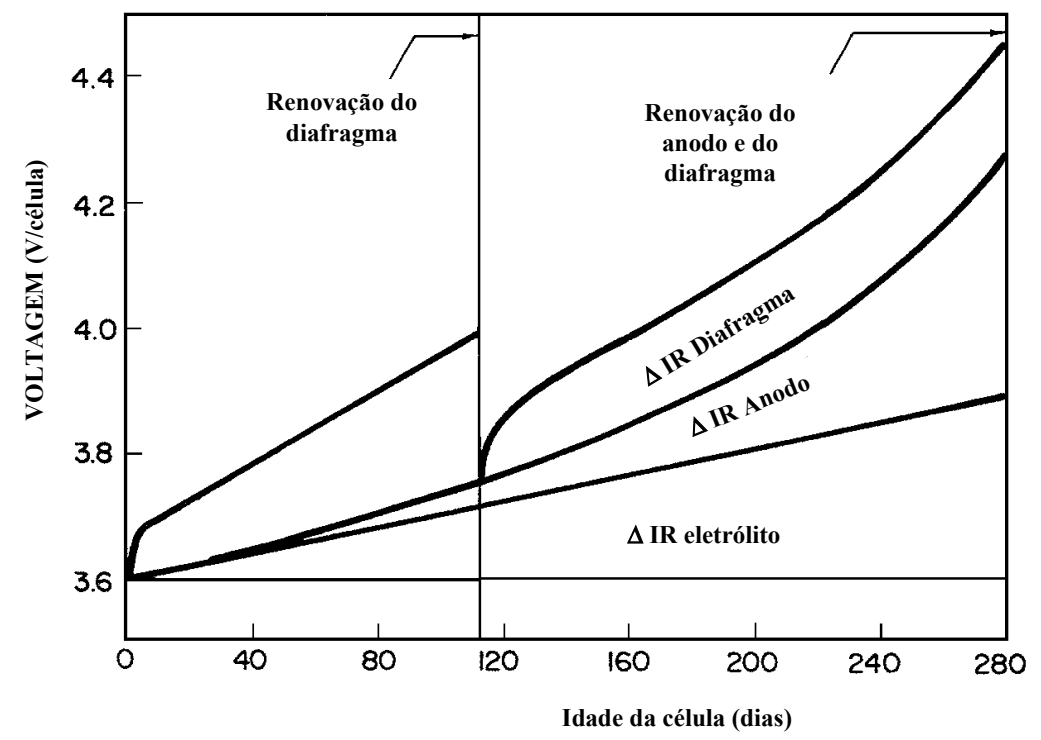

Figura 3.3 Variação de voltagem da célula diafragma (Hine, 1985)

Queda de voltagem no metal : o valor desta parcela da voltagem é em geral pequeno, mas não pode ser negligenciada quando há células eletrolíticas operando em série, estando associada ao tipo de material utilizado na 
construção das células. O cobre pode ser usado na confecção das células para reduzir essa voltagem. Porém, tem um alto custo de investimento.

A voltagem aplicada nas células possui grande importância na indústria de cloro-soda, pois qualquer diminuição de uma destas parcelas de voltagens pode gerar redução no consumo de energia elétrica e conseqüentemente a diminuição nos custos de produção.

A Tabela 3.2 mostra as condições de operação e o balanço de voltagem de uma célula diafragma tipo Hooker H-4 (Hine, 1985).

Tabela 3.2 - Condição de operação e balanço de voltagem da célula diafragma tipo "Hooker H-4" (Hine, 1985).

Intensidade de corrente

Densidade de corrente

Voltagem

Eficiência de corrente

Salmoura de alimentação, @ 65 C

Concentração de $\mathrm{NaOH}$ no licor de célula

Razão $\mathrm{NaCl} / \mathrm{NaOH}$

Concentração de $\mathrm{NaCl}$ no anodo

Temperatura

Anólito

Católito

(A)

$150 \mathrm{kA}$ ca. $27 \mathrm{~A} / \mathrm{dm}^{2}$

$3.788 \mathrm{~V}$

$96.53 \%$

$315 \mathrm{~g} / \mathrm{L}$

$140 \mathrm{~g} / \mathrm{L}$

1.3405

$266.10 \mathrm{~g} / \mathrm{L}$

$94.19^{\circ} \mathrm{C}$

$100.19^{\circ} \mathrm{C}$

Potencial reversível

Anodo

Catodo

Voltagem de decomposição

Sobre voltage do anodo com DSA

Sobre voltage do catodo

Queda de voltagem na solução

Queda de voltagem no diafragma

Queda de voltagem no metal

(B)

Voltagem terminal

$\begin{array}{cc}E_{A} & 1.32 \\ E_{C} & -0.90 \\ E_{d} & 2.25 \\ \eta_{A} & 0.03 \\ -\eta_{c} & 0.30 \\ I R \text { (solução) } & 0.35 \\ \text { IR(diafragma) } & 0.60 \\ \text { IR (metal) } & 0.26 \\ V_{T} & 3.79 \mathrm{~V}\end{array}$




\subsubsection{Efeito da temperatura}

Em geral, a resistência elétrica de uma substância varia com a temperatura. A resistência de substâncias não metálicas diminui com o aumento da temperatura e para todos os metais puros ocorre o inverso. Para intervalo de temperatura entre $0 \mathrm{e}$ $100^{\circ} \mathrm{C}$, a variação da resistência do metal é diretamente proporcional à temperatura, (Gray; Wallace, 1958 e Knowlton 1941).

Para a célula eletrolítica, constituída por diferentes tipos de materiais, o catodo de aço, o anodo de cobre, o diafragma de amianto, o anólito como solução de salmoura e o católito, sendo licor de célula, a variação da resistência total da célula com a temperatura sofre ações diferentes para cada tipo de material. Logo, o comportamento da resistência da célula em função da temperatura depende dos materiais utilizados em sua construção como também das características do processo, como composição, concentração do anólito e do católito.

\subsubsection{Efeito das bolhas de gás na condutividade da solução}

Quando na reação do eletrodo ocorre a formação de bolhas de gás, estas se dispersam no eletrólito podendo diminuir fortemente a sua condutividade. $\mathrm{O}$ efeito das bolhas pode ser classificado como redução da área de superfície de contato do eletrodo e incremento na resistividade da solução eletrolítica.

Gardiner (1963) apud Hine (1985) verificou que para o tipo de célula Olin E11, para distâncias entre o anodo e catodo superiores a 0,3 polegadas, a resistividade da solução não foi afetada pela formação das bolhas de cloro, mas sofreu influência quando esta distância foi menor.

MacMullin; Mills; Fuehlen (1971) apud Hine (1985) constataram que em células diafragma tipo Hooker, a circulação de salmoura reduz a queda de voltagem entre os eletrodos.

Tobias (1959) apud Hine (1985), propôs uma equação para correlacionar resistividade com a fração de gás na célula eletrolítica (Eq. 3-34).

$\zeta / \zeta_{0}=(1-\varphi)^{-3 / 2}$ 
em que $\zeta_{0}$ é a resistividade livre de bolhas e $\varphi$ é a fração média de bolhas.

Esse efeito das bolhas de gás na condutividade no eletrólito pode ser reduzido de três formas:

$>$ utilizando eletrodos perfurados na célula eletrolítica, diminuindo o acúmulo de gás na superfície do eletrodo;

com a recirculação do eletrólito, reduz-se a fração de gás dentro da zona de eletrólise melhorando sua condutividade;

aumento da pressão, reduzindo o volume ocupado pelas bolhas de gás na solução;

\subsubsection{Efeito do pH}

$\mathrm{O}$ efeito da variação do $\mathrm{pH}$ de um eletrólito está ligado à condutividade da solução eletrolítica. Decréscimos de $\mathrm{pH}$, ou seja, incremento de acidez, favorecem efeitos de condutividade da solução, diminuindo a resistência interna da célula eletrolítica e contribuindo para redução da voltagem de decomposição da mesma (Knowlton, 1941).

\subsubsection{Efeito da vazão de salmoura}

A influência da vazão de salmoura através da célula está associada ao fornecimento de íons $\mathrm{Na}^{+}$e $\mathrm{Cl}^{-}$e à ocorrência do efeito de migração contrária de íons $\mathrm{OH}^{-}$do lado catódico para o lado anódico.

Para vazões de salmoura reduzidas, aumenta-se a possibilidade dos íons $\mathrm{OH}^{-}$, formados a partir da eletrólise da água no lado catódico, migrarem para o lado anódico (pólo positivo) através do diafragma, causando perdas destes íons, como também de $\mathrm{Cl}_{2}$, para formarem hipoclorito e cloratos, reduzindo a eficiência da célula. 


\subsection{Evaporação}

$\mathrm{Na}$ unidade industrial estudada, o processo de evaporação tem como objetivo disponibilizar soda cáustica líquida a 50\% em massa, utilizando o licor de célula proveniente da eletrólise como insumo.

O licor de célula é introduzido na linha de circulação entre o evaporador e o trocador de calor que está sendo alimentado com vapor. A condensação do vapor fornece calor para o licor que é forçado a circular entre os dois equipamentos. No evaporador é aplicado vácuo por uma coluna barométrica, promovendo a ebulição do licor de células. Ocorre a evaporação da água, aumentando a concentração de soda e sal no licor. Existem evaporadores de um ou mais efeitos (estágios). $\mathrm{Na}$ Carbocloro o evaporador é de três estágios.

Elevando a concentração de $\mathrm{NaOH}$ no licor, diminui a solubilidade de $\mathrm{NaCl}$ no mesmo, ocorrendo a formação de cristais. $\mathrm{O}$ licor de células, contendo $\mathrm{NaCl}$ em suspensão, é enviado para um hidroclone, onde ocorre a separação da soda e dos cristais de sal. Os cristais são enviados para as centrífugas e a soda, contendo $1 \%$ de $\mathrm{NaCl}$, é enviada para resfriamento, podendo então ser comercializada.

O balanço energético de um evaporador de um único estágio é apresentado a seguir (McCabe e Smith ,1976).

No processo de evaporação, o calor latente do vapor que condensa é transferido para evaporar a água contida no licor. Para análise energética, são necessários dois balanços de entalpia, um para o lado do vapor outro para lado do licor.

$\underline{\text { Vapor }}$

Considerando que a diferença entre a entalpia específica do vapor, $H_{v}$, e do condensado, $H_{l}$, é igual ao calor latente de condensação, $K_{L}$, sendo negligenciadas as energias cinética e potencial em comparação à quantidade de calor trocada, e considerando o trabalho realizado igual a zero, o balanço de energia é equacionado do seguinte modo: 
$q_{\text {vapor }}=W T_{\text {vapor }}\left(H_{l}-H_{v}\right)=W T_{\text {vapor }} K_{L}$

$\underline{\text { Licor }}$

$H_{\text {licor-e }}, H_{\text {licor-s }}$ e $H_{H_{2} O-v}$ são as entalpias específicas de entrada e saída do licor de alimentação e da água na fase vapor respectivamente. $W T_{\text {licor-e }}$ e $W T_{\text {licor-s }}$ são as vazões. Tem-se:

$q_{\text {licor }}=\left(W T_{\text {licor-e }}-W T_{\text {licor-s }}\right) H_{\mathrm{H}_{2} \mathrm{O}-\mathrm{v}}-W T_{\text {licor-e }} H_{\text {licor-e }}+W T_{\text {licor-s }} H_{\text {licor-s }}$

Admitindo que o calor perdido pelo vapor seja igual ao calor recebido pelo licor,

$-q_{\text {vapor }}=q_{\text {licor }}$

$\mathrm{Ou}$

$q_{\text {licor }}=-W T_{\text {vapor }}\left(H_{l}-H_{v}\right)=\left(W T_{\text {licor-e }}-W T_{\text {licor }-\mathrm{s}}\right) H_{\mathrm{H}_{2} \mathrm{O}-\mathrm{v}}-W T_{\text {licor-e }} H_{\text {licor-e }}+W T_{\text {licor-s }} H_{\text {licor }-\mathrm{s}}$

Negligenciando o calor de diluição da solução, as entalpias $H_{\text {licor-e }}$ e $H_{\text {licor-s }}$ podem ser calculadas a partir do calor específico da solução.

Adotando a temperatura $T$ como referência e igual a $T_{\text {licor-s, }} H_{\text {licor-s }}$ é igual a zero, simplificando a equação:

$q_{\text {licor }}=-W T_{\text {vapor }}\left(H_{l}-H_{v}\right)=\left(W T_{\text {licor-e }}-W T_{\text {licor-s }}\right) H_{H_{2} \mathrm{O}-\mathrm{v}}-W T_{\text {licor-e }} H_{\text {licor-e }}$

como o $H_{\text {licor-e }}$ pode ser calculado a partir do calor específico, $c_{p N a O H}$, suposto constante no intervalo de temperatura de entrada e saída do licor, $T_{\text {licor-e }}$ e $T_{\text {licor-s }}$ respectivamente, tem-se: 
$q_{\text {licor }}=-W T_{\text {vapor }}\left(H_{l}-H_{v}\right)=\left(W T_{\text {licor-e }}-W T_{\text {licor-s }}\right) H_{\mathrm{H}_{2} \mathrm{O}-\mathrm{v}}-W T_{\text {licor-e }} c_{p N a \mathrm{OH}}\left(T_{\text {licor-e }}-T_{\text {licor-Naoh }}\right)$

Desconsiderando a elevação de temperatura no ponto de ebulição no licor de saída, tem-se a diferença de entalpia igual ao calor latente, $H_{\mathrm{H}_{2} \mathrm{O}-\mathrm{v}}=K_{L}$, resumindo a equação para:

$q_{\text {licor }}=-W T_{\text {vapor }}\left(H_{l}-H_{v}\right)=\left(W T_{\text {licor }-e}-W T_{\text {licor }-\mathrm{s}}\right) K_{L}-W T_{\text {licor }-e} c_{p N a O H}\left(T_{\text {licor }-e}-T_{\text {licor-Naoh }}\right)$

A entalpia da solução de $\mathrm{NaOH}$ e água pode variar com a temperatura e com a fração mássica dos componentes na solução, conforme mostrado no gráfico da fig. 3.4 .

O ponto de ebulição de solução aquosa de $\mathrm{NaOH}$ varia de acordo com a pressão aplicada sobre o sistema de evaporação, como pode ser visto no gráfico da fig 3.5 .

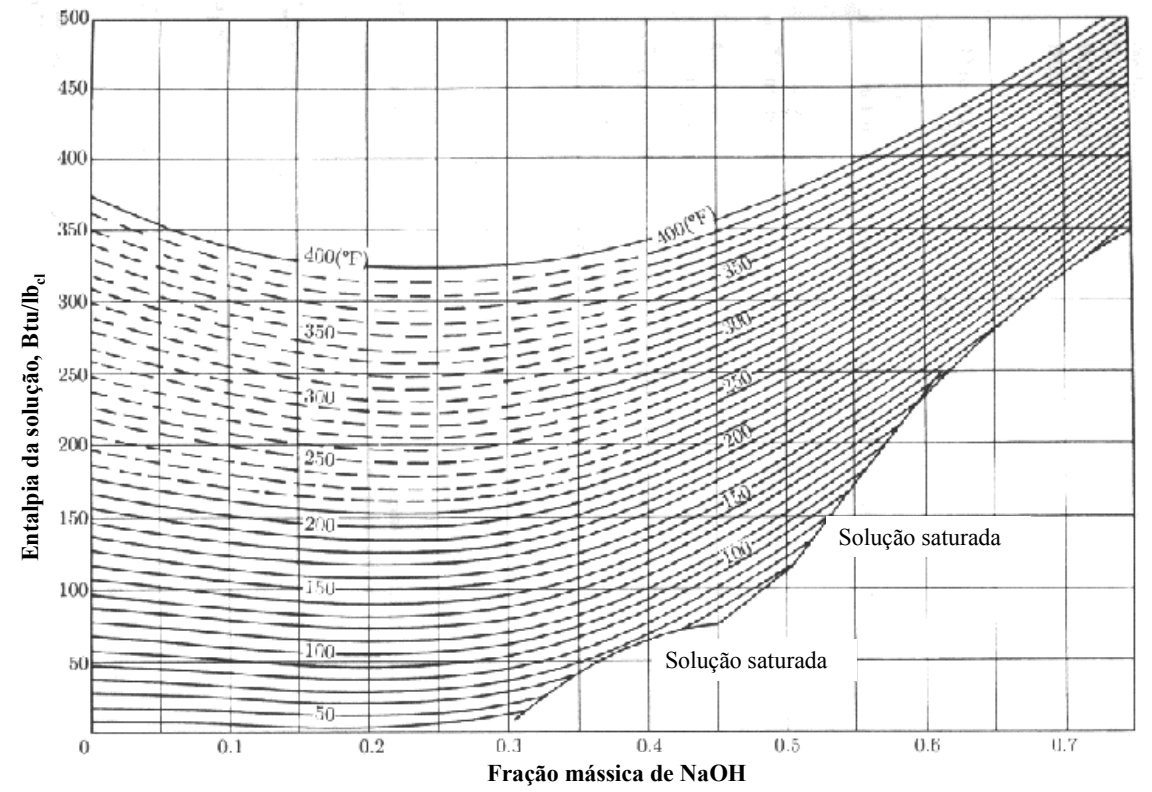

Figura 3.4 Diagrama de Entalpia para solução aquosa de $\mathrm{NaOH}$ em função da concentração. (McCabe; Smith , 1976) 


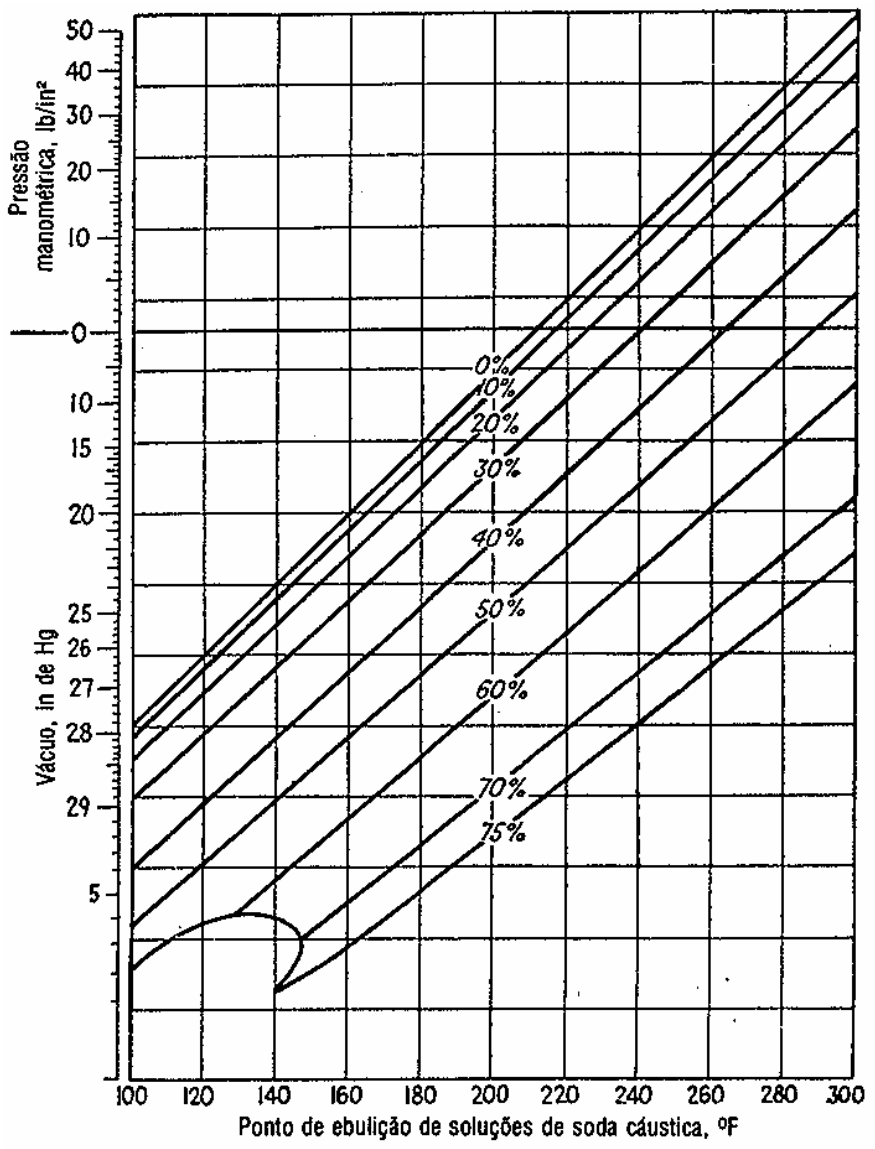

Figura 3.5 Variação do ponto de ebulição de soluções de $\mathrm{NaOH}$ com a pressão (Kern, 1950) 


\section{OBJETIVO}

A produção de cloro-soda envolve números vultosos, quanto a taxas de produção, consumo de energia e de matérias-primas. Atualmente não existe um modelo que possa predizer, com base fenomenológica, as melhores condições de operação da planta quando considerado o custo de produção, eficiência energética e produtiva, para uma planta de produção de cloro-soda com tecnologia diafragma.

Com base nessa constatação, o objetivo deste trabalho é desenvolver modelos matemáticos, utilizando redes neurais, para simulação das etapas de eletrólise em células de diafragma e para a evaporação, visando um estudo para otimização das duas etapas do processo, quanto aos custos referentes ao consumo de energia elétrica e de vapor. 


\section{REVISÃO BIBLIOGRÁFICA}

\subsection{Modelagem de processos químicos por redes neurais (RN)}

\subsubsection{Introdução}

Redes neurais, $\mathrm{RN}$, constituem-se em uma técnica de inteligência artificial utilizada no reconhecimento de padrões de informação. Tatibana; Kaetsu (2006) apresentam uma síntese do histórico de estudos para desenvolvimento de redes neurais, que será mostrado a seguir.

As primeiras informações mencionadas sobre neurocomputação datam de 1943, em artigos de McCulloch e Pitts, em que sugeriam a construção de uma máquina baseada ou inspirada no cérebro humano.

Em 1949, Donald Hebb escreveu um livro entitulado "The Organization of Behavior" (A Organização do Comportamento) que perseguia a idéia de que o condicionamento psicológico clássico está presente em qualquer parte dos animais pelo fato de que esta é uma propriedade de neurônios individuais. Em 1951, foi construído o primeiro neurocomputador por Mavin Minsky, que operava com sucesso a partir de um ponto de partida técnico, ajustando seus pesos automaticamente. Apesar de nunca ter executado qualquer função de processamento de informação interessante, serviu de inspiração para as idéias de estruturas que o sucederam.

Em 1956, no "Darthmouth College" nasceram os dois paradigmas da Inteligência Artificial, a simbólica e a conexionista. A Inteligência Artificial Simbólica tenta simular o comportamento inteligente humano, desconsiderando os mecanismos responsáveis por tal. Já a Inteligência Artificial Conexionista acredita que construíndo-se um sistema que simule a estrutura do cérebro, esse sistema apresentará inteligência, ou seja, será capaz de aprender, assimilar, errar e aprender com seus erros. Frank Rosenblatt e Charles Wightman criaram em 1957 o neurocomputador Mark I Perceptron, voltado para o reconhecimento de padrões . 
Em seguida, Bernard Widrow, com a ajuda de alguns estudantes, desenvolveu um novo tipo de elemento de processamento de redes neurais chamado de Adaline, equipado com uma poderosa lei de aprendizado, que diferentemente do Perceptron, ainda permanece em uso.

Os anos seguintes foram marcados pela falta de credibilidade dos estudos na área, devido à publicação de muitos artigos e livros que previam máquinas tão poderosas quanto o cérebro humano que surgiriam em um curto espaço de tempo.

A partir de 1980, muitos dos pesquisadores passaram a publicar diversas propostas para a exploração de desenvolvimento de redes neurais, bem como suas aplicações. Em 1986 foi dado um passo gigantesco na evolução da técnica de redes neurais, com o livro "Parallel Distributed Processing" (Processamento Distribuído Paralelo) editado por David Rumelhart e James McClelland (1986), iniciando um período de estudos e desevolvimento que perdura até hoje.

$\mathrm{Na}$ engenharia química, sua utilização iniciou-se recentemente com trabalhos em detecção e diagnóstico de falhas (Hoskins; Himmelblau et al., 1988, 1990; Venkatasubramanian et al., 1990; Watanabe et al., 1989), assim como em modelagem e controle de processos químicos (Bhat et al., 1990; Bhat; McAvoy, 1990; Ungar et al., 1990; Psichogios; Ungar, 1991; Su et al , 1992).

Uma das virtudes da técnica de redes neurais é a característica de "aprender" com o que está ocorrendo no processo, contornando em muitos casos as dificuldades de obtenção de modelos fenomenológicos representativos do processo. As premissas para o sucesso da modelagem e controle de processos via rede neural são a necessidade do conhecimento das principais variáveis do processo, como também uma base de dados de qualidade, ou seja, que contenha todas as informações importantes do processo e o domínio desejado.

Geralmente são empregadas duas classes de rede: a rede de múltiplas camadas, cuja informação segue uma única direção ("multilayer feedforward network"), e a rede recursiva ("recurrent network"). Essas duas classes de rede são mostradas respectivamente nas Figuras 5.1 e 5.2.

No desenvolvimento de um modelo de rede neural podemos distinguir os seguintes passos: análise do processo e construção da base de dados, configuração de uma estrutura de rede neural e treinamento ou aprendizado da rede. 
O aprendizado ou treinamento é um problema de otimização e freqüentemente exige a apresentação da base de dados à rede por milhares de vezes, deparando-se com as mesmas dificuldades associadas à otimização de processos, tais como: convergência, existência de mínimos locais, esforço computacional, entre outras.

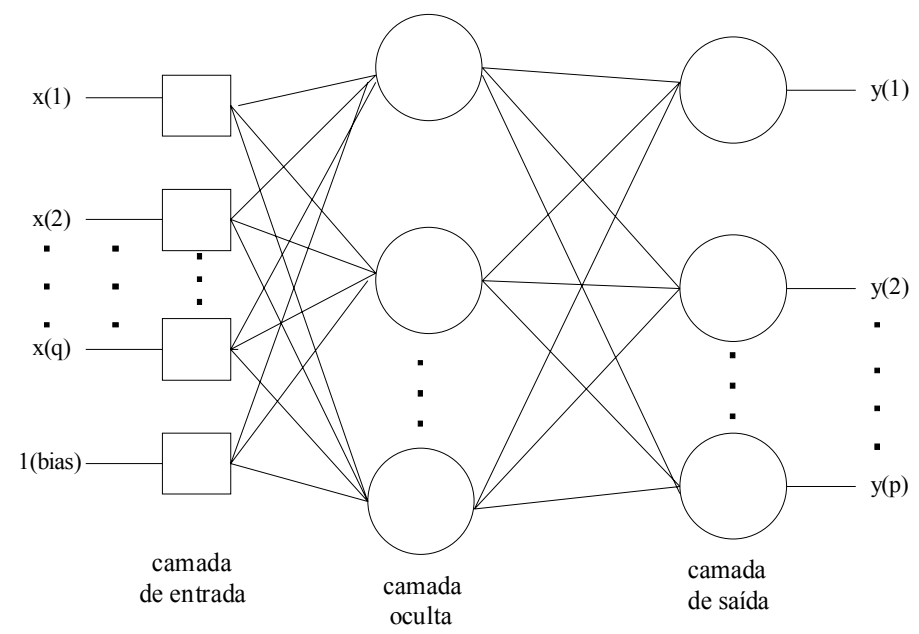

Figura 5.1 - Rede de múltiplas camadas com sentido único (“multilayer feedforward network").

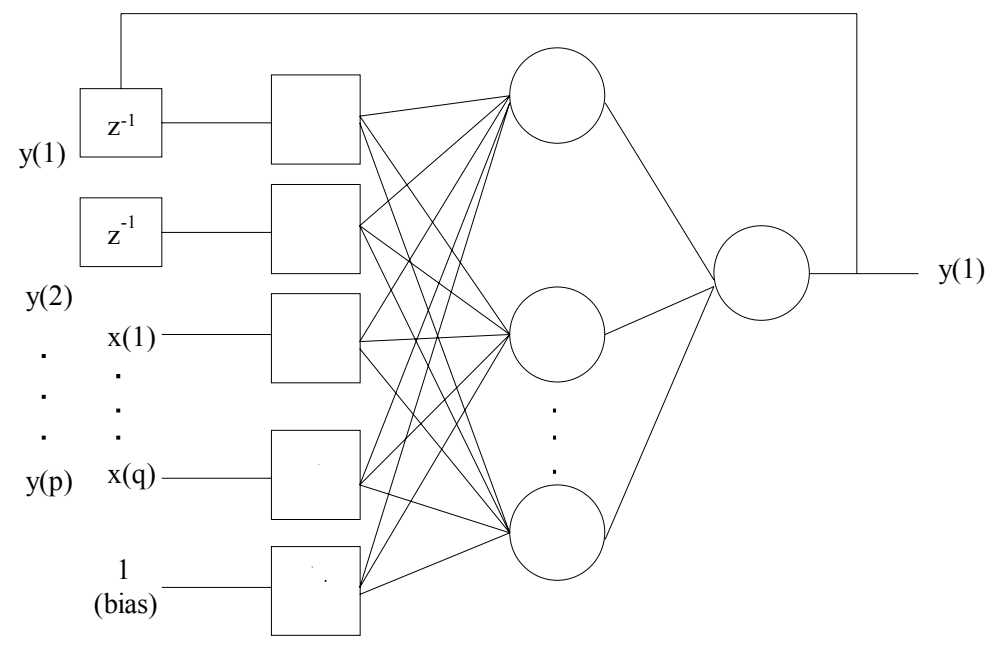

Figura 5.2 - Rede recursiva ("recurrent network").

O tipo de rede "feedforward network" é geralmente o mais utilizado na modelagem e simulação de processos químicos. 
Nessa rede, os neurônios de uma camada são conectados a todos os neurônios da camada seguinte. Cada informação que sai de um neurônio de uma camada ( $i$ ) é ponderada por um dado peso $(W i, j)$ e enviada a todos os neurônios da camada seguinte $(j)$. A convergência da rede neural está ligada à melhor escolha possível do conjunto de pesos W. A rede escolhida possui três camadas: a camada de entrada de dados, a camada oculta ("hidden layer") e a camada de saída. A camada de entrada não efetua nenhum processamento: apenas faz a normalização das variáveis. A fim de diminuir as dificuldades de convergência, todos os dados do conjunto de aprendizagem são normalizados entre zero e um. Além dos dados de entrada, alimenta-se também um valor de referência ("bias") à rede.

A Figura 5.3 apresenta um neurônio de uma camada $j$ da estrutura da rede. Todas as variáveis de entrada $X i$ são ponderadas com um valor $W i, j$ e somadas, conforme a Equação (5-1):

$$
S_{j}=\sum_{i=1}^{n} W_{i, j} X_{i}+W_{n+1, j}
$$

A saída do neurônio, $O j$, é, então, calculada a partir da expressão:

$$
O_{j}=f\left(S_{j}\right)
$$

A relação entre a entrada e a saída dos neurônios é dada por uma função ativadora sigmoidal, do tipo:

$$
f(z)=\frac{1}{1+e^{-z}}
$$

Hunt et al. (1992) apresentam outras formas desta relação $f(z)$, utilizadas em modelagem e controle de processos químicos, bem como um apanhado de recomendações quanto à utilização de um ou outro tipo de rede neural. 


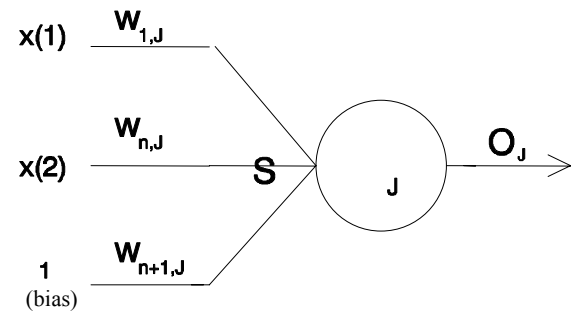

Figura 5.3 - Representação de um neurônio $j$ da estrutura da rede

\subsubsection{Treinamento de redes neurais}

O treinamento de uma rede neural (ou aprendizado) consiste de uma adaptação dos pesos, $W_{i, j}$, aplicados sobre as informações entre as camadas de neurônios, de forma a minimizar o erro quadrático, expresso na forma da função $E R$, abaixo. Essa função representa o valor acumulado para todos os dados experimentais, (de 1 a $\delta$ ), das somas dos erros quadráticos entre os valores experimentais e os calculados pela rede neural, para todas as saídas da rede (de 1 a $p$ ):

$\min (E R)=\min \left(\sum_{m=1}^{\delta} \sum_{k=1}^{p}\left(Y_{k, \text { calc }}^{(m)}-Y_{k, \exp }^{(m)}\right)^{2}\right)$

Para se obter o conjunto de pesos $\left(W_{i, j}\right)$, é preciso ter, em primeiro lugar, um conjunto de dados formado por subconjuntos de pares (entrada e saída) do processo, que constituem o conjunto de aprendizado ("learning set"). Esse conjunto deve ser montado de tal forma que se contemplem todas as informações relevantes do processo. Tendo esse conjunto de dados, utiliza-se um algoritmo de otimização, a fim de se obter o conjunto de pesos que satisfaça um critério dado, por exemplo, pela Equação (5-4).

O algoritmo mais utilizado para determinar o conjunto de pesos (W) é o de retropropagação ("backpropagation"), que é uma derivação do gradiente descendente (Rumelhart e McClelland, 1986). Este é obtido a partir da minimização do resíduo quadrático $(E R)$ com respeito a $W_{i, j}$. Desta forma, o gradiente $\delta E R / \delta W_{i, j}$ pode ser calculado e, conseqüentemente, a direção a ser seguida no processo de minimização 
do resíduo. Em cada passo da otimização, $m$, a atualização dos pesos pode ser dada pela equação:

$W_{i, j}{ }^{(m+1)}=W_{i, j}{ }^{(m)}+\Delta W_{i, j}{ }^{(m)}$

Esta atualização pode ser feita, alternativamente, utilizando a técnica do "momento", baseada na inclusão do termo de momento, $\alpha$, proporcional à variação dos pesos, tal que $0<\alpha<1$ :

$W_{i, j}{ }^{(m+1)}=(1-\alpha) W_{i, j}{ }^{(m)}+\alpha \cdot \Delta W_{i, j}{ }^{(m)}$

A diferença entre o método do gradiente descendente e o "backpropagation" é que este último usa apenas um subconjunto de dados entrada/saída de cada vez, enquanto o método do gradiente tradicional emprega todos os dados do conjunto de aprendizado.

Para a camada de saída, a variação dos pesos referentes ao neurônio de saída $k$, incidentes sobre a saída do neurônio $j$, da camada oculta, a cada iteração $m$, é dada por:

$\Delta W_{j, k}^{(m)}=\eta \cdot f^{\prime}\left(S_{k}\right)\left(Y_{k}^{(m)}-O_{k}^{(m)}\right) O_{j}^{(m)}$

Para a camada oculta, a variação dos pesos referentes ao neurônio oculto $j$, incidentes sobre a entrada $X_{i}$, a cada iteração $m$, é dada por:

$\Delta W_{i, j}^{(m)}=\eta \cdot f^{\prime}\left(S_{j}\right)\left\{\left[\sum_{k=1}^{p} f^{\prime}\left(S_{k}\right)\left(Y_{k}^{(m)}-O_{k}^{(m)}\right) W_{j, k}^{(m-1)}\right] X_{i}^{(m)}\right\}$

Nas Equações (7) e (8), f' é a derivada da função sigmoidal, dada por:

$f^{\prime}(z)=\frac{e^{-z}}{\left(1+e^{-z}\right)^{2}}$ 
No algoritmo de retropropagação, em cada iteração, são calculadas inicialmente as saídas da camada oculta $\left(O_{j}\right)$ e da camada de saída $\left(O_{k}\right)$, com os pesos estimados na iteração anterior, pelas Eqs. (5-1) a (5-3), para os $n$ neurônios da camada oculta e $p$ neurônios da camada de saída; em seguida, as saídas da rede são utilizadas para o cálculo dos novos valores dos pesos, utilizando-se as Eqs. (5-9), (58) e (5-7) para as variações e a Eq. (5-5) ou (5-6) para os novos valores. Isso é feito para cada apresentação dos pontos experimentais. Assim, inicialmente os erros são propagados para trás, na rede, e utilizados para estimar os novos valores dos pesos nas camadas anteriores.

Uma vez determinado o conjunto de pesos (W) que minimiza o resíduo $(E R)$, para simular o processo basta multiplicar um conjunto de dados de entrada qualquer pelos respectivos pesos, respeitando a estrutura da rede, obtendo-se o conjunto de resultados após a camada de saída da rede.

Modelos baseados em redes neurais têm sido utilizados para várias finalidades na engenharia química, entre as quais podemos citar:

- otimização de processos industriais aplicando diferentes técnicas de otimização (Nascimento et at., 2000);

- simulação da taxa de reações fotoquímicas (Gob et al., 2000);

- processos industriais de polimerização (Nascimento et al., 1999a)

- previsão de teores de ozônio na atmosfera em áreas urbanas (Guardani et al., 2003; Guardani; Nascimento, 2003)

- identificação de dados suspeitos em sistemas multivariados (Alves; Nascimento, 2002).

\subsection{Metodologia para otimização via redes neurais}

Os modelos matemáticos baseados em redes neurais desenvolvidos no presente trabalho, com base no ajuste a dados de operação da unidade industrial, foram utilizados em um estudo voltado à otimização da operação do processo. Para isso, foi elaborada uma função objetivo correspondente ao custo horário de operação, 
a qual foi utilizada em estudos de minimização. As restrições de igualdade e desigualdade dessa função objetivo são:

a) Restrições de igualdade: equações de balanços de massa e de energia, associadas aos consumos de energia elétrica na etapa de eletrólise e de vapor na etapa de evaporação, sendo os modelos matemáticos de cada etapa representados por modelos de redes neurais.

b) Restrições de desigualdade: representadas pelas faixas de validade dos modelos, para as variáveis de processo consideradas.

No presente trabalho, a metodologia de otimização adotada baseia-se no trabalho publicado por Nascimento; Giudici; Guardani (2000). Esses autores utilizaram modelos de processos baseados em redes neurais e adotaram um algoritmo de busca direta do mínimo global na faixa de validade dos modelos. Para isso, é constituída inicialmente uma malha de dimensão $p$ para as $p$ variáveis de otimização, com número de passos definido pelo usuário. A busca baseia-se no cálculo direto do valor da função objetivo em cada ponto da grade. Uma vez identificado o mínimo global, pode ser atribuída pelo usuário uma faixa de tolerância para o valor da função objetivo. O procedimento de busca é, então, repetido, sendo retidos todos os conjuntos de valores das variáveis de otimização para os quais o valor da função objetivo situa-se dentro da tolerância. No final do processo, é obtido um conjunto de valores das variáveis de otimização para os quais a função objetivo situa-se dentro da tolerância; cada um desses conjuntos corresponde a uma condição operacional. A decisão sobre qual (ou quais) dessas condições é mais favorável para operação da unidade industrial fica a critério do usuário. Essa decisão, muitas vezes, leva em consideração também aspectos qualitativos, não incluídos no modelo do processo.

Entre as vantagens apresentadas por esta metodologia podemos descrever as seguintes:

Resultados são obtidos a partir da varredura de toda a malha de soluções possíveis do processo, em que as variáveis podem ser alteradas dentro da precisão da instrumentação. 
Fácil identificação de múltiplos pontos ótimos, pois toda a grade de resultados é calculada, evitando-se o problema de mínimos locais que surgem em vários métodos convencionais.

Uma vez definido e testado o modelo do processo a ser otimizado, o processo de otimização obedece às seguintes etapas em busca dos pontos que minimizem ou maximizem a função objetivo conforme a seguir. Alves (2003) também descreve o procedimento em busca do ótimo global utilizando a mesma metodologia.

1. Busca-se o mínimo ou máximo global, calculando-se toda a malha de valores para a função objetivo, sem estabelecer limites de tolerância para as variáveis dependentes e restrições para as variáveis independentes. Nesta etapa as variáveis são alteradas dentro da faixa de domínio.

2. Definir tolerância para as variáveis dependentes, de acordo com o mínimo ou máximo global encontrado, por exemplo, 5 ou $10 \%$.

3. Definir restrições para as variáveis independentes. Estas restrições podem estar vinculadas a condições de segurança do processo, qualidade do produto ou quantidade de resíduo gerado. Outras variáveis independentes, que fazem parte do modelo, podem variar dentro da faixa de domínio.

4. Aplicando-se as tolerâncias e restrições estabelecidas anteriormente, calcula-se o conjunto de valores da função objetivo.

5. Uma vez definido todo o conjunto de resultados que atendam as condições de tolerância e restrições, são escolhidas as melhores de acordo com a função objetivo desejada.

\subsection{Análise das correlações entre as variáveis de processo}

A análise de correlações entre as variáveis de processo no presente trabalho foi baseada na análise de componentes principais (PCA), e é provavelmente a mais antiga técnica de análise multivariada.

O PCA é uma técnica de análise multivariável voltada a explicar a estrutura de variância e covariância de um conjunto de variáveis através de algumas combinações lineares dessas variáveis (Johnson, 1998). 
O objetivo principal na sua aplicação é reduzir o número de variáveis que representam um determinado processo, sendo que as variáveis originais devem ter uma certa dependência, enquanto que as novas variáveis, componentes principais, são independentes entre si. Outra característica quando utilizamos o PCA é a possibilidade de identificação de variáveis com maior significância no processo, porém a variância total do processo se mantém inalterada.

Se para representarmos a variabilidade de um determinado processo são requeridas $p$ variáveis, podemos reduzir o número destas variáveis que representam o processo para $k$ componentes principais, porém a quantidade e qualidade das informações existentes nestas novas variáveis é praticamente a mesma existente nas $p$ variáveis originais. Se temos $n$ medidas para $p$ variáveis originais passaremos a $n$ medidas para os $k$ componentes principais.

Pode-se definir PCA como sendo uma combinação linear das $p$ variáveis, representando o novo sistema de coordenadas obtido pela rotação do sistema de coordenadas originais, sendo que os novos eixos representam a máxima variabilidade e uma simplificação na descrição da estrutura de covariância. Observase que o PCA depende unicamente da matriz de covariância ou da matriz de correlação das variáveis $x_{1}, x_{2}, \ldots, x_{\mathrm{n}}$.

Considerando uma população representada pelo vetor randômico $\mathbf{x}$, em que

$$
\mathbf{X}=\left(x_{1}, \ldots, x_{n}\right)^{T}
$$

E a média da população, como

$\mu_{\mathbf{x}}=E\{\mathbf{X}\}$

então, a matriz de covariância pode ser representada pela equação,

$\mathbf{C}_{\mathbf{x}}=E\left\{\left(\mathbf{x}-\mu_{x}\right)\left(\mathbf{x}-\mu_{x}\right)^{T}\right\}$ 
em que os elementos da matriz $\mathbf{C}_{\boldsymbol{x}}$ representam as covariâncias entre as variáveis dos componentes $\boldsymbol{x}_{\mathrm{i}}$ e $\boldsymbol{x}_{\mathrm{j}}$, e os elementos da diagonal principal, $\mathbf{C}_{\boldsymbol{i} i}$, representam a própria variância de cada variável.

A variância de uma variável indica a dispersão dos valores em torno de seu valor médio. Se duas variáveis $\boldsymbol{x}_{\mathrm{i}}$ e $\boldsymbol{x}_{\mathrm{j}}$ não são correlacionadas, então a covariância é zero $\left(\mathbf{C}_{i j}=\mathbf{C}_{j i}=\mathbf{0}\right)$

A matriz de covariância é simétrica. De uma matriz simétrica, tal como a matriz de covariância, pode-se calcular uma base ortogonal encontrando seus autovalores e autovetores. Os autovalores e os autovetores correspondentes são as soluções da equação

$$
\mathrm{C}_{x} \mathbf{e}_{i}=\lambda_{i} \mathbf{e}_{\mathrm{i}}, i=1, \ldots, n
$$

Para uma matriz de covariância, que é positiva definida, os $\lambda i$ são distintos. Estes valores podem ser encontrados através das soluções da equação característica

$$
\left|\mathbf{C}_{\mathbf{x}}-\lambda \mathbf{I}\right|=0
$$

Em que I é a matriz identidade.

Se $\lambda$ é o autovalor da matriz de covariância $\mathbf{C}_{\boldsymbol{x}}$, existe um vetor $\mathbf{x}$ diferente de zero para o qual é válida a equação:

$\mathbf{C}_{x} \mathbf{x}=\lambda \mathbf{x}$

dizemos então que $\mathbf{x}$ é o autovetor da matriz $\mathbf{C}_{\boldsymbol{x}}$.

Supondo que o vetor $\mathbf{x}=\left[x_{1}, x_{2}, \ldots, x_{n}\right]^{T}$ tem a matriz de covariância $\mathbf{C}_{\boldsymbol{x}}$ com os autovalores $\lambda_{1} \geq \lambda_{2} \geq \ldots \geq \lambda_{p} \geq 0$ e aplicando a propriedade $\mathbf{C}_{\boldsymbol{x}} \mathbf{x}=\lambda \mathbf{x}$, tem-se 


$$
\begin{aligned}
& Y_{1}=a_{11} x_{1}+a_{12} x_{2}+\ldots+a_{1 \mathrm{p}} x_{\mathrm{p}} \\
& Y_{2}=a_{21} x_{1}+a_{22} x_{2}+\ldots+a_{2 \mathrm{p}} x_{\mathrm{p}} \\
& \vdots \\
& Y_{\mathrm{p}}=a_{\mathrm{p} 1} x_{1}+a_{\mathrm{p} 2} x_{2}+\ldots+a_{\mathrm{pp}} x_{\mathrm{p}}
\end{aligned}
$$

O primeiro componente principal é uma combinação linear com o máximo de variância, ou seja $\operatorname{Var}\left(Y_{1}\right)=\mathrm{a}_{1}{ }^{T} \mathrm{C}_{x} \mathrm{a}_{1}$ é máxima. Como a variância de $\mathrm{Y}_{1}$ pode ser aumentada indefinidamente quando multiplicada por qualquer $\mathrm{a}_{1}$, adotam-se autovetores normalizados.

$\mathrm{O}$ segundo componente principal é uma combinação linear $\mathrm{a}_{1}{ }^{\prime} \mathrm{X}$ que maximiza $\operatorname{Var}\left(\mathrm{a}_{2}{ }^{T} \mathrm{X}\right)$ sujeito $\mathrm{a}_{2}{ }^{T} \mathrm{a}_{2}=1$ e $\operatorname{Cov}\left(\mathrm{a}_{1}{ }^{T} \mathrm{X}, \mathrm{a}_{2}{ }^{T} \mathrm{X}\right)=0$

$\mathrm{O}$ i-ésimo componente principal é uma combinação linear $\mathrm{a}_{i}{ }^{\prime} \mathrm{X}$ que maximiza $\operatorname{Var}\left(\mathrm{a}_{i}{ }^{\prime} \mathrm{X}\right)$ sujeito $\mathrm{a}_{i}{ }^{T} \mathrm{a}_{i}=1$ e $\operatorname{Cov}\left(\mathrm{a}_{i}{ }^{T} \mathrm{X}, \mathrm{a}_{k}{ }^{T} \mathrm{X}\right)=0$ para $k<i$

\section{4 - Análise discriminante}

Com base na técnica análise discriminante, foi realizada a análise dos dados no capítulo 7 para identificação de grupos distintos.

Resumidamente a análise discriminante é uma técnica de análise multivariada, tendo como objetivo a separação de grupos distintos de observações e na alocação de novas observações em grupos previamente definidos. Os objetivos imediatos para as técnicas de discriminação e classificação são respectivamente os seguintes:

Classificar as características diferenciadas de observações em populações conhecidas. A tentativa é encontrar discriminantes aos quais os valores numéricos são tais que as populações são separadas o tanto quanto possível.

Separar observações dentro de duas ou mais classes previamente definidas. A ênfase é definir regras que podem ser utilizadas para agrupar novas observações em classes já definidas. 
Johnson; Wichern (1998) descrevem a técnica de análise discriminante para identificação de grupos distintos e classificação de novas observações em grupos já definidos. 


\section{BASE DE DADOS}

\subsection{Sala de Células Diafragma}

A análise dos dados foi realizada utilizando dois grupos de dados distintos. A primeira base de dados, denominada grupo I, foi constituída por registros coletados de cada uma das 407 células que operaram no período de 1995 a 2004, contemplando dois tipos de células, totalizando 8067 registros, sendo estes obtidos com freqüência média de três vezes ao dia, coletados em três células diferentes, por exemplo, das células 1, 2 e 3. No dia seguinte são realizadas outras três coletas, células 4, 5 e 6, e assim por diante. Após cerca de 30 dias, totaliza-se a coleta dos registros em todas as células e volta-se a coletar amostras das células 1, 2 e 3.

Já a segunda base de dados foi formada com dados coletados de cada um dos dois circuitos existentes, no período de 1999 a 2005, denominada grupo II, totalizando 2996 registros. Cada um dos circuitos em questão é constituído por 46 células, dispostas paralelamente em dois grupos de 23. Logo os registros das variáveis analisadas são resultado da influência das 46 células. A freqüência destes registros é diária para cada um dos dois circuitos.

Na tabela 6.1 são descritas as variáveis contempladas nos dois grupos de dados considerados para a eletrólise.

O estudo considerando as duas bases de dados foi motivado pelos seguintes fatores:

no conjunto de dados por células foram incluídas as seguintes variáveis de entrada: peso do diafragma, tempo de vida da célula e nível de salmoura para ajuste da RN.

com base em testes exploratórios, verificou-se maior sensibilidade entre variáveis de entrada e saída utilizando a base de dados por células;

foi observada, também, menor sensibilidade entre variáveis de entrada e saída, porém menor influência de ruídos que não são características do processo quando utilizada a base de dados por circuito; 
a comprovação das características do processo através de duas bases de dados distintas e não de apenas uma;

Tabela 6.1. Variáveis de processo contempladas nos grupos de dados I e II da eletrólise.

\begin{tabular}{|c|c|c|c|}
\hline Grupo & Sigla & Variáveis & Unidade \\
\hline \multirow{15}{*}{ I } & $W T_{d i a}$ & $\begin{array}{l}\text { Peso do diafragma, (quantidade da mistura de teflon e amianto depositada } \\
\text { sobre o catodo da célula) }\end{array}$ & $\mathrm{kg}$ \\
\hline & $D O L$ & Tempo de operação da célula & dia \\
\hline & $\mathrm{C}_{\mathrm{NaOH}-\mathrm{l}}$ & Concentração de $\mathrm{NaOH}$ no licor (área catódica da célula) & $\mathrm{g} / \mathrm{L}$ \\
\hline & $\mathrm{C}_{\mathrm{NaCl}}$ & Concentração de $\mathrm{NaCl}$ na salmoura de alimentação & $\mathrm{g} / \mathrm{L}$ \\
\hline & $C_{\mathrm{NaCl}-1}$ & Concentração de $\mathrm{NaCl}$ no licor (área catódica da célula) & $\mathrm{g} / \mathrm{L}$ \\
\hline & $T_{\text {licor }}$ & Temperatura do licor (área catódica da célula) & ${ }^{\circ} \mathrm{C}$ \\
\hline & $I$ & Intensidade de corrente aplicada na célula & $\mathrm{kA}$ \\
\hline & $Q$ & Vazão de salmoura de alimentação & $\mathrm{M}^{3}$ \\
\hline & $L$ & Nível de salmoura (área anódica da célula) & $\mathrm{cm}$ \\
\hline & $C_{C a}$ & Concentração de cálcio na salmoura de alimentação & $\mathrm{mg} / \mathrm{L}$ \\
\hline & $C_{M g}$ & Concentração de magnésio na salmoura de alimentação & $\mathrm{mg} / \mathrm{L}$ \\
\hline & $C_{F e}$ & Concentração de ferro na salmoura de alimentação & $\mathrm{mg} / \mathrm{L}$ \\
\hline & $p H$ & Potencial hidrogeniônico & \\
\hline & $V$ & Voltagem da célula & $\mathrm{V}$ \\
\hline & $\varepsilon$ & $\begin{array}{l}\text { Eficiência de corrente, (relação entre massa de gás cloro produzido na célula } \\
\text { e a massa de gás cloro que teoricamente se produz nas mesmas condições) }\end{array}$ & $\%$ \\
\hline \multirow{10}{*}{ II } & $\mathrm{C}_{\mathrm{NaOH}-\mathrm{l}}$ & Concentração de $\mathrm{NaOH}$ no licor (saída do circuito) & $\mathrm{g} / \mathrm{L}$ \\
\hline & $C_{\mathrm{NaCl}}$ & Concentração de $\mathrm{NaCl}$ na salmoura de alimentação & $\mathrm{g} / \mathrm{L}$ \\
\hline & $T_{\text {licor }}$ & Temperatura do licor (saída do circuito) & ${ }^{\circ} \mathrm{C}$ \\
\hline & $T_{\text {sal }}$ & Temperatura da salmoura de alimentação & ${ }^{\circ} \mathrm{C}$ \\
\hline & $I$ & Intensidade de corrente aplicada no circuito & $\mathrm{kA}$ \\
\hline & $C_{C a}$ & Concentração de cálcio na salmoura de alimentação & $\mathrm{mg} / \mathrm{L}$ \\
\hline & $C_{M g}$ & Concentração de magnésio na salmoura de alimentação & $\mathrm{mg} / \mathrm{L}$ \\
\hline & $p H$ & Potencial hidrogeniônico & \\
\hline & $C E$ & Consumo de energia elétrica no circuito & MWh \\
\hline & $\varepsilon$ & $\begin{array}{l}\text { Eficiência de corrente, (relação entre massa de gás cloro produzido no } \\
\text { circuito e a massa de gás cloro que teoricamente se produz nas mesmas } \\
\text { condições }\end{array}$ & $\%$ \\
\hline
\end{tabular}


Nas figuras 6.1 e 6.2 são mostrados o modelo de uma unidade de eletrólise diafragma e de uma célula eletrolítica e os pontos de coleta de cada variável no processo.

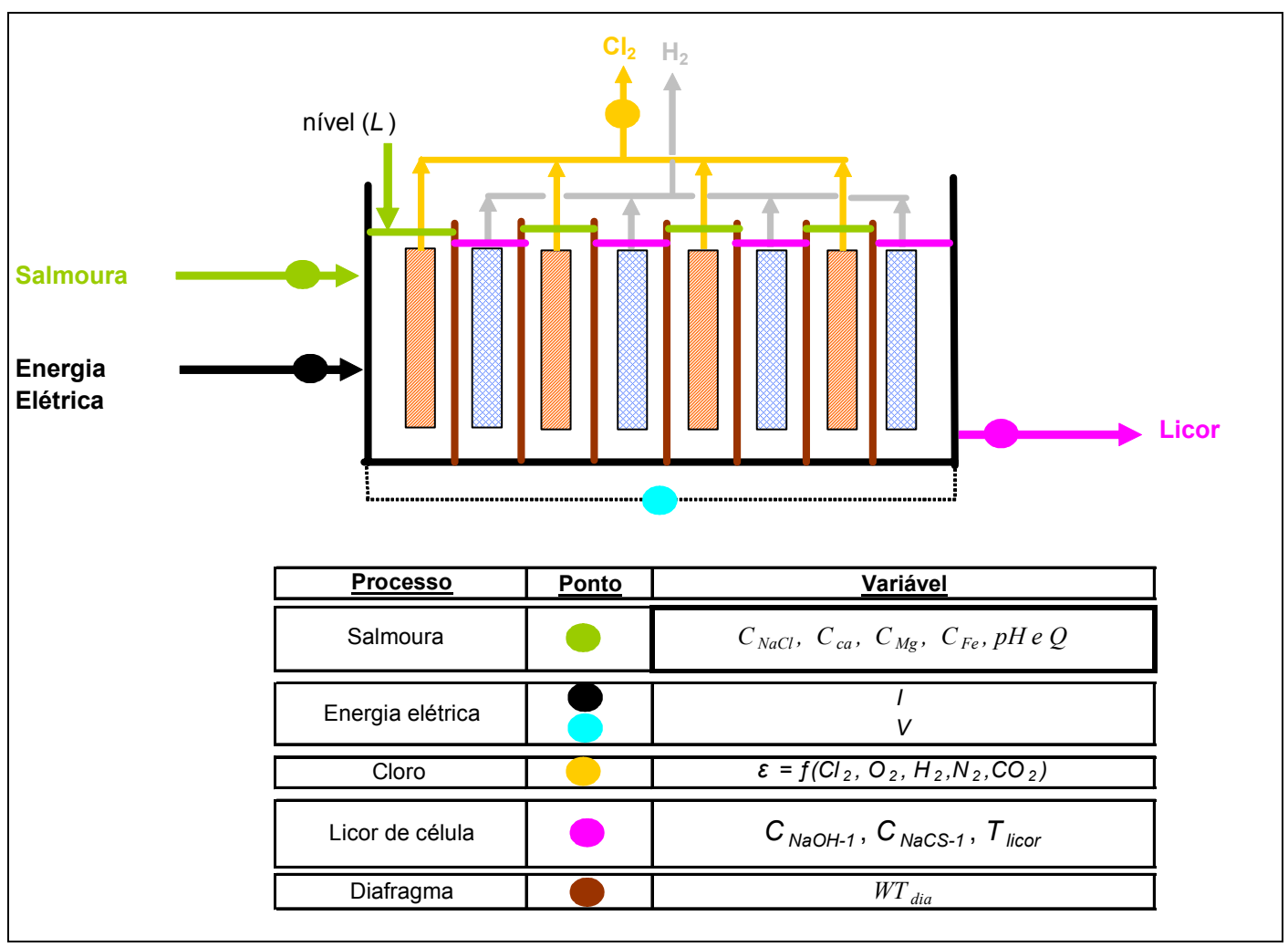

Figura 6.1 - Modelo de célula eletrolítica tipo diafragma

O objetivo de utilizar-se uma base de dados para um período tão extenso é verificar se houve mudanças de comportamento do processo ao longo dos anos utilizando ferramentas de análise estatística multivariada. Pesou também o fato da variável corrente elétrica empregada nas células eletrolíticas, com forte influência na voltagem, estar praticamente estabilizada já há alguns anos, desde 2002, após o racionamento de energia. Esse fato poderia alterar a influência desta variável quando do ajuste da rede neural. 


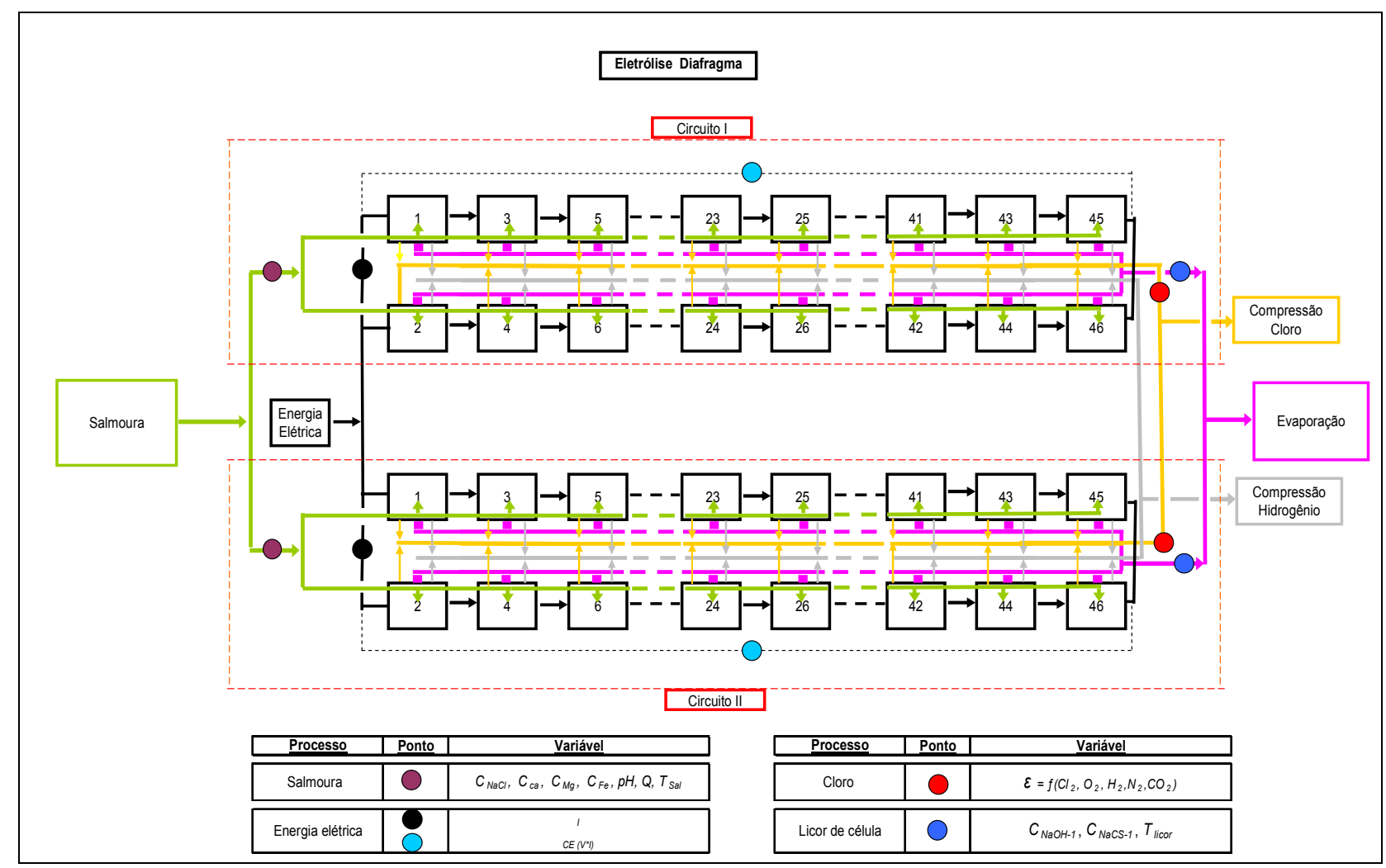

Figura 6.2 - Modelo de unidade de eletrólise diafragma contendo dois circuitos de 46 células cada um.

Além disso, algumas variáveis possuem poucos registros devido à baixa freqüência em que são analisadas, sendo necessários registros de vários anos para montagem de uma amostragem mais representativa, como as análises de cálcio, magnésio e ferro quando consideramos considerados dados do grupo I.

Inicialmente, foi realizado um trabalho de detecção e eliminação de "outliers" através de ferramentas de estatística básica, como análise de gráficos de linha e histogramas, incluindo aqui leituras medidas fora da escala de medição do instrumento. Também foram desconsiderados registros incompletos, ou seja, que não continham informações de uma ou mais variáveis consideradas importantes no processo.

Após eliminação de "outliers" o total de registros válidos para os grupos I e II foram 6867 e 2308 , respectivamente. 


\subsection{Evaporação}

Para o estudo da unidade de evaporação, foram coletados dados de processo organizados em apenas um grupo, contendo um total de 159 dados coletados num período de 5 meses. O numero número de registros ficou reduzido devido ao fato de algumas variáveis apresentarem pouca freqüência de análise, como, por exemplo, a concentração de licor. Essa variável é analisada três vezes ao dia, ou seja, uma análise para cada oito horas de operação.

Para a constituição do banco de dados, optou-se por trabalhar com valores médios diários, estabelecendo uma mesma freqüência para cada uma das variáveis que serão incluídas na obtenção do modelo. Outro recurso utilizado foi considerar registros para o banco de dados em regime estacionário de operação.

Tabela 6.2. Variáveis do processo de evaporação.

\begin{tabular}{|c|l|c|}
\hline Sigla & \multicolumn{1}{|c|}{ Variáveis } & Unidade \\
\hline$P_{3}$ & Pressão aplicada no evaporador do $3^{\circ}$ efeito & $\mathrm{mmHg}$ \\
\hline$P_{2}$ & Pressão aplicada no evaporador do $2^{\circ}$ efeito & $\mathrm{mmHg}$ \\
\hline$P_{1}$ & Pressão aplicada no evaporador do $1^{\circ}$ efeito & $\mathrm{mmHg}$ \\
\hline$T_{\text {licor-3 }}$ & Temperatura do licor (entrada $3^{\circ}$ efeito) & ${ }^{\circ} \mathrm{C}$ \\
\hline$C_{\text {NaOH-2 }}$ & Concentração de NaOH (entrada $3^{\circ}$ efeito) & $\mathrm{g} / \mathrm{L}$ \\
\hline$W T_{\text {NaOH }}$ & Produção de NaOH na evaporação (100\% em peso) & $\mathrm{t} / \mathrm{h}$ \\
\hline$W T_{\text {vapor }}$ & Consumo de vapor na evaporação & $\mathrm{t} / \mathrm{h}$ \\
\hline
\end{tabular}




\section{RESULTADOS DAS ANÁLISES DE DADOS}

\subsection{Sala de células diafragma}

O objetivo da análise estatística dos dados da eletrólise foi a identificação de características relevantes nos dados de operação do processo que pudessem afetar a modelagem do mesmo.

Para os dados do grupo I, as análises estatísticas tiveram os seguintes objetivos:

$>$ identificação de grupos por tipo de célula;

$>$ identificação de grupos distintos por ano de operação;

$>$ representatividade das variáveis de entrada e saída no processo;

$>$ análise de correlação das variáveis de processo;

Para os dados do grupo II, as análises estatísticas tiveram os seguintes objetivos:

$>$ identificação de grupos distintos por ano de operação;

$>$ representatividade das variáveis de entrada e saída no processo;

\subsubsection{Identificação de grupos distintos}

\subsubsection{Dados do grupo I}

Foi realizada análise discriminante baseada na técnica de discriminante quadrático (Johnson e Wichern, 1998), a qual faz a classificação dos dados em grupos considerando que estes apresentem diferentes matrizes de covariância. Foram adotadas duas abordagens: a primeira para verificar se há diferença entre medidas das células tipos 1 e 2; a segunda para verificar se há diferenças nas medidas ao 
longo do tempo de operação (o que poderia indicar alterações no regime operacional da unidade industrial).

A diferença entre as células tipo 1 e 2 são devido a constituição do diafragma. Nas células tipo 1 o diafragma é composto por uma mistura de fibras de amianto e teflon, enquanto que as células tipo 2 são constituídas por um diafragma a base de uma fibra sintética.

\section{Tipo 1 versus Tipo 2}

A fim de melhorar a precisão do resultado, foram utilizados apenas registros com datas coincidentes para os dois tipos de células. Desta forma, variáveis de concentração de salmoura na alimentação e corrente elétrica empregada nas células eletrolíticas, que são condições de processo e não característica do tipo de célula, são iguais para o conjunto de dados em estudo, totalizando 249 registros tanto para o tipo 1 como para tipo 2 .

Tabela 7.1 A função discriminante resultante para cada um dos dois tipos de células considerando dez variáveis de processo.

\begin{tabular}{ccc}
\hline Variável & Tipo 1 & Tipo 2 \\
\hline Termo independente & -29568 & -29549 \\
$D O L$ & -0 & -0 \\
$C_{N a C l-1}$ & -2 & -2 \\
$C_{N a O H}$ & -3 & -3 \\
$Q$ & -296 & -295 \\
$l$ & -0 & -0 \\
$T_{l i c o r}$ & 34 & 34 \\
$C_{N a C l}$ & 172 & 173 \\
$I$ & 9 & 9 \\
$V$ & -61 & -65 \\
$\varepsilon$ & 10 & 10 \\
\hline
\end{tabular}

Com estas duas funções discriminantes foram obtidos os resultados descritos a seguir. 
Do total de 249 registros das células tipo 1, 188 foram corretamente agrupados como tipo 1 e 61 foram agrupados como tipo 2, gerando um índice de acerto de $75,5 \%$.

Do total de 249 registros das células tipo 2, 191 foram corretamente agrupados como tipo 2 e 58 foram agrupados como tipo 1, gerando um índice de acerto de $76,7 \%$.

Tabela 7.2 Análise discriminante, número de observações e porcentagem de classificação nos anos dentro de cada classe, utilizando 10 variáveis de processo.

\begin{tabular}{cccccc}
\hline $\begin{array}{c}\text { Tipo de } \\
\text { Célula }\end{array}$ & $\begin{array}{c}\text { Total de } \\
\text { registros }\end{array}$ & $\begin{array}{c}\text { Registros } \\
\text { corretos }\end{array}$ & $\mathbf{( \% )}$ & $\begin{array}{c}\text { Registros } \\
\text { incorretos }\end{array}$ & $\mathbf{( \% )}$ \\
\hline 1 & 249 & 188 & 75,5 & 61 & 24,5 \\
2 & 249 & 191 & 76,7 & 58 & 23,3 \\
\hline Total & 498 & 379 & 76,1 & 119 & 23,9 \\
\hline
\end{tabular}

O resultado com índice de acerto de 76,1 \% não evidencia a existência de dois grupos distintos, ou seja, as diferenças das características entre as células tipo 1 e 2 não ficaram caracterizadas na análise discriminante.

\section{Comparativo Anual}

Para esta análise foram resgatados 6006 dados de processo para células tipo 1. Dos anos observados, 1995 e 2004 foram os que apresentaram maiores índices de acerto no agrupamento pelas suas respectivas funções discriminantes: 80,6 e 79,2 \% respectivamente. Porém estes anos são os que possuem menor tamanho da amostra, : 36 para 1995 e 53 para 2004.

$\mathrm{O}$ ano que apresentou o pior índice de acerto no agrupamento foi o ano de 2001 com 25,2 \%, indicando grande índice de sobreposição em relação aos outros anos.

O índice de acerto global de classificação utilizando análise discriminante foi de 50,6\%. A análise discriminante apresentou índices de acerto baixos, conforme a tabela 7.3, não sendo possível a discriminação de algum grupo. Portanto, com base 
nessa análise, não se evidenciam condições distintas de processo ao longo do período de 10 anos.

Tabela 7.3. Análise discriminante, número de observações e porcentagem de classificação.

\begin{tabular}{cccccc}
\hline Ano & $\begin{array}{c}\text { Total de } \\
\text { registros }\end{array}$ & $\begin{array}{c}\text { Registros } \\
\text { corretos }\end{array}$ & $\mathbf{( \% )}$ & $\begin{array}{c}\text { Registros } \\
\text { incorretos }\end{array}$ & $\mathbf{( \% )}$ \\
\hline 95 & 36 & 29 & 80,6 & 7 & 19,4 \\
96 & 369 & 180 & 48,8 & 189 & 51,2 \\
97 & 744 & 424 & 57,0 & 320 & 43,0 \\
98 & 799 & 293 & 36,7 & 506 & 63,3 \\
99 & 934 & 627 & 67,1 & 307 & 32,9 \\
00 & 925 & 602 & 65,1 & 323 & 34,9 \\
01 & 819 & 206 & 25,2 & 613 & 74,8 \\
02 & 806 & 296 & 36,7 & 510 & 63,3 \\
03 & 521 & 342 & 65,6 & 179 & 34,4 \\
04 & 53 & 42 & 79,2 & 11 & 20,8 \\
\hline Total & 6006 & 3041 & 50,6 & 2965 & 49,4 \\
\hline
\end{tabular}

\subsubsection{Dados do grupo II}

\section{Comparativo Anual}

Utilizando análise discriminante quadrática, para dados do grupo II o índice geral de acerto para os anos entre 1999 e 2005 foi de 79,6 \%.

Os anos de 2000, 2004 e 2005 foram os que apresentaram maiores índices, com 93,1, 96,6 e $100 \%$ respectivamente de acerto. Entretanto apenas nos anos de 2004 e 2005 é verificado pequeno número de pontos de outros anos que podem ser agrupados para estes dois anos, com 13 pontos para 2004 e nenhum ponto para 2005 do total de 996.

$\mathrm{O}$ ano de 2002 foi o que apresentou o pior resultado, com apenas 56,5\% de acerto. 
Tabela 7.4. Análise discriminante, número de observações e porcentagem de classificação nos anos dentro de cada classe, utilizando 12 variáveis de processo.

\begin{tabular}{cccccc}
\hline Ano & $\begin{array}{c}\text { Total de } \\
\text { registros }\end{array}$ & $\begin{array}{c}\text { Registros } \\
\text { corretos }\end{array}$ & $\mathbf{( \% )}$ & $\begin{array}{c}\text { Registros } \\
\text { incorretos }\end{array}$ & $\mathbf{( \% )}$ \\
\hline 99 & 168 & 141 & 83,9 & 27 & 16,1 \\
00 & 217 & 202 & 93,1 & 15 & 6,9 \\
01 & 214 & 152 & 71,0 & 62 & 29,0 \\
02 & 207 & 117 & 56,5 & 90 & 43,5 \\
03 & 190 & 144 & 75,8 & 46 & 24,2 \\
04 & 118 & 114 & 96,6 & 4 & 3,4 \\
05 & 31 & 31 & 100,0 & 0 & 0,0 \\
\hline Total & 1145 & 901 & 78,7 & 244 & 21,3 \\
\hline
\end{tabular}

A análise discriminante apresentou índices de acerto global de 78,7 \% considerando o período de 1999 a 2005, conforme tabela 7.4, indicando que não se pode afirmar a caracterização de sete grupos distintos para o referido período. Entretanto, fica evidente a formação de grupos distintos se analisarmos isoladamente os anos de $2004(96,6 \%)$ e 2005 com (100,0\%).

\subsubsection{Análise de Componentes Principais (PCA)}

\subsubsection{Dados do grupo I}

Utilizando os recursos de PCA do Minitab, objetivando reduzir o número de variáveis originais do processo com base na sua covariância, foi realizada a análise para todo o conjunto de variáveis de processo do grupo I, mas exclusivamente aqueles dados que tinham registros das variáveis $C_{C a}$ e $C_{M g}$, totalizando 292 registros.

Esta análise se justifica, porque é conhecido que tais compostos podem aumentar a obstrução no diafragma alterando as características de rendimento e do tempo de vida das células.

Empregando-se o PCA, o número de variáveis pode ser reduzido de 15 para 10 variáveis, atingindo a proporção de 91,2 \% da variância total. 
Outro fato observado é que nenhum dos componentes principais apresentou forte influência na variância global, sendo o valor encontrado para o primeiro componente igual a $22,4 \%$ (ver tabela 7.5$)$.

Tabela 7.5. Autovalores, porcentagem da variância e proporção da variância acumulada obtidos na análise de componentes principais.

\begin{tabular}{cccc}
\hline $\begin{array}{c}\text { Componente } \\
\text { Principal }\end{array}$ & Autovalores & $\mathbf{( \% )}$ & (\%) Acumulada \\
\hline 1 & 3.356 & 22.4 & 22.4 \\
2 & 2,339 & 15,6 & 38,0 \\
3 & 1,375 & 9,2 & 47,1 \\
4 & 1,277 & 8,5 & 55,7 \\
5 & 1,220 & 8,1 & 63,8 \\
6 & 1,063 & 7,1 & 70,9 \\
7 & 0,859 & 5,7 & 76,6 \\
8 & 0,812 & 5,4 & 82,0 \\
9 & 0,733 & 4,9 & 86,9 \\
10 & 0,653 & 4,4 & 91,2 \\
11 & 0,480 & 3,2 & 94,4 \\
12 & 0,303 & 2,0 & 96,5 \\
13 & 0,217 & 1,4 & 97,9 \\
14 & 0,173 & 1,2 & 99,1 \\
15 & 0,141 & 0,9 & 100,0 \\
\hline
\end{tabular}

Para o componente principal 1 (Figura 7.1), com 22,4 \% da variância, constata-se que as variáveis de maior influência são $Q, T_{\text {licor }}$, I e $V$.

Para o componente principal 2 (Figura 7.2), com 15,6 \% da variância, constata-se que as variáveis de maior influência são $C_{\mathrm{NaOH}}, C_{\mathrm{NaCl}-1}, T_{\text {licor }}$, e $\varepsilon$.

A seguir são representados graficamente os autovetores dos Componentes Principais 1 e 2 . 




Figura 7.1. Coeficientes das variáveis de processo para o $1^{\circ}$ componente principal, dados grupo I, eletrólise diafragma

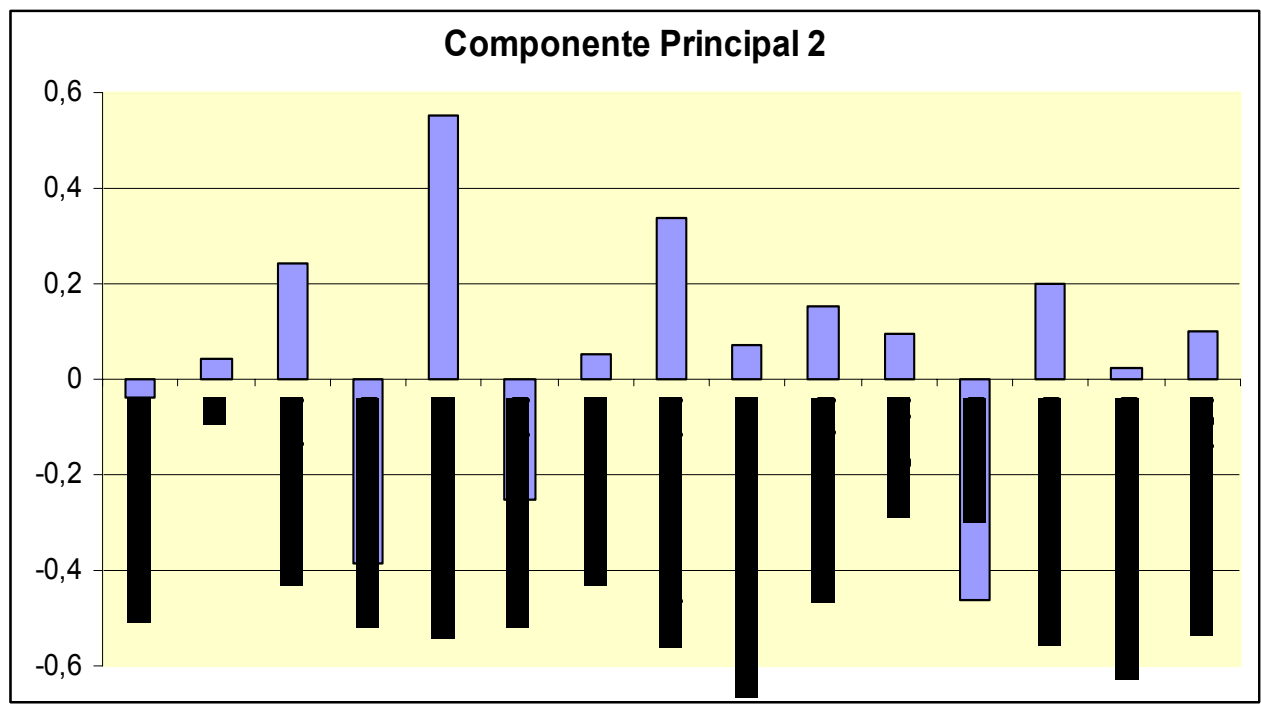

Figura 7.2. Coeficientes das variáveis de processo para o $2^{\circ}$ componente principal, dados grupo I, eletrólise diafragma

Com base na observação dos 7 primeiros componentes principais do total de 15 , representando variância total acumulada de 76,6 \%, não se verifica-se claramente que alguma das variáveis de processo da eletrólise tenha influência destacada sobre qualquer dos componentes principais, conforme apresentado na tabela 7.6. 
Tabela 7.6. Análise de Componentes Principais, Autovetores correspondentes aos 7 primeiros componentes principais e respectivos autovetores.

\begin{tabular}{cccccccc}
\hline Variável & $\mathbf{1}$ & $\mathbf{2}$ & $\mathbf{3}$ & $\mathbf{4}$ & $\mathbf{5}$ & $\mathbf{6}$ & $\mathbf{7}$ \\
\hline$W T_{d i a}$ & 0,003 & $-0,037$ & $\mathbf{- 0 , 4 0 4}$ & 0,094 & $\mathbf{0 , 5 8 2}$ & $-0,104$ & $\mathbf{0 , 5 3 0}$ \\
$p H$ & $-0,204$ & 0,042 & $\mathbf{- 0 , 3 1 5}$ & $-0,251$ & 0,039 & $\mathbf{0 , 3 8 9}$ & $-0,025$ \\
$D O L$ & 0,054 & 0,245 & $\mathbf{0 , 5 0 5}$ & $\mathbf{- 0 , 4 7 9}$ & 0,052 & 0,13 & 0,235 \\
$C_{N a C l-1}$ & 0,297 & $\mathbf{- 0 , 3 8 8}$ & 0,171 & $\mathbf{- 0 , 3 3 4}$ & 0,122 & 0,094 & 0,039 \\
$C_{N a O H}$ & $-0,089$ & $\mathbf{0 , 5 5 4}$ & $-0,109$ & 0,267 & $-0,163$ & $-0,022$ & $-0,053$ \\
$Q$ & $\mathbf{0 , 3 8 3}$ & $-0,25$ & $-0,042$ & $-0,053$ & 0,072 & 0,031 & $-0,002$ \\
$l$ & 0,209 & 0,054 & $-0,099$ & 0,124 & $\mathbf{- 0 , 3 9 6}$ & 0,212 & $\mathbf{0 , 7 0 1}$ \\
$T_{l i c o r}$ & $\mathbf{0 , 3 9 6}$ & $\mathbf{0 , 3 3 6}$ & 0,084 & 0,032 & 0,001 & 0,081 & $-0,063$ \\
$C_{N a C l}$ & $-0,099$ & 0,07 & $-0,223$ & $-0,294$ & $-0,26$ & 0,53 & $-0,005$ \\
$I$ & $\mathbf{0 , 4 7 8}$ & 0,152 & $-0,063$ & 0,133 & 0,073 & $-0,008$ & $-0,012$ \\
$V$ & $\mathbf{0 , 4 4 7}$ & 0,097 & 0,010 & 0,200 & $-0,014$ & 0,193 & $-0,182$ \\
$E$ & 0,106 & $\mathbf{- 0 , 4 6 1}$ & $-0,152$ & 0,204 & $\mathbf{- 0 , 4 1 6}$ & 0,021 & $-0,113$ \\
$\boldsymbol{C}_{\boldsymbol{C a}}$ & 0,165 & 0,199 & $-0,147$ & $\mathbf{- 0 , 3 9 7}$ & $-0,125$ & $\mathbf{- 0 , 4 8 8}$ & $-0,032$ \\
$\boldsymbol{C}_{\boldsymbol{M g}}$ & 0,103 & 0,024 & $\mathbf{- 0 , 4 2 7}$ & $\mathbf{- 0 , 3 6 7}$ & $\mathbf{- 0 , 3 0 4}$ & $\mathbf{- 0 , 3 6 8}$ & 0,002 \\
$\boldsymbol{C}_{\boldsymbol{F e}}$ & 0,157 & 0,102 & $\mathbf{- 0 , 3 7 7}$ & $-0,135$ & $\mathbf{0 , 3 1 6}$ & 0,26 & $\mathbf{- 0 , 3 4 1}$ \\
\hline
\end{tabular}

Pelos valores apresentados utilizando PCA não se consegue evidenciar a existência de um componente principal com alta representatividade na variância do processo.Quanto à redução do número de variáveis, para uma variância aceitável de cerca de $90 \%$, o processo pode ser representado pelos 10 primeiros componentes principais contra as 15 variáveis originais.

Em função dos resultados verificados com PCA, optou-se em realizar os testes de modelagem utilizando todas as 15 variáveis originais, e não os componentes principais como uma combinação linear das variáveis originais.

\subsubsection{Dados do grupo II}

Utilizando o PCA, foi realizada análise de componentes principais para todo o conjunto de 10 variáveis do processo com dados do grupo II. 
Foram realizados dois ensaios, o primeiro considerando todos os registros do grupo II e o segundo com os registros apenas do ano de 2004, denominados grupo II04, devido aos resultados verificados na análise discriminante onde se evidenciou a formação de grupos distintos nos anos de 2004 e 2005.

Os resultados obtidos pela análise de componentes principais para os dois grupos de dados citados acima, mostraram que, para uma representatividade acima de $90 \%$ da variância, o número de variáveis pode ser reduzido de 10 para 8 variáveis para o grupo II e de 10 para 7 para o grupo II-04, não identificando nenhum componente principal com alta representatividade em ambos os grupos (tabela 7.7).

Tabela 7.7. Análise de Componentes Principais, proporção da variância e proporção da variância acumulada.

\begin{tabular}{ccccc}
\hline $\begin{array}{c}\text { Componente } \\
\text { Principal }\end{array}$ & $\begin{array}{c}\text { Grupo II } \\
(\%)\end{array}$ & $\begin{array}{c}\text { Grupo II } \\
\text { (\%) Acum. }\end{array}$ & $\begin{array}{c}\text { Grupo II-04 } \\
(\%)\end{array}$ & $\begin{array}{c}\text { Grupo II-04 } \\
\text { (\%) Acum. }\end{array}$ \\
\hline 1 & 24,8 & 24,8 & 20,7 & 20,7 \\
2 & 22,4 & 47,2 & 15,9 & 36,5 \\
3 & 11,5 & 58,7 & 12,9 & 49,4 \\
4 & 10,4 & 69,1 & 10,3 & 59,7 \\
5 & 9,3 & 78,4 & 9,2 & 68,8 \\
6 & 8,2 & 86,7 & 9 & 77,8 \\
7 & 6 & 92,6 & 7,6 & 85,5 \\
8 & 3,9 & 96,5 & 5,7 & 91,1 \\
9 & 2,9 & 99,5 & 5,4 & 96,5 \\
10 & 0,5 & 100 & 3,5 & 100 \\
\hline
\end{tabular}

Para o componente principal 1 do grupo II (Figura 7.3), com $24,8 \%$ da variância, constata-se que as variáveis de maior influência são $V, I$ e $T_{\text {licor }}$. Enquanto, que para o grupo II-04, as variáveis de maior influência são concentração $C_{\mathrm{NaOH}-1}$, $T_{\text {licor }}$ e $\varepsilon$. Esta distinção de resultados pode ser justificada devido ao fato de que, no ano de 2004, a corrente elétrica aplicada nas células ficou praticamente inalterada durante o ano inteiro, o que ocorreu com os dados do grupo II. 


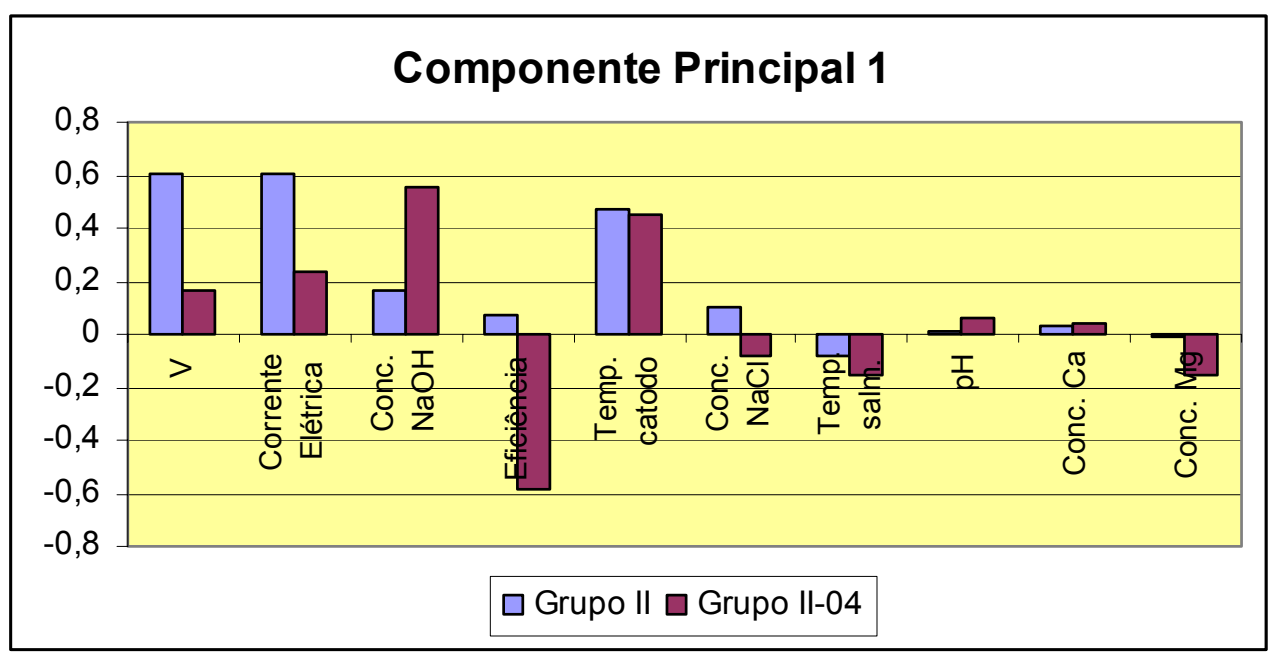

Figura 7.3. Coeficientes das variáveis de processo para o $1^{\circ}$ componente principal para dados do grupo II.

Para os demais componentes principais também não se evidencia a mesma tendência quanto à influência das variáveis nos dois grupos de dados. Para o segundo componente do grupo II, as variáveis de maior influência foram $C_{\mathrm{NaCl}}, C_{\mathrm{Ca}}$ e $T_{\mathrm{sal}}$, enquanto que no grupo II-04 os maiores coeficientes foram $V, I, C_{C a}, C_{M g}$.

Pela análise de componentes principais não se conseguiu reduzir significativamente o número de variáveis, mantendo a representatividade em torno de 90 \%, indicando uma dispersão na importância das variáveis do processo, ou melhor, por essa metodologia todas as variáveis devem ser consideradas para um estudo de modelagem.

\subsubsection{Análise de Correlação}

Analisando-se os coeficientes de correlação, com dados do grupo I, as variáveis de maior coeficiente de correlação para a eficiência de corrente foram $D O L$ $(-0,425)$ e $C_{\mathrm{NaOH}}(-0,328)$, porem estes não evidenciam estas correlações, ao observar os valores destes coeficientes. Na operação, células mais velhas operam com concentrações de $\mathrm{NaOH}$ mais altas, devido obstrução gradativa do diafragma, logo tendem a ter uma eficiência de corrente menor, conforme mencionado no item 3.1.8.

Para a voltagem os resultados foram $T_{\text {licor }}(0,641)$ e $I(0,582)$. Na operação a tanto a intensidade de corrente como a temperatura do licor influenciam na voltagem, conforme mencionado nos itens 3.1 .5 e 3.1 .3 respectivamente. 


\subsection{Evaporação}

\subsubsection{Análise de Componentes Principais}

Aplicando-se a PCA para o conjunto de dados, conseguiu-se reduzir o número de variáveis de 7 para 3 com representatividade de $87,9 \%$ da variância total do processo, sendo $48,9 \%, 24,8 \%$ e $14,2 \%$ a variância dos $1^{\circ}, 2^{\circ}$ e $3^{\circ}$ componentes principais respectivamente (tabela 7.8 ).

Tabela 7.8 - Análise dos Componentes Principais, autovalores, proporção da variância e proporção da variância acumulada.

\begin{tabular}{cccc}
\hline $\begin{array}{c}\text { Componente } \\
\text { Principal }\end{array}$ & Autovalores & $(\mathbf{\%})$ & (\%) Acumulada \\
\hline 1 & 3,426 & 48,9 & 48,9 \\
2 & 1,737 & 24,8 & 73,8 \\
3 & 0,992 & 14,2 & 87,9 \\
4 & 0,423 & 6,0 & 94,0 \\
5 & 0,305 & 4,4 & 98,3 \\
6 & 0,111 & 1,6 & 99,9 \\
7 & 0,006 & 0,1 & 100,0 \\
\hline
\end{tabular}

No primeiro componente (Figura 7.4), com 48,9\% de variância, observa-se uma distribuição de importância entre 5 variáveis $P_{2}, P_{3}, W T_{\text {vapor }}, W T_{\mathrm{NaOH}}$ e $T_{\text {licor-3. }}$. 


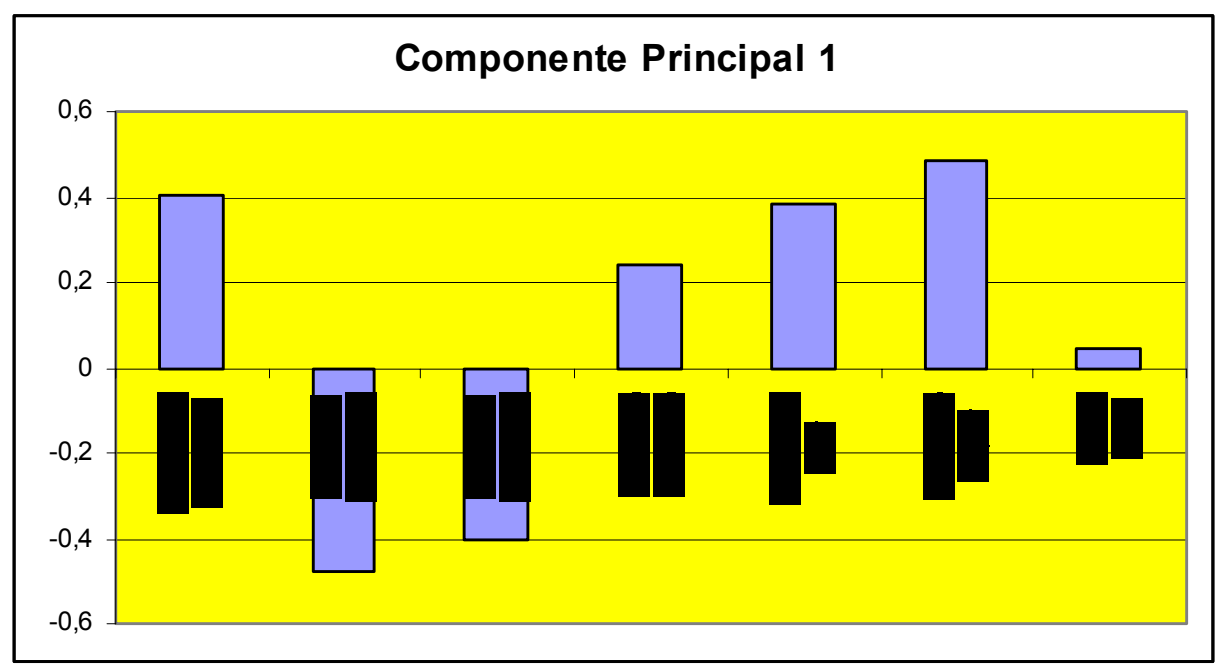

Figura 7.4. Coeficientes das variáveis de processo para o $1^{\circ}$ componente principal, evaporação

No segundo componente (Figura 7.5), com $24,8 \%$ de variância, observa-se também que das 7 variáveis originais 5 tem influência significativa $P_{1}, P_{2}, P_{3}$, $W T_{\mathrm{NaOH}}$ e $\mathrm{C}_{\mathrm{NaOH}-2}$.

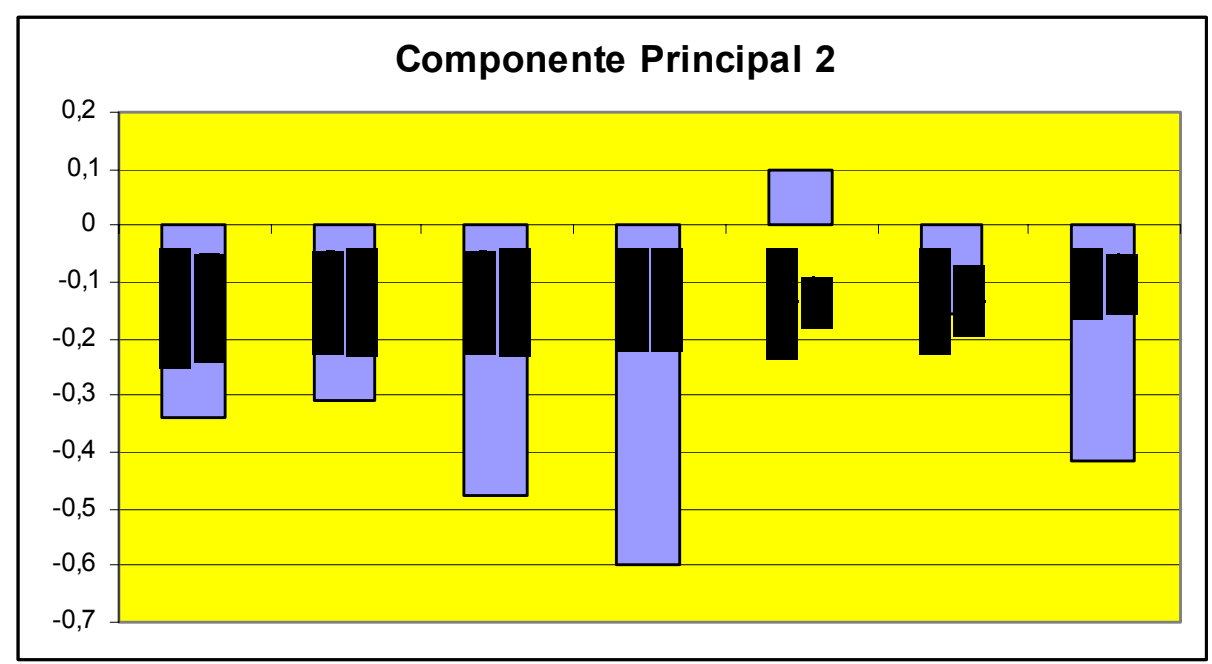

Figura 7.5. Coeficientes das variáveis de processo para o $2^{\circ}$ componente principal, evaporação 
$\mathrm{Na}$ Tabela 7.9 são representados os sete componentes principais e seus respectivos autovetores, onde os maiores autovetores de cada um dos componentes são representados com valores em negrito.

Tabela 7.9. Componentes principais e respectivos autovetores.

\begin{tabular}{cccccccc}
\hline Variável & $\mathbf{1}$ & $\mathbf{2}$ & $\mathbf{3}$ & $\mathbf{4}$ & $\mathbf{5}$ & $\mathbf{6}$ & $\mathbf{7}$ \\
\hline$P_{3}$ & $\mathbf{- 0 , 4 7 9}$ & $\mathbf{- 0 , 3 0 7}$ & $-0,010$ & $-0,186$ & $\mathbf{0 , 3 0 0}$ & 0,210 & $\mathbf{- 0 , 7 1 3}$ \\
$P_{2}$ & $\mathbf{- 0 , 4 0 1}$ & $\mathbf{- 0 , 4 7 6}$ & $-0,101$ & $-0,268$ & 0,139 & 0,237 & $\mathbf{0 , 6 7 4}$ \\
$P_{1}$ & 0,242 & $\mathbf{- 0 , 5 9 7}$ & $-0,179$ & $-0,269$ & $\mathbf{- 0 , 5 8 5}$ & $\mathbf{- 0 , 3 2 6}$ & $-0,175$ \\
$T_{\text {licor }-3}$ & $\mathbf{0 , 3 8 3}$ & 0,099 & $\mathbf{0 , 4 8 0}$ & $\mathbf{- 0 , 7 5 0}$ & 0,212 & 0,076 & 0,000 \\
$W T_{\text {vapor }}$ & $\mathbf{0 , 4 8 8}$ & $-0,154$ & $-0,254$ & 0,134 & $-0,050$ & $\mathbf{0 , 8 0 5}$ & $-0,077$ \\
$C_{N a O H-2}$ & $\mathbf{- 0 , 4 7 9}$ & $\mathbf{- 0 , 3 0 7}$ & $-0,010$ & $-0,186$ & $\mathbf{0 , 3 0 0}$ & 0,210 & $\mathbf{- 0 , 7 1 3}$ \\
$W T_{\text {NaOH }}$ & $\mathbf{0 , 4 0 6}$ & $\mathbf{- 0 , 3 4 0}$ & $-0,235$ & 0,174 & $\mathbf{0 , 7 0 6}$ & $\mathbf{- 0 , 3 6 8}$ & 0,020 \\
\hline
\end{tabular}

Considerando uma variância aceitável de 87,9 \%, podemos reduzir o número de variáveis utilizando análise de componentes principal principais de sete para três. Porém os coeficientes das variáveis originais indicam que, mesmo considerando apenas três componentes, todas as variáveis originais deverão ser consideradas em um estudo de modelagem do processo.

\subsubsection{Análise de Correlação}

Utilizando Análise de Correlação do Minitab, onde é calculado o coeficiente de correlação linear para cada par de variáveis, constata-se que os maiores coeficientes, em relação ao $W T_{\text {vapor }}$, foram $P_{1}, P_{2}, P_{3}$, e $W T_{N a O H}$. As variáveis de entrada que indicaram maiores índices de correlação entre si foram $P_{2}$ e $P_{3}, P_{1} e$ $W T_{\mathrm{NaOH}}$, e $T_{\text {licor-3 }} \operatorname{com} P_{2}$ e $P_{3}$.

O resultado da influência das pressões no consumo de vapor se justifica, conforme pode ser verificado na figura 3-5.

A correlação do nível de produção de soda com o consumo de vapor está associada a uma maior quantidade de água a ser evaporada, o que implica maior o consumo de vapor. 
Observando-se os coeficientes de correlação (tabela 7.1), a variável $C_{\mathrm{NaOH}-2}$ foi exceção aos resultados esperados, pois esta não indica correlação com o consumo de vapor. Porém sabe-se que quanto maior a concentração de licor, menor a quantidade de água a ser evaporada e menor será o consumo de vapor.

Tabela 7.10. Análise de Correlação, coeficientes de correlação entre variáveis.

\begin{tabular}{ccccccc}
\hline Variável & $\boldsymbol{P}_{\mathbf{3}}$ & $\boldsymbol{P}_{\mathbf{2}}$ & $\boldsymbol{P}_{\mathbf{1}}$ & $\boldsymbol{T}_{\text {licor-3 }}$ & $\boldsymbol{W}_{\text {vapor }}$ & $\boldsymbol{C}_{\mathrm{NaOH}-\mathbf{2}}$ \\
\hline$P_{3}$ & $*$ & $*$ & $*$ & $*$ & $*$ & $*$ \\
$P_{2}$ & 0,949 & $*$ & $*$ & $*$ & $*$ & $*$ \\
$P_{1}$ & $-0,116$ & 0,176 & $*$ & $*$ & $*$ & $*$ \\
$T_{\text {licor-3 }}$ & $-0,606$ & $-0,559$ & 0,174 & $*$ & $*$ & $*$ \\
$W_{\text {vapor }}$ & $-0,711$ & $-0,513$ & 0,574 & 0,453 & $*$ & $*$ \\
$C_{\text {NaOH-2 }}$ & 0,104 & 0,155 & 0,283 & 0,208 & 0,019 & $*$ \\
$W T_{\text {NaOH }}$ & $-0,441$ & $-0,253$ & 0,599 & 0,350 & 0,795 & 0,145 \\
\hline
\end{tabular}




\section{RESULTADOS DO AJUSTE DE MODELOS DE REDES NEURAIS (RN)}

Para a preparação dos dados, ajuste dos modelos de $\mathrm{RN}$ e análise de resultados foram utilizados programas desenvolvidos no LSCP-DEQ-EPUSP (Nascimento e Guardani, 2000).

\subsection{Sala de Células Diafragma}

Utilizando as bases de dados dos grupos I e II, foram adotadas as seguintes abordagens para ajuste de $\mathrm{RN}$, de acordo com as variáveis de saída selecionadas: voltagem e eficiência de corrente.

Para os dados do grupo I, foram testadas inicialmente três abordagens para a $\mathrm{RN}$, utilizando todos os registros disponíveis, com uma e duas saídas. O objetivo foi verificar qual a resposta inicial da rede em relação aos registros disponíveis.

Em seguida foram realizadas mais duas abordagens, porém exclusivamente com registros contendo análises de cálcio, magnésio e ferro, e com apenas uma saída na RN.

Também foram realizados testes utilizando registros do ano de 1998 e posteriormente registros de 2001, tendo-se somente uma saída. Desta forma seria verificado se restringindo o período de registros, o modelo testado apresentaria alterações significativas na resposta da rede.

Nos últimos testes realizados com dados do grupo I, em vez de utilizar registros de todas as células, foram utilizados registros de apenas uma célula, tendo modelos de $\mathrm{RN}$ com uma única saída e posteriormente evoluindo para um modelo de três saídas, onde a concentração de $\mathrm{NaOH}$ no licor passou de variável de entrada para variável de saída . Com estes ensaios, contendo dados de uma única célula, seria verificado a influência das variáveis relativas a diferenças na montagem das células, peso e espessura do diafragma por exemplo, sobre o ajuste da RN.

Para os dados do grupo II, foram utilizados todos os registros, obtidos com dados coletados de cada um dos circuitos, grupo de 46 células, para os testes da RN, 
porém tendo como variável de saída o consumo de energia e eficiência de corrente. Neste caso, uma outra base de dados seria testada, contemplando registros por circuito (conjunto de 46 células). Na tabela 8.1 são mostradas as diferentes abordagens para as $\mathrm{RN}$ testadas.

Tabela 8.1. Abordagens para as RN testadas.

\begin{tabular}{|c|c|c|c|c|}
\hline Grupo & Entrada & Saída & Registro & Abordagem \\
\hline \multirow{10}{*}{$\underline{I}$} & \multirow{7}{*}{$\begin{array}{c}\mathrm{WT}_{\text {dia }} \\
\mathrm{DOL} \\
\mathrm{C}_{\mathrm{NaOH}-1} \\
\mathrm{C}_{\mathrm{NaCl}} \\
\mathrm{C}_{\mathrm{NaCl}-1} \\
\mathrm{~T}_{\text {licor }} \\
\mathrm{I} \\
\mathrm{Q} \\
\mathrm{L} \\
\mathrm{C}_{\mathrm{Ca}} \\
\mathrm{C}_{\mathrm{Mg}} \\
\mathrm{C}_{\mathrm{Fe}} \\
\mathrm{pH}\end{array}$} & \multirow{3}{*}{$\varepsilon$} & todos & 1 \\
\hline & & & $\begin{array}{c}\operatorname{com~Ca}, \mathrm{Mg} \mathrm{e} \\
\mathrm{Fe}\end{array}$ & 2 \\
\hline & & & por ano & 3 \\
\hline & & \multirow{3}{*}{ V } & todos & 5 \\
\hline & & & $\begin{array}{c}\text { com Ca, } \mathrm{Mg} \mathrm{e} \\
\mathrm{Fe}\end{array}$ & 6 \\
\hline & & & por ano & 7 \\
\hline & & $\mathrm{V}, \varepsilon$ & todos & 9 \\
\hline & $\begin{array}{c}\mathrm{DOL} \\
\mathrm{C}_{\mathrm{NaOH}-1} \\
\mathrm{C}_{\mathrm{NaCl}-1}\end{array}$ & $\varepsilon$ & por célula & 4 \\
\hline & $\begin{array}{l}\text { I } \\
\text { Q } \\
\text { L }\end{array}$ & V & por célula & 8 \\
\hline & $\begin{array}{c}\mathrm{DOL} \\
\mathrm{C}_{\mathrm{NaCl}-1} \\
\mathrm{~T}_{\text {licor }} \\
\mathrm{I} \\
\mathrm{Q} \\
\end{array}$ & $\begin{array}{c}\mathrm{C}_{\mathrm{NaOH}-1} \\
\mathrm{~V} \\
\mathrm{E}\end{array}$ & por célula & 12 \\
\hline \multirow{2}{*}{$\underline{I I}$} & $\begin{array}{c}\mathrm{C}_{\mathrm{NaOH}-1} \\
\mathrm{C}_{\mathrm{NaCl}-1} \\
\mathrm{~T}_{\text {licor }} \\
\mathrm{I}\end{array}$ & $\mathrm{CE}$ & todos & 10 \\
\hline & $\begin{array}{c}\mathrm{T}_{\mathrm{sal}} \\
\mathrm{C}_{\mathrm{Ca}} \\
\mathrm{C}_{\mathrm{Mg}} \\
\mathrm{pH}\end{array}$ & $\mathrm{E}$ & todos & 11 \\
\hline
\end{tabular}


Resultados

A seqüência das abordagens testadas foi estabelecida de forma a se obter o modelo mais simples possível que pudesse representar o processo em estudo, sendo que para cada abordagem foram realizados ensaios com diferentes números de neurônios de acordo com os resultados apresentados. Para os modelos que apresentaram resultados mais promissores, foram realizados ensaios variando-se a configuração da rede entre 4 e 10 neurônios.

A primeira abordagem testada foi a número 9, no qual buscava-se, a partir do conjunto de dados de todas as células, obter um único modelo que representasse as variáveis eficiência de corrente e voltagem. O resultado foi a falta de concordância entre os valores calculados pela $\mathrm{RN}$ e os dados de processo para as duas variáveis em questão.

As abordagens testadas em seguida foram a 1 e 5 , nas quais foi utilizado o mesmo conjunto de dados, porém considerando apenas uma única variável de saída. Não houve ajuste da RN para predizer a eficiência de corrente nem para a voltagem.

O próximo passo foi testar as abordagens 2 e 6 , em que foram incluídas as variáveis de concentração de cálcio, magnésio e ferro na salmoura. Porém devido a se tratarem de análises de laboratório, o conjunto de dados para ajuste da $\mathrm{RN}$ diminuiu consideravelmente para cerca de 300. Também nestas abordagens não se verificou ajuste da RN para as duas variáveis em questão.

Buscou-se então reduzir o período de dados coletados do processo de dez para um ano, admitindo-se a hipótese de que alterações nas condições de processo em um período tão longo poderiam dificultar o ajuste da RN. Foram realizados ensaios isoladamente com dados de 1998 e 2001. O resultado foi que as duas abordagens, testadas, 3 e 7, não apresentaram concordância entre os valores calculados pela $\mathrm{RN}$ e os dados de processo.

Em função da falta de bons resultados obtidos nas abordagens anteriores, foi feita a opção de trocar o conjunto de dados obtidos a partir de cada célula pelo conjunto de dados obtidos a partir de cada um dos dois circuitos, em que os dados de processo resultam das condições de operação de 46 células. Outra alteração adotada foi a substituição da variável voltagem pelo consumo de energia que é medida por 
circuito. Para a eficiência de corrente, abordagem 11, não houve ajuste da $\mathrm{RN}$, mas para o consumo de energia, abordagem 10, ocorreu ajuste da $\mathrm{RN}$ até valores de 580 MWh, sendo que para valores maiores verificou-se falta de concordância entre os resultados calculados pela $\mathrm{RN}$ e os dados de processo.

Por último foram testadas as abordagens 4,8 e 12, nas quais foram utilizados apenas dados de processo de uma única célula buscando-se um melhor ajuste da RN. Foram realizados testes com três células, em que todos os dados coletados no processo, cerca de 30 por célula, foram utilizados para treinamento da $\mathrm{RN}$.

A seguir são apresentados os resultados das abordagens na seqüência 4, 8, 12 e 10.

\section{Abordagem 4}

Os resultados para esta abordagem indicaram ajuste entre os valores calculados de eficiência de corrente pela $\mathrm{RN}$ e os dados de processo. Entretanto, este resultado foi obtido tomando como referência o ajuste da $\mathrm{RN}$ de treinamento, motivado pela pequena quantidade de registros, 30, disponíveis para cada célula.

Para esta abordagem, como também para as abordagens 8 e 12, foram utilizados os dados coletados durante a vida de operação de três células, escolhidas aleatoriamente, porém em períodos de operação distintos.

Nos três ensaios verificou-se concordância entre os valores calculados de eficiência de corrente pela $\mathrm{RN}$ e os dados de processo.

Verifica-se comportamento semelhante do erro quadrático para as três células, com queda acentuada até 1000 apresentações e uma redução menos acentuada a partir deste ponto, atingindo valores próximos a zero no final das 10000 apresentações.

Na comparação entre os valores calculados de eficiência de corrente pela $\mathrm{RN}$ e os dados de processo observa-se que o coeficiente angular da reta de ajuste, assim como o coeficiente de determinação, estão sempre acima de 0,97 para a RN com NH igual a 4. Para NH igual a 6 e 8 praticamente ocorre a repetição dos resultados. 
Nas figuras 8.1.a e 8.1.b são representados os erros quadráticos e a comparação dos valores calculados de eficiência de corrente pela $\mathrm{RN}$ e dados de processo, para NH igual a 4.

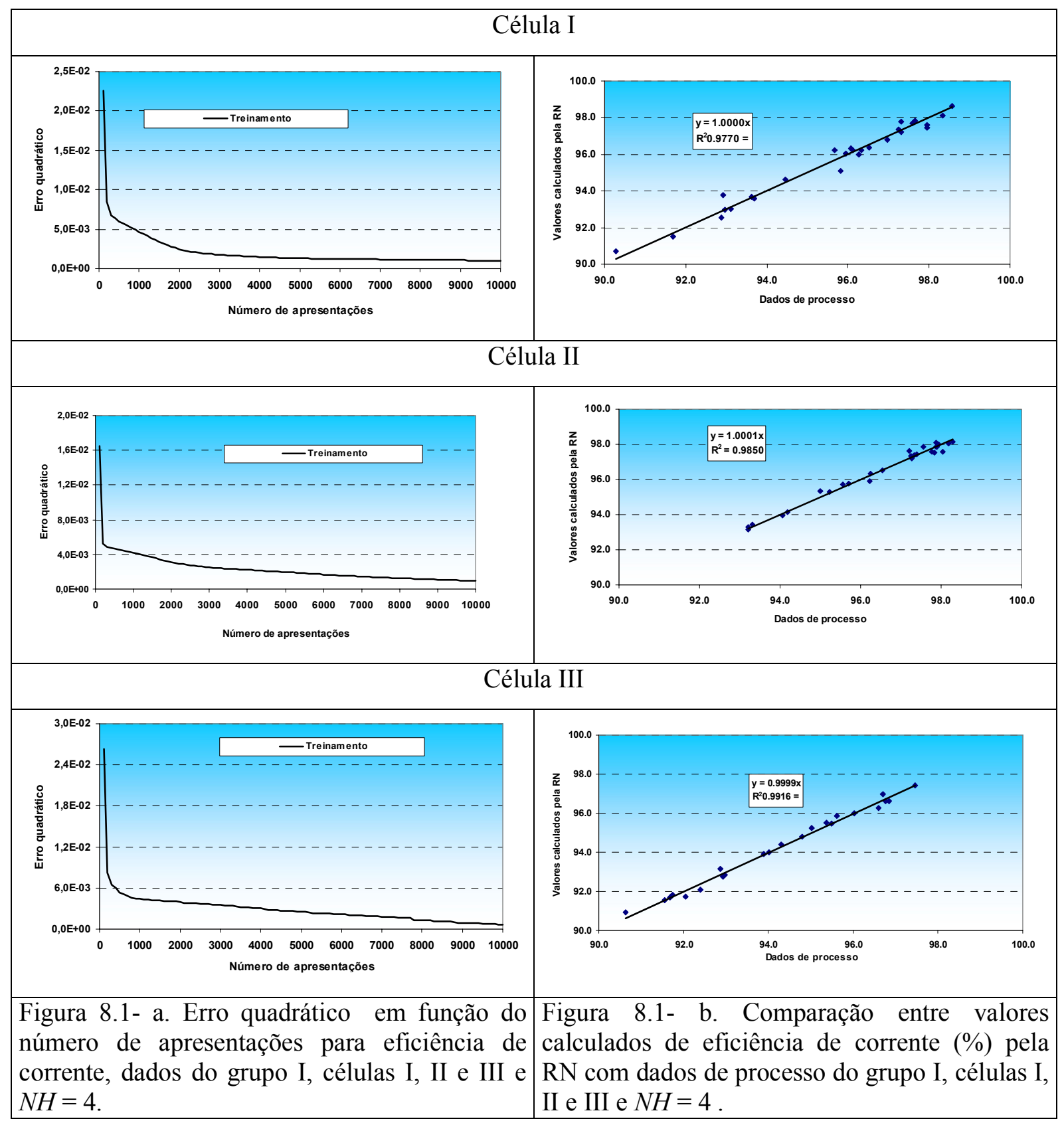

Como o número de dados testados é inferior a 40, para os testes de consistência da $\mathrm{RN}$ na análise dos erros entre os valores calculados e dados de processo, foi utilizada a representação gráfica da função distância para verificação 
do comportamento dos desvios em relação aos valores de processo, em vez do gráfico de distribuição das diferenças, quando o número de dados testados deve ser superior a 40 .

Na representação gráfica da função distância das diferenças entre os valores calculados de voltagem pela $\mathrm{RN}$ e os dados de processo, observa-se o efeito de simetria nos três modelos testados e resultados semelhantes para as três células, conforme pode ser observado nas figuras 8.2-a, 8.2-b e 8.2-c.

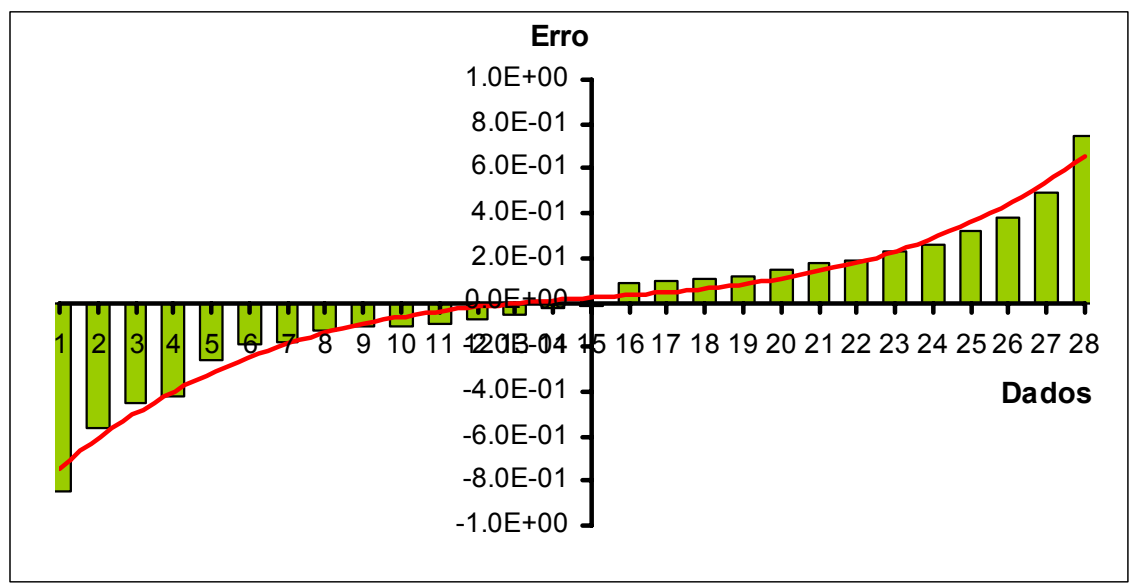

Figura 8.2-a Função distância entre valores calculados de eficiência pela RN e dados de processo para célula I, NH igual a 4.

Figura 8.2-b Função distância entre valores calculados de eficiência pela $\mathrm{RN}$ e dados de processo para célula II, $\mathrm{NH}$ igual a 4.

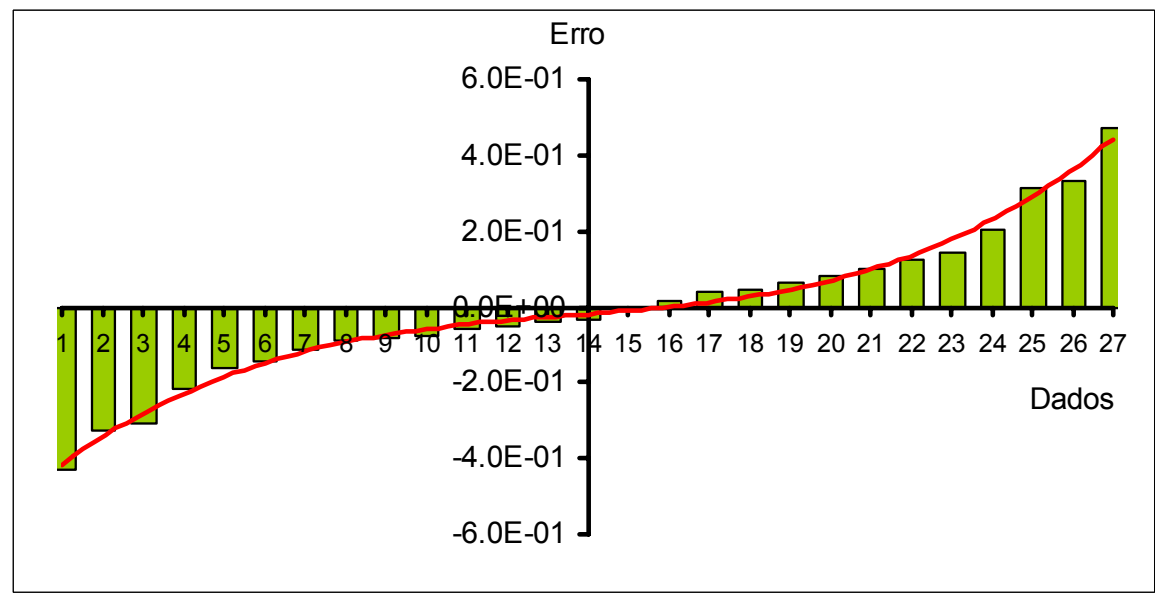




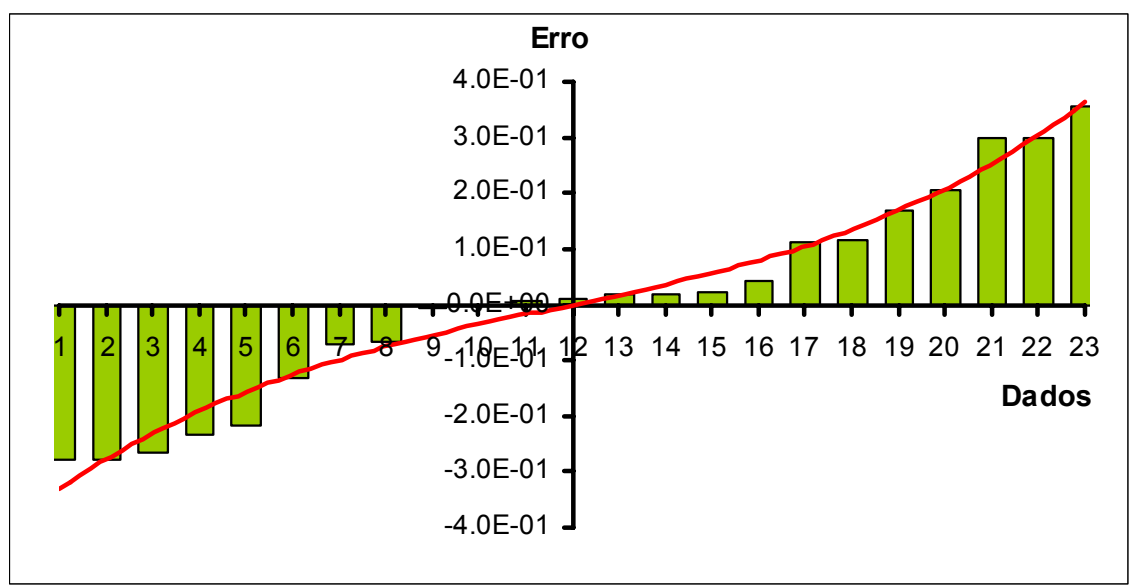

Figura 8.2-c Função distância entre valores calculados de eficiência pela RN e dados de processo para célula III, NH igual a 4.

\section{Abordagem 8}

Analisando-se agora a variável de saída voltagem, verificou-se ajuste dos modelos das três células quando comparados os valores calculados pela $\mathrm{RN}$ e os dados de processo. Nesta abordagem também se repete o problema do pequeno número de dados disponíveis para ajuste dos modelos. Por isso, todos os dados foram alocados no conjunto de aprendizado (LS). O perfil da variação do erro quadrático para as três células apresentou diferenças no transcorrer das apresentações, porém apresentando valores próximos de zero quando do final das 10000 apresentações.

Comparando os valores calculados de voltagem pela $\mathrm{RN}$ e os dados de processo observa-se que os coeficientes angulares e de determinação estão acima de 0,96 para a $\mathrm{RN}$ com $\mathrm{NH}$ igual a 4. Para $\mathrm{NH}$ igual a 6 e 8 não ocorreu melhora acentuada no ajuste da RN. Nas figuras 8.3-a e 8.3-b são representados os erros quadráticos e a comparação dos valores calculados de voltagem pela $\mathrm{RN}$ e dados de processo, para $\mathrm{NH}$ igual a 4.

Representando graficamente a função distância das diferenças entre os valores calculados de voltagem pela $\mathrm{RN}$ e os dados de processo, observa-se o efeito de simetria mais acentuado nos modelos das células I e III e em menor grau no modelo da célula II, devido ao erro no valor de 0,09 . 
Nas figuras 8.4-a, 8.4-b e 8.4-c são representadas a função distância das diferenças entre os valores calculados de voltagem pela $\mathrm{RN}$ e dados de processo para NH igual a 4.

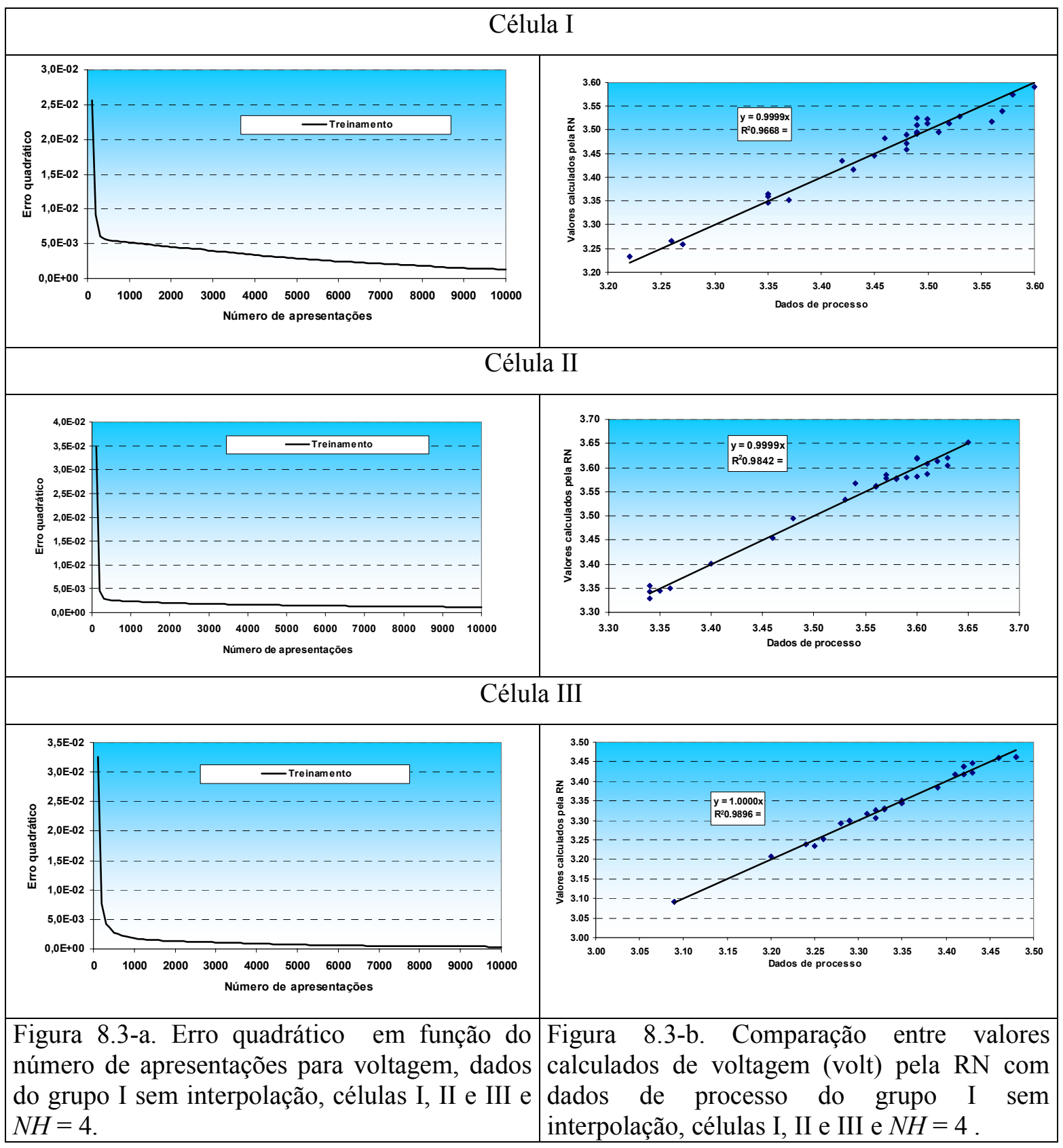




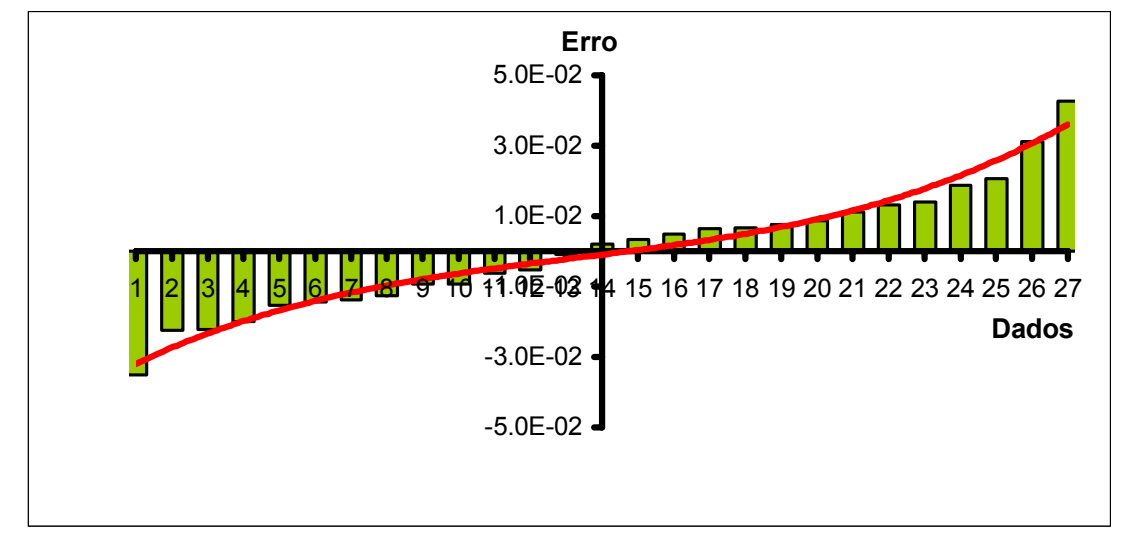

Figura 8.4-a Função distância entre valores calculados de voltagem pela $\mathrm{RN}$ e dados de processo para célula I, NH igual a 4 .
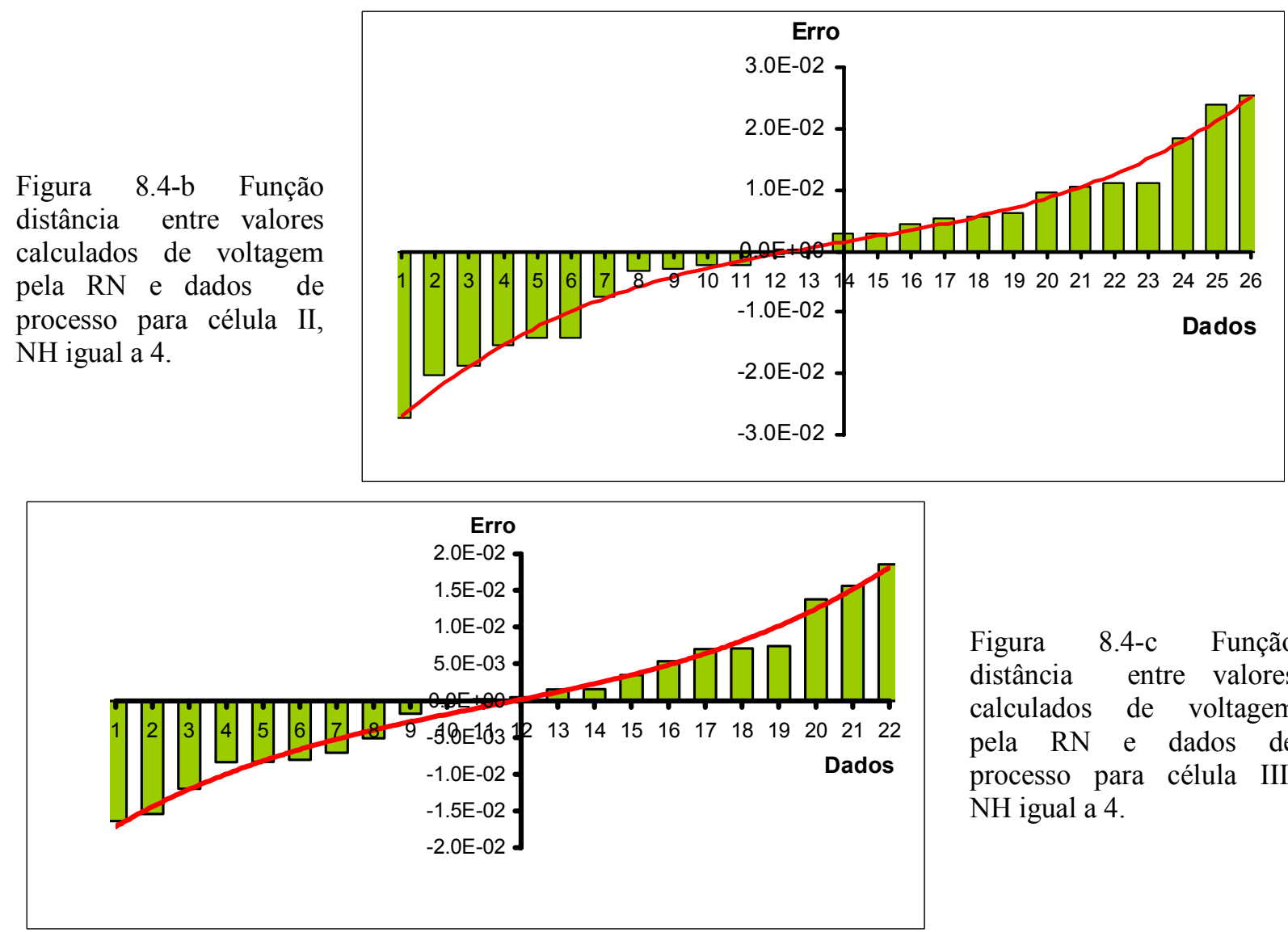

Figura 8.4-c Função distância entre valores calculados de voltagem pela RN e dados de processo para célula III, NH igual a 4.

\section{Abordagem 12}

Buscando-se simplificar o modelo de ajuste, foram realizados testes com esta abordagem, segundo a qual um único modelo seria capaz de representar a eficiência de corrente e a voltagem. Além disso foi reduzido o número de variáveis de entrada 
de sete para cinco, sendo retirada do modelo a variável nível de célula e alterada a concentração de $\mathrm{NaOH}$ para variável de saída na RN. Essa estrutura é coerente com as informações do próprio processo de eletrólise, pois o $\mathrm{NaOH}$ é um produto da reação; as variáveis de entrada nesse modelo correspondem àquelas controladas na operação do processo.

Foram testados modelos com 2, 4 e 6 neurônios e 50.000 apresentações, sendo constatados melhores resultados no ajuste da $\mathrm{RN}$ para modelos com $\mathrm{NH}$ igual a 6. Como ocorrido nas abordagens 4 e 8 , devido ao pequeno número de dados, todos os dados disponíveis foram alocados no conjunto de treinamento. Na tabela 8.2 são mostrados os resultados dos ajustes.

Tabela 8.2. Resultados do ajuste dos modelos de RN com três saídas para as células

I, II e III.

\begin{tabular}{|c|c|c|c|c|c|}
\hline Célula & NH & $\begin{array}{c}\text { Erro } \\
\text { Quadrático }\end{array}$ & $\begin{array}{c}\text { Variável de } \\
\text { saída }\end{array}$ & $\begin{array}{c}\text { Coeficiente } \\
\text { angular }\end{array}$ & $\begin{array}{c}\text { Coeficiente } \\
\text { de } \\
\text { determinação }\end{array}$ \\
\hline \multirow{9}{*}{ I } & \multirow{3}{*}{2} & \multirow{3}{*}{0,055} & Conc. $\mathrm{NaOH}$ & 0,177 & 0,175 \\
\hline & & & Voltagem & 0,741 & 0,804 \\
\hline & & & Eficiência & 0,822 & 0,810 \\
\hline & \multirow{3}{*}{4} & \multirow{3}{*}{0,015} & Conc. $\mathrm{NaOH}$ & 0,894 & 0,890 \\
\hline & & & Voltagem & 0,893 & 0,881 \\
\hline & & & Eficiência & 0,910 & 0,877 \\
\hline & \multirow{3}{*}{6} & \multirow{3}{*}{0,005} & Conc. $\mathrm{NaOH}$ & 1,000 & 0,984 \\
\hline & & & Voltagem & 1,000 & 0,921 \\
\hline & & & Eficiência & 1,000 & 0,960 \\
\hline \multirow{9}{*}{ II } & \multirow{3}{*}{2} & \multirow{3}{*}{0,052} & Conc. $\mathrm{NaOH}$ & 0,564 & 0,519 \\
\hline & & & Voltagem & 0,877 & 0,921 \\
\hline & & & Eficiência & 0,697 & 0,730 \\
\hline & \multirow{3}{*}{4} & \multirow{3}{*}{0,013} & Conc. $\mathrm{NaOH}$ & 0,968 & 0,890 \\
\hline & & & Voltagem & 0,974 & 0,968 \\
\hline & & & Eficiência & 0,937 & 0,947 \\
\hline & \multirow{3}{*}{6} & \multirow{3}{*}{0,006} & Conc. $\mathrm{NaOH}$ & 1,000 & 0,952 \\
\hline & & & Voltagem & 1,000 & 0,981 \\
\hline & & & Eficiência & 1,000 & 0,975 \\
\hline \multirow{9}{*}{ III } & \multirow{3}{*}{2} & \multirow{3}{*}{0,029} & Conc. $\mathrm{NaOH}$ & 0,545 & 0,538 \\
\hline & & & Voltagem & $\mathbf{0 , 8 0 7}$ & 0,749 \\
\hline & & & Eficiência & 0,905 & 0,899 \\
\hline & \multirow{3}{*}{4} & \multirow{3}{*}{0,014} & Conc. $\mathrm{NaOH}$ & 0,626 & 0,626 \\
\hline & & & Voltagem & 0,976 & 0,976 \\
\hline & & & Eficiência & 0,962 & 0,969 \\
\hline & \multirow{3}{*}{6} & \multirow{3}{*}{0,004} & Conc. $\mathrm{NaOH}$ & 0,999 & 0,963 \\
\hline & & & Voltagem & 1,000 & 0,947 \\
\hline & & & Eficiência & 1,000 & 0,977 \\
\hline
\end{tabular}


Com base nos resultados mais promissores, são apresentados a seguir os resultados dos testes de consistência de ajuste da $\mathrm{RN}$ para modelos com $\mathrm{NH}$ igual a 6 para as células I, II e III.

Na comparação do ajuste da RN para as três variáveis de saída verificou-se que tanto o coeficiente angular da reta de ajuste quanto o de determinação ficaram acima de 0,92 para os modelos das três células.

Para o modelo da célula I observa-se redução significativa no erro quadrático, fig. 8.5-a, e um melhor ajuste da RN para a concentração de licor com coeficientes acima de 0,98 , conforme pode ser observado quando comparados os valores calculados pela RN com os dados de processo, fig. 8.5-b, 8.5-c e 8.5-d.

\begin{tabular}{|c|c|}
\hline \multicolumn{2}{|c|}{ Célula I } \\
\hline 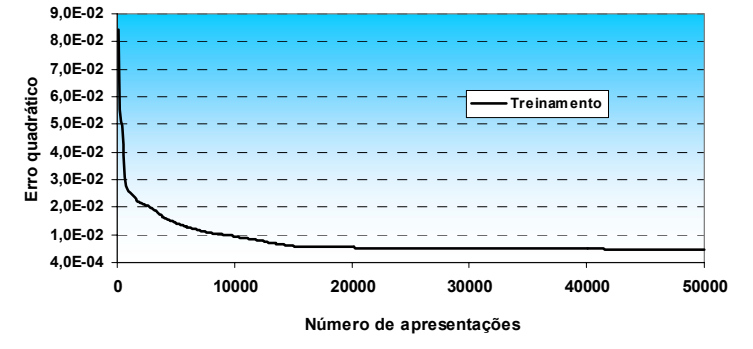 & 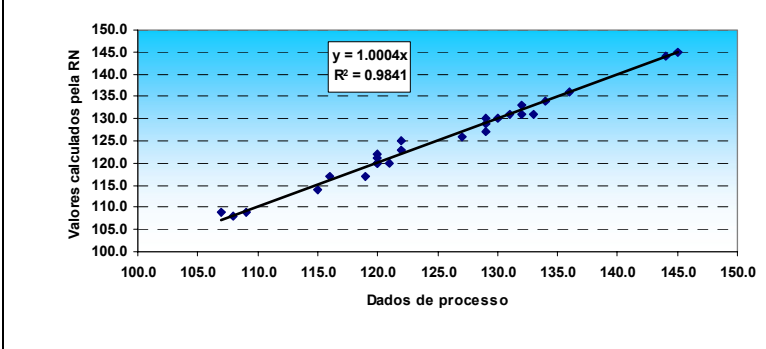 \\
\hline $\begin{array}{l}\text { Figura 8.5-a. Erro quadrático em função do } \\
\text { número de apresentações para concentração de } \\
\mathrm{NaOH} \text {, voltagem e eficiência, dados do grupo } \\
\text { I, e } \mathrm{NH}=6 \text {. }\end{array}$ & $\begin{array}{l}\text { Figura 8.5-b. Comparação entre valores } \\
\text { calculados de concentração de } \mathrm{NaOH}(\mathrm{g} / \mathrm{L}) \\
\text { pela RN com dados de processo do grupo I, e } \\
N H=6 \text {. }\end{array}$ \\
\hline 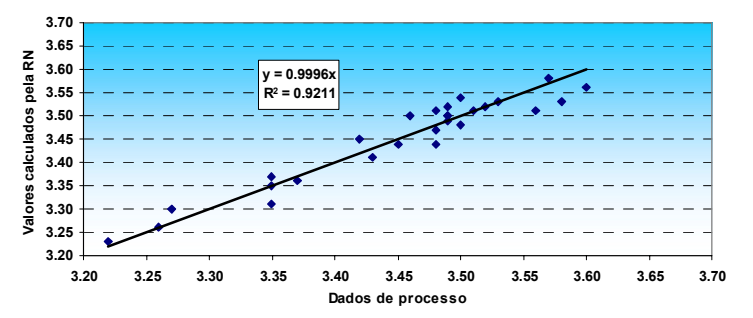 & 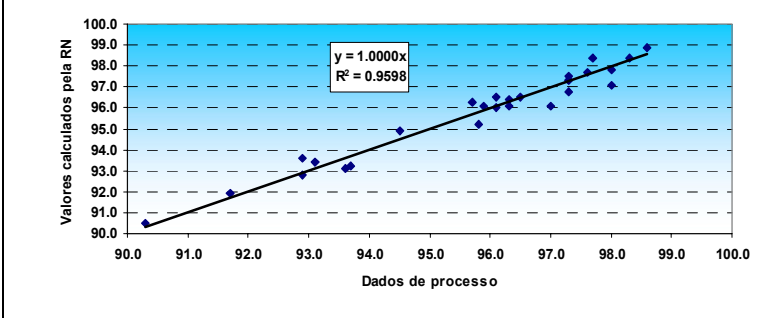 \\
\hline $\begin{array}{l}\text { Figura 8.5-c. Comparação entre valores } \\
\text { calculados de voltagem (volt) pela RN com } \\
\text { dados de processo do grupo I, e } N H=6 \text {. }\end{array}$ & $\begin{array}{l}\text { Figura 8.5-d. Comparação entre valores } \\
\text { calculados de eficiência (\%) pela RN com } \\
\text { dados de processo do grupo I, e } N H=6 \text {. }\end{array}$ \\
\hline
\end{tabular}


No modelo da célula II, observa-se também redução significativa no erro quadrático, fig. 8.6-a, porem resultados semelhantes para os coeficientes de angular da reta de ajuste e de determinação, acima de 0,95 , para as três variáveis de saída conforme pode ser observado nas figuras fig. 8.6-b, 8.6-c e 8.6-d.

\begin{tabular}{|c|c|}
\hline \multicolumn{2}{|c|}{ Célula II } \\
\hline 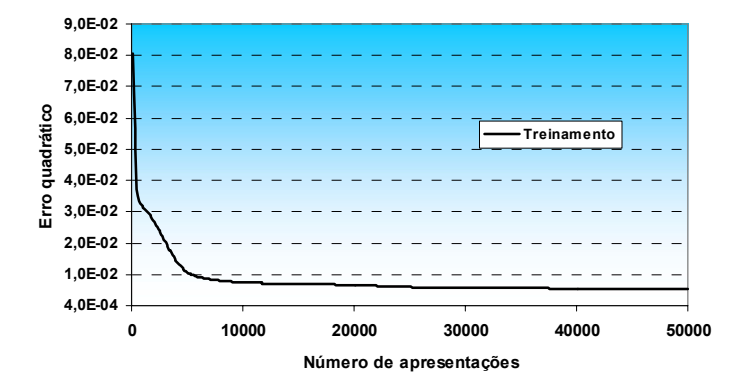 & 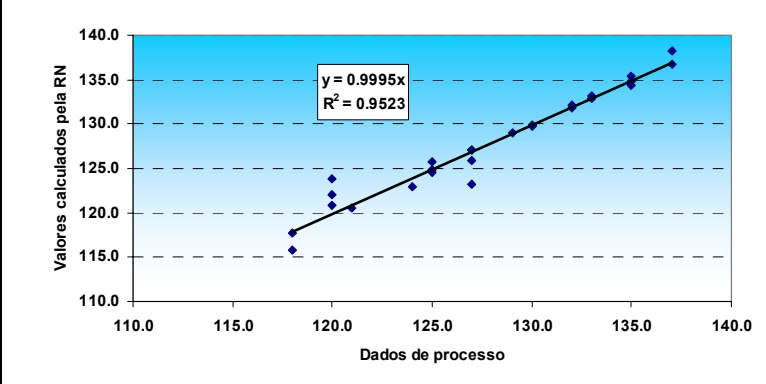 \\
\hline $\begin{array}{l}\text { Figura 8.6-a. Erro quadrático em função do } \\
\text { número de apresentações para concentração de } \\
\mathrm{NaOH} \text {, voltagem e eficiência, dados do grupo } \\
\text { I, e } \mathrm{NH}=6 \text {. }\end{array}$ & $\begin{array}{l}\text { Figura 8.6-b. Comparação entre valores } \\
\text { calculados de concentração de } \mathrm{NaOH}(\mathrm{g} / \mathrm{L}) \\
\text { pela RN com dados de processo do grupo I, e } \\
\mathrm{NH}=6 \text {. }\end{array}$ \\
\hline $\begin{array}{l}3.70 \\
3.65 \\
3.65\end{array}$ & 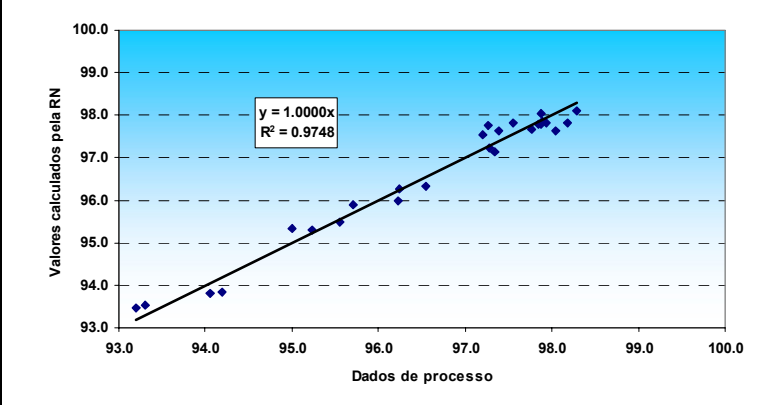 \\
\hline $\begin{array}{l}\text { Figura 8.6-c. Comparação entre valores } \\
\text { calculados de voltagem (volt) pela RN com } \\
\text { dados de processo do grupo I, e } N H=6 \text {. }\end{array}$ & $\begin{array}{l}\text { Figura 8.6-d. Comparação entre valores } \\
\text { calculados de eficiência (\%) pela RN com } \\
\text { dados de processo do grupo I, e } N H=6 \text {. }\end{array}$ \\
\hline
\end{tabular}


Quanto ao modelo da célula III, há uma redução menos acentuada do erro quadrático no transcorrer das apresentações em comparação com as células I e II, necessitando de cerca de 40.000 apresentações para se estabilizar na mesma faixa de erro, fig 8.7-a. Quanto aos coeficientes angular da reta de ajuste e de determinação verifica-se semelhança com os resultados obtidos no ajuste das células I e II, acima de 0,94 para as três variáveis de saída conforme pode ser observado nas figuras fig.

\section{7-b, 8.7-c e 8.7-d.}

\begin{tabular}{|c|c|}
\hline \multicolumn{2}{|c|}{ Célula III } \\
\hline 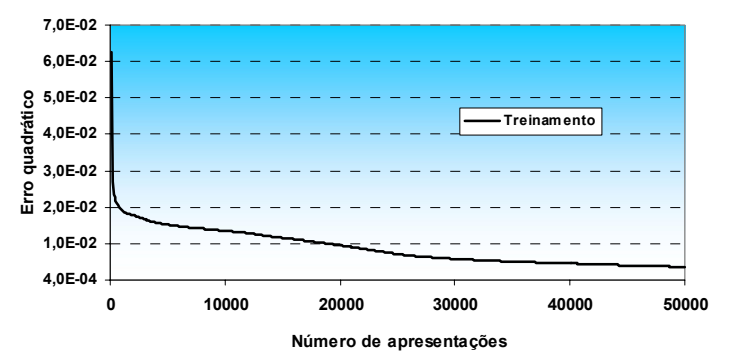 & 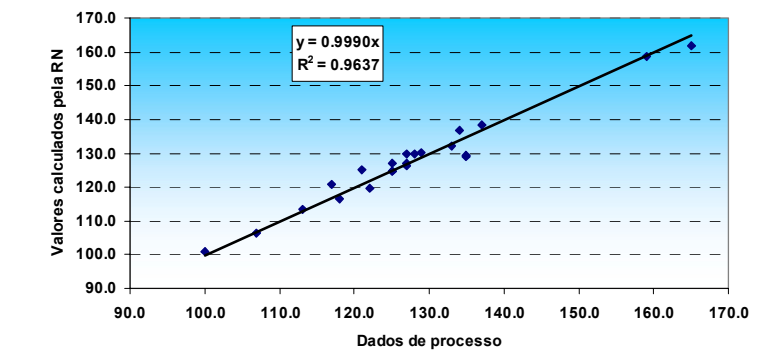 \\
\hline $\begin{array}{l}\text { Figura 8.7-a. Erro quadrático em função do } \\
\text { número de apresentações para concentração de } \\
\mathrm{NaOH} \text {, voltagem e eficiência, dados do grupo } \\
\text { I, e } \mathrm{NH}=6 \text {. }\end{array}$ & $\begin{array}{l}\text { Figura 8.7-b. Comparação entre valores } \\
\text { calculados de concentração de } \mathrm{NaOH}(\mathrm{g} / \mathrm{L}) \\
\text { pela RN com dados de processo do grupo } \mathrm{I} \text {, e } \\
\mathrm{NH}=6 \text {. }\end{array}$ \\
\hline 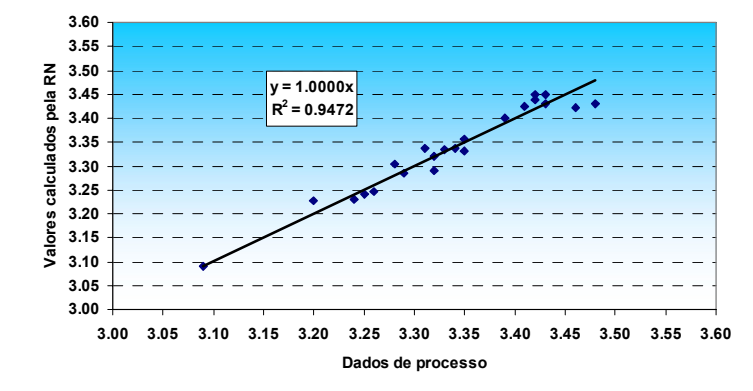 & 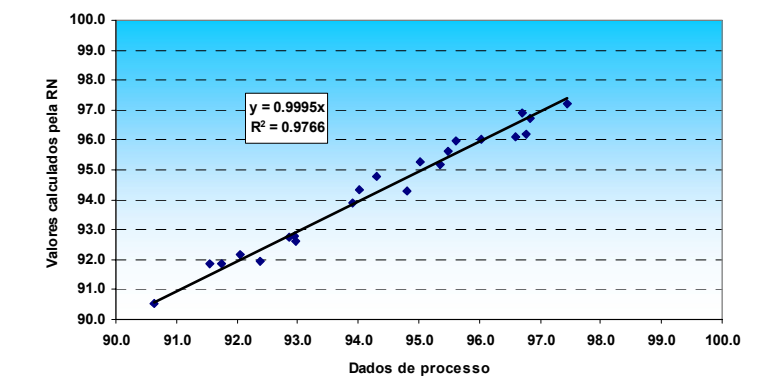 \\
\hline $\begin{array}{l}\text { Figura 8.7-c. Comparação entre valores } \\
\text { calculados de voltagem pela RN (volt) com } \\
\text { dados de processo do grupo I, e } N H=6 \text {. }\end{array}$ & $\begin{array}{l}\text { Figura 8.7-d. Comparação entre valores } \\
\text { calculados de eficiência pela RN }(\%) \text { com } \\
\text { dados de processo do grupo I, e } N H=6 \text {. }\end{array}$ \\
\hline
\end{tabular}

Analisando a função distância das diferenças entre os valores calculados pela RN e os dados de processo para as células I, II e III, verifica-se simetria na 
representação gráfica para a três variáveis de saída, concentração de $\mathrm{NaOH}$, voltagem e eficiência de corrente nas para os modelos das células I, II e III, indicando consistência no ajuste da RN.

Nas figuras 8.8, 8.9 e 8.10 são representadas a função distância das diferenças entre os valores calculados pela $\mathrm{RN}$ e dados de processo dos modelos das células I, II e III respectivamente, para cada variável de saída.

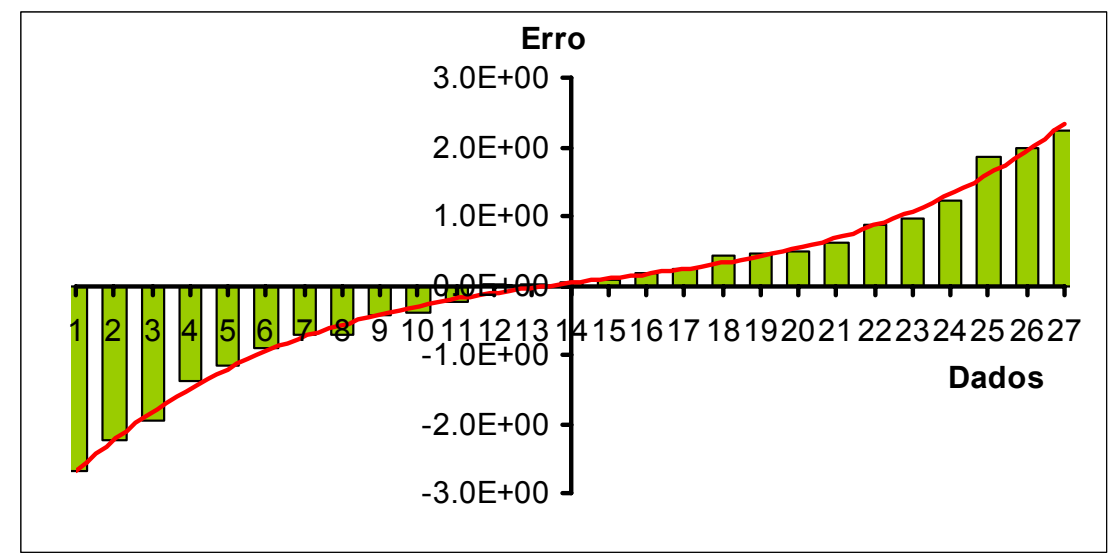

Figura 8.8-a Função distância entre valores calculados de concentração de $\mathrm{NaOH}$ pela $\mathrm{RN}$ e dados de processo para célula I, NH igual a 6.

Figura 8.8-b Função distância entre valores calculados de voltagem pela RN e dados de processo para célula I, NH igual a 6 .





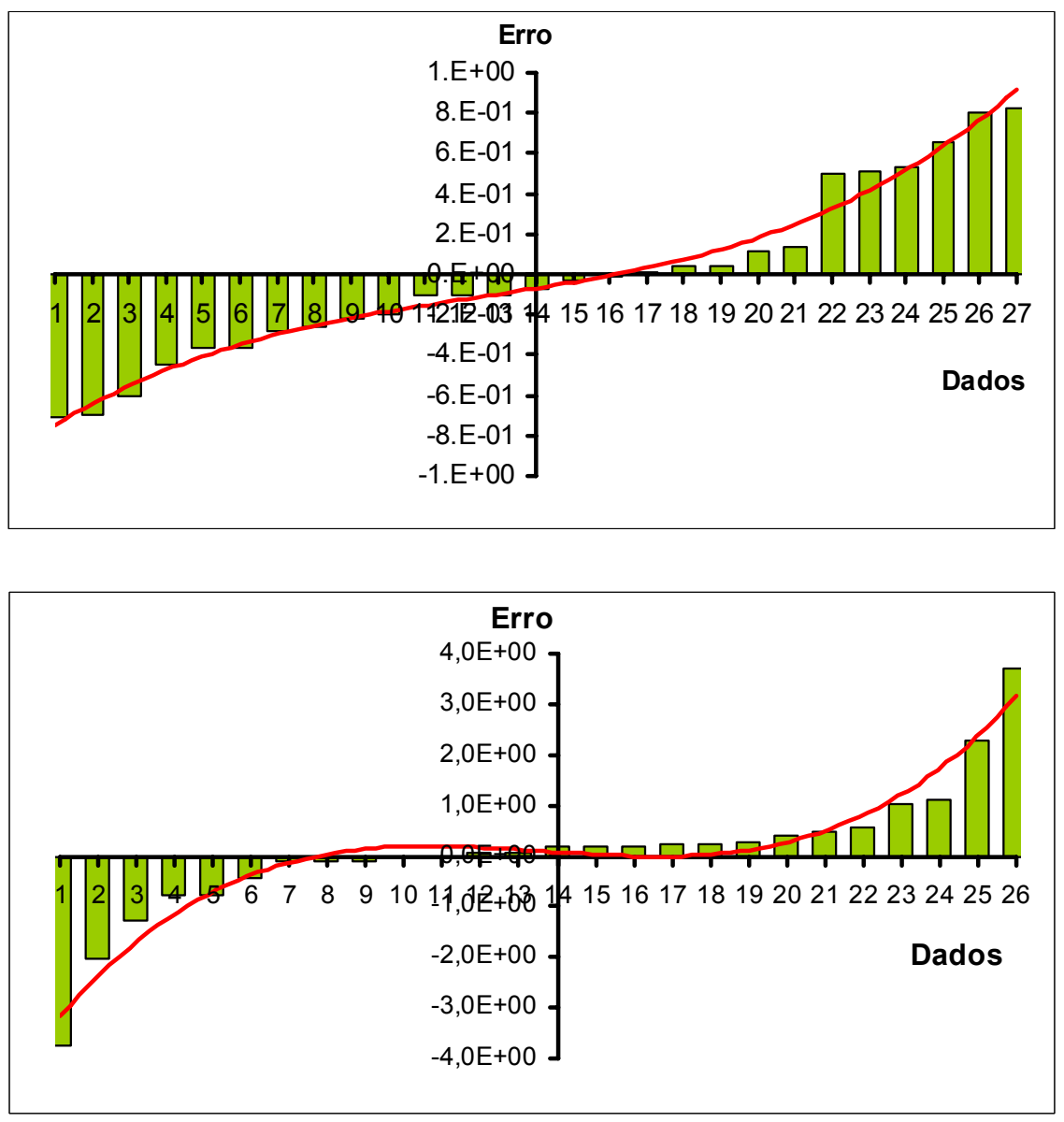

Figura 8.8-c Função distância entre valores calculados de eficiência pela RN e dados de processo para célula $\mathrm{I}, \mathrm{NH}$ igual a 6 .

Figura 8.9-a Função distância entre valores calculados de concentração de $\mathrm{NaOH}$ pela $\mathrm{RN}$ e dados de processo para célula II, $\mathrm{NH}$ igual a 6 .
Figura 8.9-b Função distância entre valores calculados de voltagem pela RN e dados de processo para célula II, NH igual a 6.

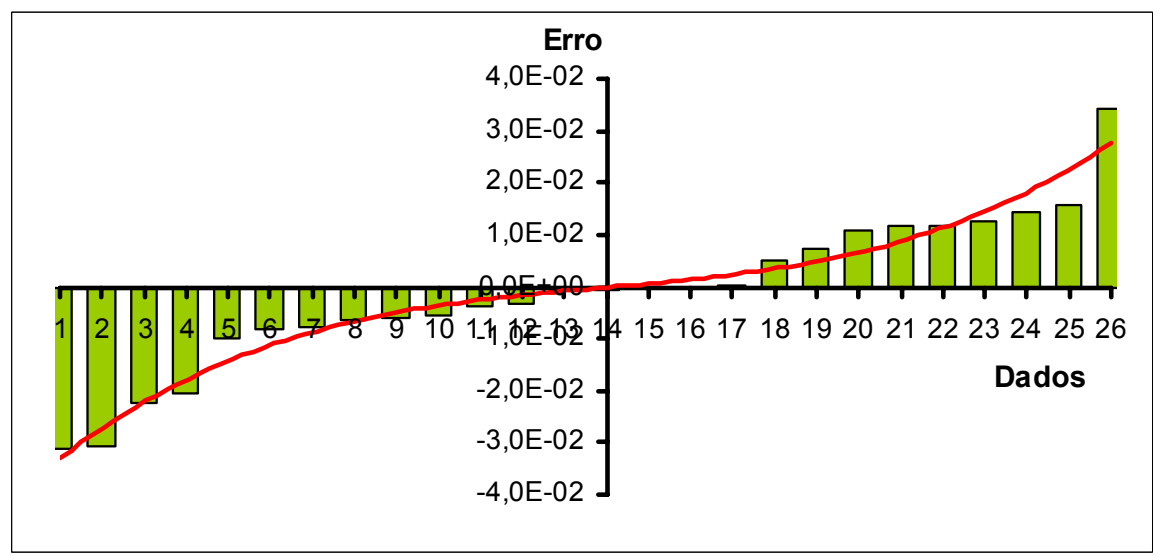




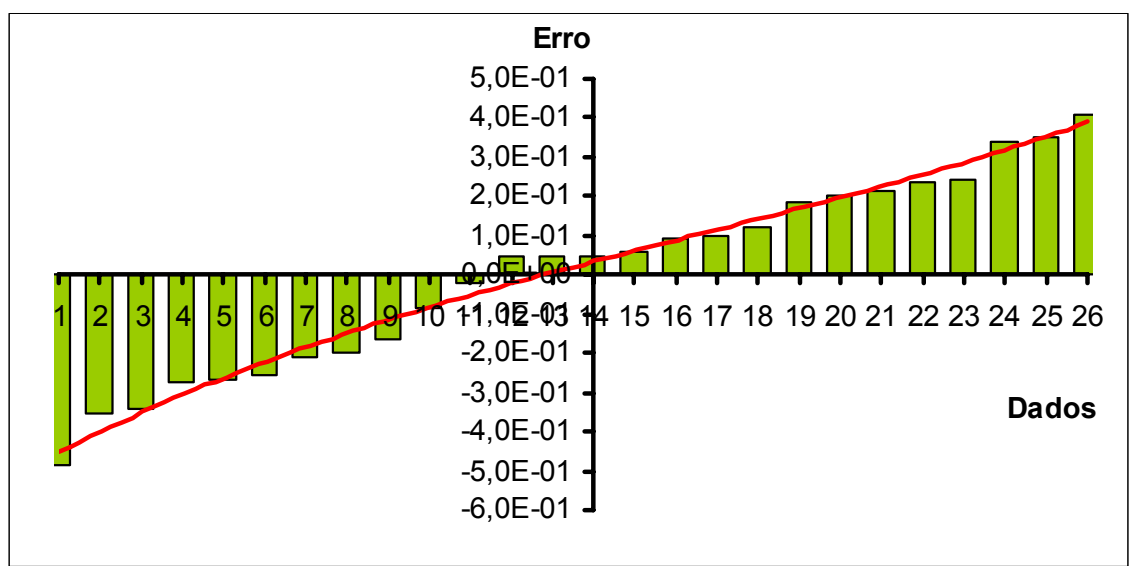

Figura 8.9-c Função distância entre valores calculados de eficiência pela RN e dados de processo para célula II, NH igual a 6 .

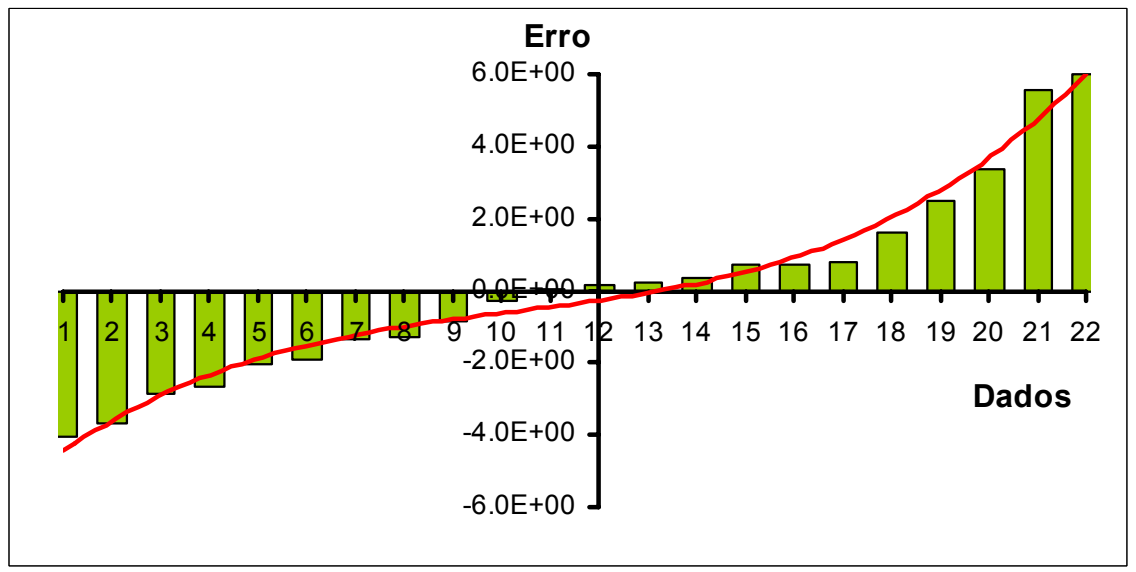

Figura 8.10-a Função distância entre valores calculados de concentração de $\mathrm{NaOH}$ pela $\mathrm{RN}$ e dados de processo para célula III, NH igual a 6 .

Figura 8.10-b Função distância entre valores calculados de voltagem pela RN e dados de processo para célula III, NH igual a 6.

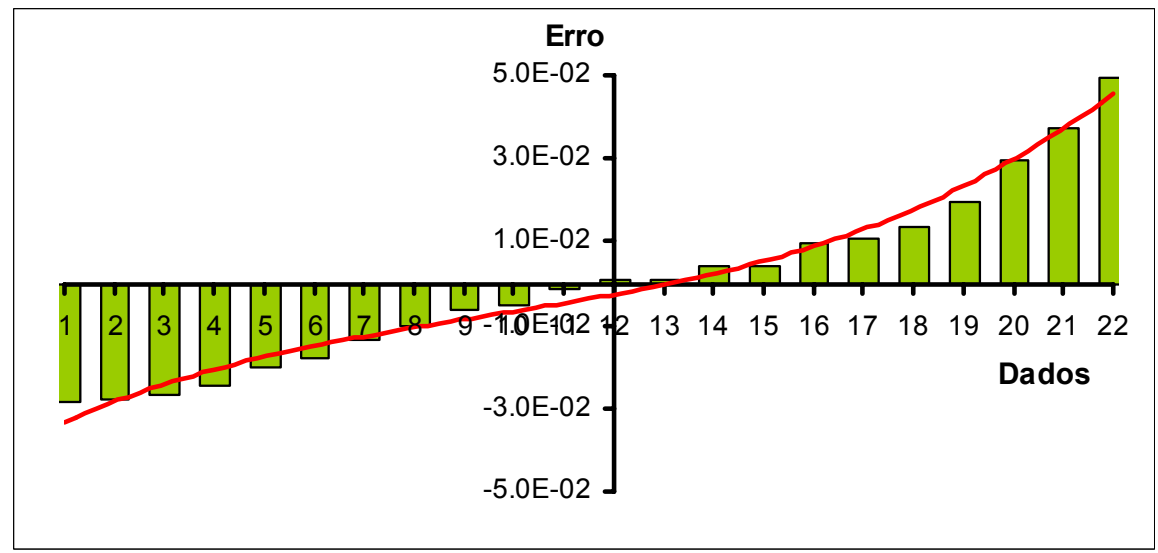




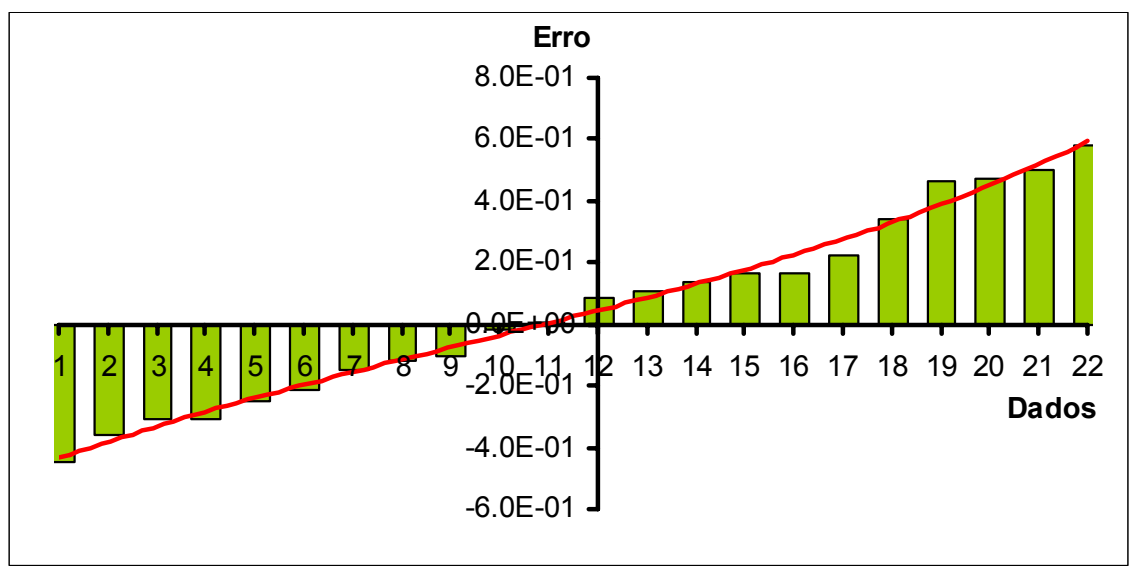

Figura 8.10-c Função distância entre valores calculados de eficiência pela RN e dados de processo para célula III, NH igual a 6.

Análises estatísticas também foram utilizadas para testar a consistência destes modelos, comparando os valores calculados pela $\mathrm{RN}$ com os dados de processo de cada uma das variáveis de saída. Foram utilizadas as ferramentas estatísticas do Minitab, "One-Way Analysis of Variance” para comparação das médias e "Regression>Regression" para verificar se a regressão é significativa.

Para utilizarmos a ferramenta "One-Way Analysis of Variance" é necessário assegurar que os grupos formados pelos conjuntos de dados calculados pela $\mathrm{RN}$ e pelos dados de processo tenham a mesma variância. Para tanto foi realizado o teste "ANOVA> Test for Equal Variances" para os dois conjuntos de dados, verificando se apresentam a mesma variância. Uma vez confirmada que as variâncias são estatisticamente iguais é realizado o teste para as médias dos dois grupos.

A hipótese fundamental testada é "p-value" $>0,05$, ou seja com grau de incerteza de 5\%, para grupos com variâncias estatisticamente iguais. Os ensaios realizados mostraram que os modelos das três células indicaram a mesma variância na comparação entre os valores calculados pela $\mathrm{RN}$ com os dados de processo para as três variáveis de saída.

Na tabela 8.3 são mostrados os valores de "p-value", para teste de igual variância, na comparação entre os valores calculados pela $\mathrm{RN}$ de cada modelo e os dados de processo. 
Tabela 8.3. Teste ANOVA para hipótese de variância estatisticamente iguais entre os valores calculados pela $\mathrm{RN}$ e dados de processo.

\begin{tabular}{|c|l|c|}
\hline Célula & \multicolumn{1}{|c|}{ Variável de Saída } & Valor de p \\
\hline \multirow{3}{*}{ I } & Concentração NaOH no licor & 1,00 \\
\cline { 2 - 3 } & Voltagem & 0,98 \\
\cline { 2 - 3 } & Eficiência de corrente & 0,95 \\
\hline \multirow{3}{*}{ II } & Concentração NaOH no licor & 0,70 \\
\cline { 2 - 3 } & Voltagem & 0,71 \\
\cline { 2 - 3 } & Eficiência de corrente & 0,49 \\
\hline \multirow{3}{*}{ III } & Concentração NaOH no licor & 0,60 \\
\cline { 2 - 3 } & Voltagem & 0,82 \\
\cline { 2 - 3 } & Eficiência de corrente & 0,83 \\
\hline
\end{tabular}

Comprovada as variâncias iguais para cada par de conjunto de dados, valores calculados pela RN e dados de processo, foi realizado o teste "One-Way Analysis of Variance" para comparação das médias. Neste teste verificou-se em todas as comparações realizadas que as médias são estatisticamente iguais, confirmando a consistência dos modelos utilizados, conforme mostrado na tabela 8.4.

Tabela 8.4. Teste ANOVA, para hipótese de médias estatisticamente iguais entre os valores calculados pela $\mathrm{RN}$ e dados de processo.

\begin{tabular}{|c|l|c|}
\hline Célula & \multicolumn{1}{|c|}{ Variável de Saída } & Valor de p \\
\hline \multirow{3}{*}{ I } & Concentração NaOH no licor & 1,00 \\
\cline { 2 - 3 } & Voltagem & 0,98 \\
\cline { 2 - 3 } & Eficiência de corrente & 0,95 \\
\hline \multirow{3}{*}{ II } & Concentração NaOH no licor & 1,00 \\
\cline { 2 - 3 } & Voltagem & 0,95 \\
\cline { 2 - 3 } & Eficiência de corrente & 0,97 \\
\hline \multirow{3}{*}{ III } & Concentração NaOH no licor & 0,99 \\
\cline { 2 - 3 } & Voltagem & 0,97 \\
\cline { 2 - 3 } & Eficiência de corrente & 0,94 \\
\hline
\end{tabular}

Por último, foi utilizada a ferramenta "Regression" para comprovar se uma equação do primeiro grau, $\mathrm{Y}=\mathrm{A} \mathrm{X}+\mathrm{B}$, pode representar o modelo de variação entre os conjuntos de valores calculados pela $\mathrm{RN}$ e os dados de processo para as variáveis de saída. Adotando grau de incerteza de $5 \%$, as hipóteses testadas foram se a 
regressão é significativa, "p-value" $<0,05$, ou a regressão não é significativa, "pvalue" $>0,05$.

Alem disso também é analisado o coeficiente de determinação, $\mathrm{r}^{2}$, indicando se a porcentagem de variação dos valores calculados pela $\mathrm{RN}$ é explicada pela variação dos dados de processo.

Os resultados apresentaram "p-value" sempre igual a zero e $\mathrm{r}^{2}$ maiores que $92,0 \%$ em todas as análises realizadas, indicando consistência dos três modelos para predizer as variáveis de concentração de $\mathrm{NaOH}$, voltagem e eficiência de corrente, conforme mostrado na tabela 8.5 .

Tabela 8.5. Teste Análise de Regressão para hipótese de correlação entre os valores calculados pela $\mathrm{RN}$ e dados de processo.

\begin{tabular}{|c|l|c|c|}
\hline Célula & \multicolumn{1}{|c|}{ Variável de Saída } & Valor de p & $\mathbf{r}^{\mathbf{2}} \mathbf{( \% )}$ \\
\hline \multirow{3}{*}{ I } & Concentração NaOH no licor & 0,00 & 98,4 \\
\cline { 2 - 4 } & Voltagem & 0,00 & 92,1 \\
\cline { 2 - 4 } & Eficiência de corrente & 0,00 & 96,0 \\
\hline \multirow{3}{*}{ II } & Concentração NaOH no licor & 0,00 & 95,2 \\
\cline { 2 - 4 } & Voltagem & 0,00 & 98,1 \\
\cline { 2 - 4 } & Eficiência de corrente & 0,00 & 97,5 \\
\hline \multirow{3}{*}{ III } & Concentração NaOH no licor & 0,00 & 96,3 \\
\cline { 2 - 4 } & Voltagem & 0,00 & 94,7 \\
\cline { 2 - 4 } & Eficiência de corrente & 0,00 & 97,7 \\
\hline
\end{tabular}

\section{Abordagem 10}

Os resultados obtidos para esta abordagem, utilizando dados do grupo II, apresentaram ajuste entre os valores calculados pela $\mathrm{RN}$ e os dados de processo apenas para uma determinada faixa de valores de consumo de energia.

Observa-se que, para o conjunto de dados do circuito I, o comportamento do erro quadrático para o conjunto de treinamento e para o conjunto de teste foi praticamente o mesmo.

Para os dados do circuito II, os conjuntos de dados de treinamento e de teste da $\mathrm{RN}$ apresentaram praticamente a mesma diferença no erro quadrático durante a evolução das 10000 apresentações, estabilizando-se a partir de 1000 apresentações para NH igual a 4 e 3000 apresentações para NH igual a 6 . 
$\mathrm{Na}$ figura 8.11 são representados os erros quadráticos para os dados do circuito I e II para NH igual a 4 e 6.

\begin{tabular}{|c|c|}
\hline Circuito I & Circuito II \\
\hline 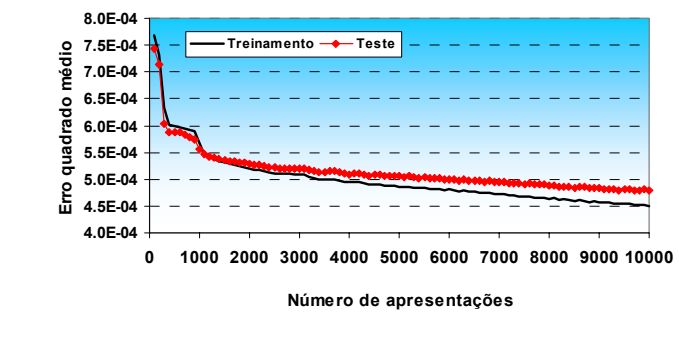 & 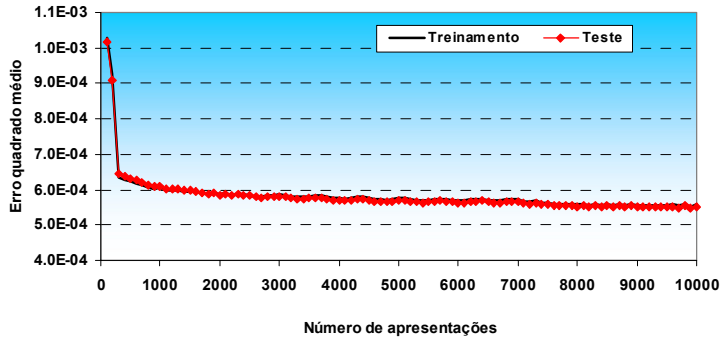 \\
\hline$N H=4$ & $N H=4$ \\
\hline 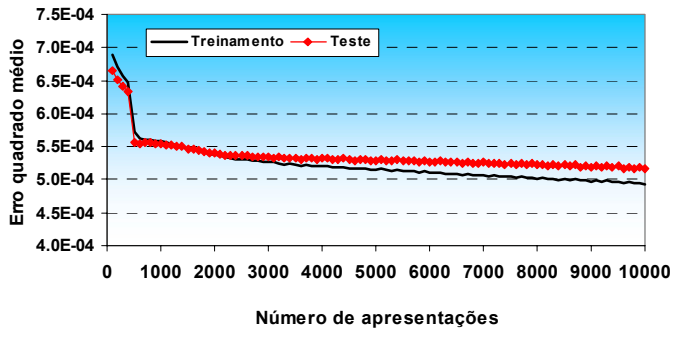 & 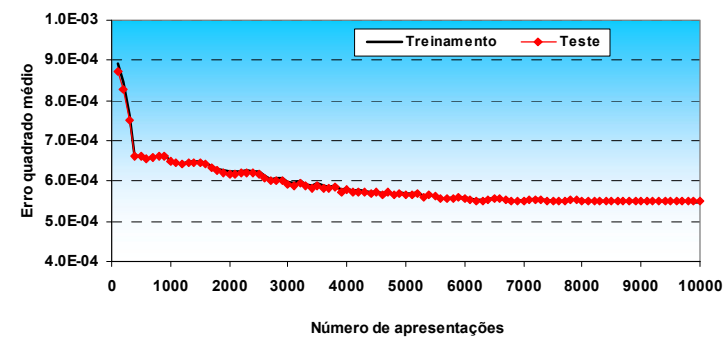 \\
\hline$N H=6$ & $N H=6$ \\
\hline
\end{tabular}

Figura 8.11 Erro quadrático em função do numero de apresentações para dados do grupo II, circuito I e II, para $N H=4$ e 6.

Comparando-se os valores de consumo de energia calculados pela $\mathrm{RN}$ e os dados de processo, observou-se um melhor ajuste da RN para NH igual a 4 e 6 em ambos os circuitos considerando dados de consumo de energia até $580 \mathrm{MWh}$ aproximadamente.

Acima de $580 \mathrm{MWh}$ verifica-se piora considerável nos resultados em todos os casos analisados, indicando a necessidade de utilizarem-se duas $\mathrm{RN}$ em vez de uma: a primeira para valores abaixo de $580 \mathrm{MWh}$ e a segunda para valores acima desse nível.A causa do não ajuste da RN para valores superiores a $580 \mathrm{MWh}$ pode estar associada ao fato da corrente elétrica estar praticamente estabilizada no patamar máximo desde 2002, concentrando uma grande quantidade de dados com consumo de energia acima de $580 \mathrm{MWh}$ dificultando o ajuste da RN para todos os pontos. 
Devido aos resultados pouco promissores destes modelos para predizer o consumo de energia, não foi dado prosseguimento aos testes de consistência.

$\mathrm{Na}$ figura 8.12 são apresentados os valores de processo e os valores calculados pela RN para dados do Grupo II, circuitos I e II, com $N H=4$ e 6.

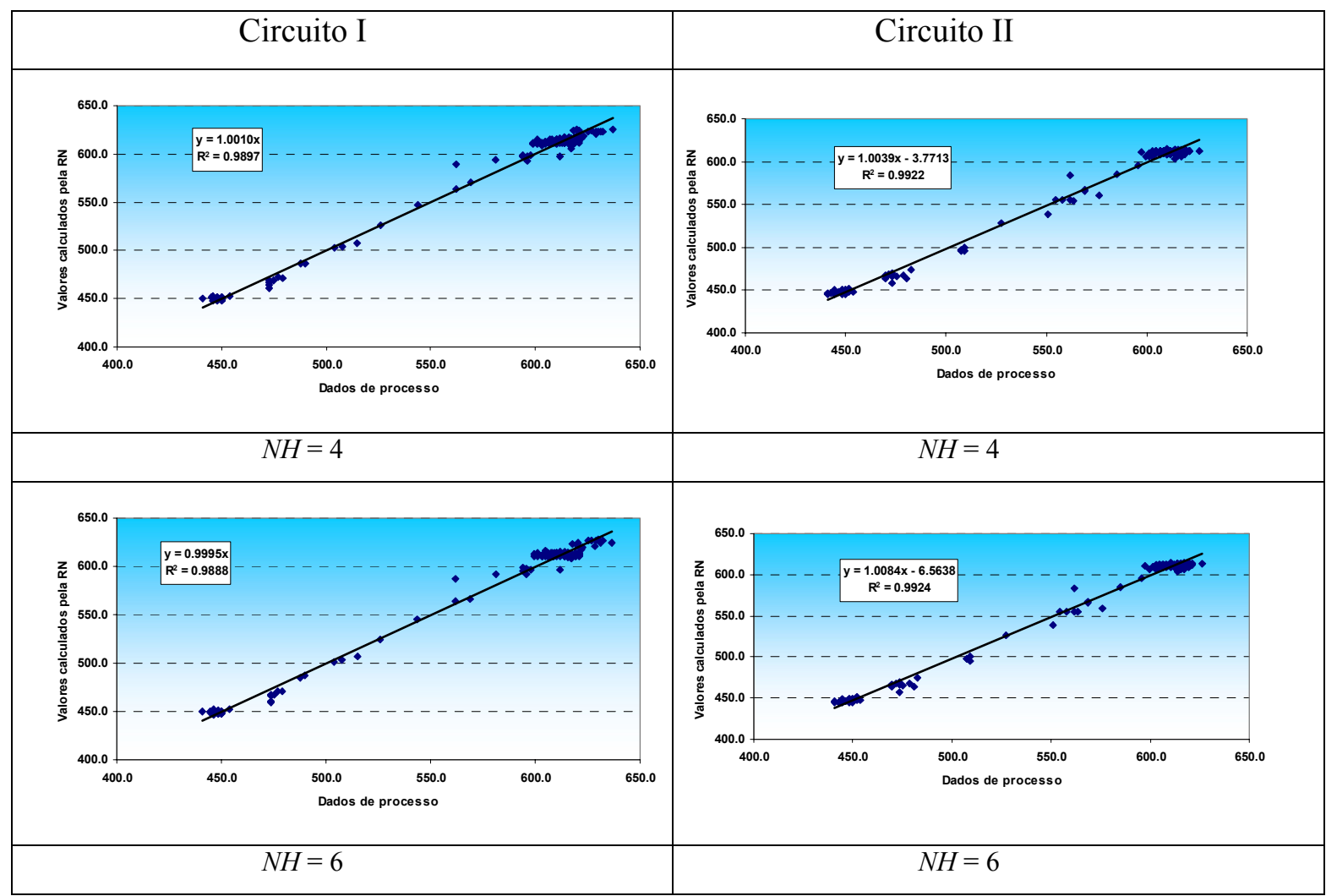

Figura 8.12. Comparação entre os valores de processo e os valores calculados pela $R N$ para dados do Grupo II, circuitos I e II, com $N H=4$ e 6 .

Observando os resultados obtidos na abordagem 10, verificou-se a necessidade de mais testes com o mesmo grupo de dados, porém com algumas alterações.

Em vez de se testar o ajuste de um único modelo de RN para toda a faixa de dados, foi realizada a tentativa com dois modelos, o primeiro para consumos de energia até $580 \mathrm{MWh}$ e o segundo para consumos superiores a esse montante.

Além da iniciativa de se trabalhar com dois modelos nesta abordagem foram expurgados do conjunto de dados os valores que se caracterizaram como condições 
transientes do processo, ou seja, para treinamento da $\mathrm{RN}$ só foram considerados dados claramente identificados com regime estacionário da unidade industrial.

Os resultados obtidos nestes novos ensaios praticamente se repetiram, com os modelos configurados para valores de consumo de energia até $580 \mathrm{MWh}$ apresentando um melhor ajuste entre os valores calculados e os dados de processo, enquanto que o modelo para valores acima de $580 \mathrm{MWh}$ apresentou diferenças acentuadas entre os valores calculados pela $\mathrm{RN}$ e os dados de processo.

$\mathrm{Na}$ figura 8.13 são representadas as comparações dos valores calculados de consumo de energia pela $\mathrm{RN}$, ajustada somente com valores abaixo de $580 \mathrm{MWh}$, e os dados de processo, para ambos os circuitos considerando $\mathrm{NH}$ igual a 4 e 6 .

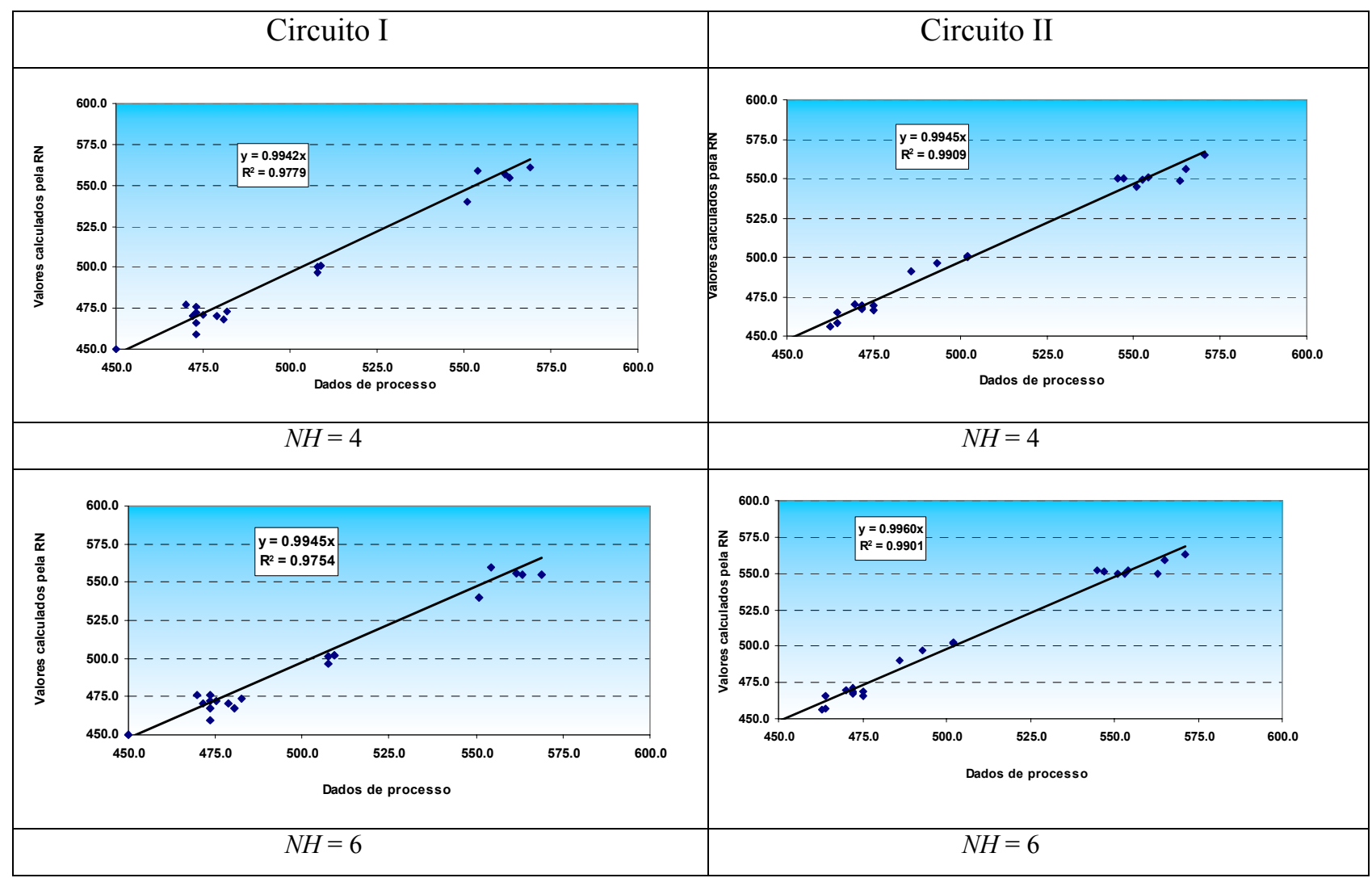

Figura 8.13. Comparação entre os valores de processo e os valores calculados pela $R N$ para dados do Grupo II, consumo de energia até $580 \mathrm{MWh}$, circuitos I e II, com $N H=4$ e 6 . 
Na figura 8.14 são representadas as comparações dos valores calculados de consumo de energia pela RN, ajustada somente com valores acima de $580 \mathrm{MWh}$, e os dados de processo, para ambos os circuitos considerando $\mathrm{NH}$ igual a 4 e 6 .

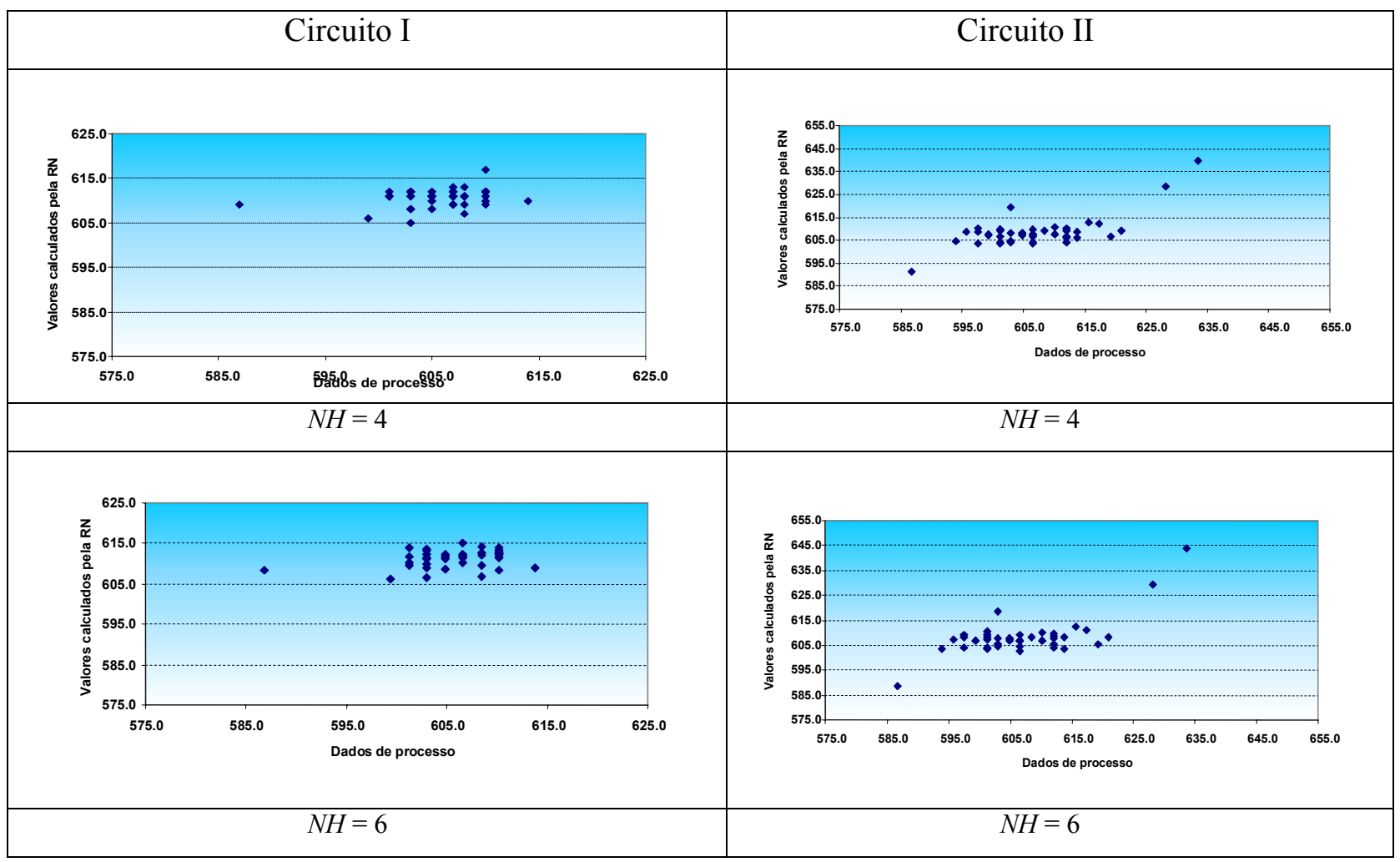

Figura 8.14. Comparação entre os valores de processo e os valores calculados pela $R N$ para dados do Grupo II, consumo de energia maior que $580 \mathrm{MWh}$, circuitos I e II, $\operatorname{com} N H=4$ e 6 .

Em função dos resultados obtidos, optou-se em utilizar o modelo da abordagem 12, com 3 saídas, concentração de $\mathrm{NaOH}$, voltagem e eficiência de corrente, a ser utilizado no estudo de otimização, apesar destes modelos terem sido ajustados a partir de uma pequena base de dados.

\subsection{Evaporação}

Para o desenvolvimento do modelo da unidade de evaporação para predizer a variável consumo de vapor foram realizados estudos utilizando duas metodologias, a primeira por modelo fenomenológico e a segunda utilizando modelos obtidos por 
RN. Este procedimento foi adotado devido à ausência de registros das variáveis em pontos considerados importantes do processo, podendo comprometer desta forma a obtenção de um modelo fenomenológico consistente para esse processo.

A seguir serão discutidos os resultados dos modelos fenomenológico e por RN.

\section{Modelo Fenomenológico}

O primeiro passo foi definir um adequado volume de controle no qual o maior número de variáveis de entrada e saída fossem conhecidas, ou seja, variáveis monitoradas no processo. Este procedimento foi necessário devido ao grande número de reciclos e interligações dentro da unidade em que não são monitoradas as variáveis de processo, impossibilitando a conciliação das entradas e saídas em todos os pontos do referido processo.

Estabelecido o volume de controle foram equacionadas as relações entre as variáveis de processo com base no fluxograma simplificado da unidade, utilizando-se conceitos de balanço de massa e energia a fim de se obter a função objetivo para o consumo de vapor. O estudo de equacionamento desse modelo é mostrado no anexo I deste trabalho.

No modelo fenomenológico, a variável consumo de vapor é função das vazões mássicas, entalpias e composição nas várias correntes do processo, e da perda de calor para o ambiente de toda a unidade.

Utilizando a função para cálculo de consumo vapor, equação 5 do anexo I, pode-se calcular a perda de calor. As variáveis consumo de vapor e vazão mássica de soda líquida a 50\% são obtidas em leituras no processo. Os valores de entalpia são obtidos a partir da composição de cada corrente do processo, porém essas não são medidas, mas podem ser obtidas através de tabelas relativas às propriedades físicas da solução de $\mathrm{NaOH}$ saturada em $\mathrm{NaCl}$, apresentadas por Diamond (1973).

Antes de iniciar o cálculo da perda de calor na unidade, foi realizado teste para verificação da consistência entre os valores tabelados de composição e os dados de processo. Foi utilizada para comparação a corrente de soda concentrada, saída do 
efeito "flash", devido à existência de dados de análise dessa corrente, pois trata-se de um indicador de especificação do produto final.

A partir dos dados de temperatura e pressão no "flash" coletados com base nos horários de análises registrados pela operação, são obtidos os valores tabelados para a concentração de $\mathrm{NaOH}$. Comparando-se esses valores com os valores obtidos do processo verifica-se uma diferença de cerca de 7\% a mais para os valores tabelados. Por exemplo, para um dado de análise laboratorial de 49,3\% encontra-se um valor tabelado de $53 \%$, sendo que o intervalo de operação, em condição normal, situa-se entre 49,2 e 50,0\%. As possíveis causas desses desvios podem ser erros de leitura do instrumento para pressão e temperatura, falta de calibração, como também defasagem entre a hora da análise de concentração de $\mathrm{NaOH}$ registrada pela operação e a realmente ocorrida, ou ainda efeito de outros componentes presentes no sistema, os quais não são previstos nas correlações para equilíbrio.

Desta forma, o desvio apresentado no resultado de concentração de $\mathrm{NaOH}$ na saída do efeito "flash" pode ocorrer também nos efeitos 1, 2 e 3. Porém essa variável não é monitorada pela operação nos três efeitos, impossibilitando uma análise destes possíveis desvios entre os valores tabelados e os dados de processo.

Assim sendo, o modelo fenomenológico para cálculo do consumo de vapor pode ficar comprometido, pois para obtenção do consumo de vapor são necessárias as vazões entre os efeitos, que dependem da composição dessas correntes. Se os valores tabelados divergem dos valores obtidos a partir dos dados de processo, as variáveis cujos cálculos dependem desses dados apresentarão os mesmos desvios em um futuro estudo de otimização.

Outro fator a ser considerado, que pode prejudicar a qualidade da resposta do modelo fenomenológico é por este ser baseado em um fluxograma no qual não são considerados os reciclos dentro da unidade. As variáveis dessas correntes, como vazão, composição e temperatura, não são medidas pela operação nesses pontos, impossibilitando a sua determinação por meio de balanço de massa e energia. Através de uma reconciliação de dados esses valores poderiam ser encontrados, porém aumentando a complexidade do modelo como também a incerteza da qualidade do resultado. 
Portanto, em virtude dos fatores citados anteriormente que caracterizam incerteza na qualidade do resultado, não foi dado prosseguimento no desenvolvimento desse modelo, optando-se pelo modelo obtido por RN conforme mostrado a seguir.

\section{Modelo de Redes Neurais}

Foram utilizadas duas abordagens para obtenção do modelo utilizando redes neurais. A primeira considerando como variável de saída o consumo de vapor e a segunda considerando a relação entre o consumo de vapor e a produção de $\mathrm{NaOH}$. Esta segunda abordagem se justifica pela tentativa de eliminar o efeito da variação de produção da unidade durante o período da coleta de dados.

Na tabela 8.6 são apresentadas as variáveis de entrada e saída das duas abordagens.

Tabela 8.6 Abordagens para as RN testadas

\begin{tabular}{|c|c|c|}
\hline Entrada & Saída & Abordagem \\
\hline$P_{3}$ & & 1 \\
$P_{2}$ & $W T_{\text {vapor }}$ & \\
$P_{1}$ & & 2 \\
$T_{\text {licor-3 }}$ & $W T_{\text {vapor }} / W T_{\mathrm{NaOH}}$ & \\
$C_{\mathrm{NaOH}-2}$ & & \\
$W T_{\mathrm{NaOH}}$ & & \\
\hline
\end{tabular}

Das duas abordagens propostas, a abordagem 1 apresentou melhores resultados de ajuste entre os valores calculados pela $\mathrm{RN}$ e os valores de processo em relação à abordagem 2. Portanto, a seguir serão discutidos os resultados da primeira abordagem, apenas. 


\section{Abordagem 1}

No ajuste da RN para este modelo foram realizados ensaios com NH igual a 2, 4, 6 e 8, constatando-se melhor resultado para $\mathrm{NH}$ igual a 6 . Na figura 8.15 é representada a evolução do erro quadrático em função do número de apresentações para as redes de treinamento e de teste.

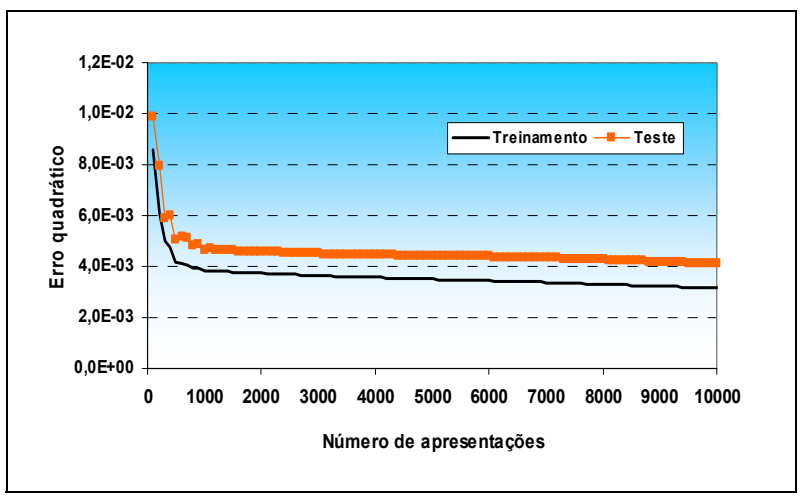

Figura 8.15 Erro quadrático em função do número de apresentações, evaporação, para $N H=6$.

$\mathrm{Na}$ comparação entre os valores calculados pela $\mathrm{RN}$ e os dados de processo verifica-se que o ajuste da $\mathrm{RN}$ foi satisfatório para o conjunto de dados disponibilizados para treinamento da $\mathrm{RN}$, pois os coeficientes de determinação e o angular da reta de ajuste ficaram próximos de 0,87 e de 1,00, respectivamente.

Para o conjunto de dados disponibilizados para teste, na comparação entre os valores calculados pela $\mathrm{RN}$ e os dados de processo, os coeficientes de determinação e o angular da reta de ajuste ficaram próximos de 0,83 e de 0,93 respectivamente, indicando ajuste da RN para este conjunto de dados.

Nas figuras 8.16 e 8.17 são mostrados os comparativos entre os valores de calculados pela $\mathrm{RN}$ e dados de processo para os conjuntos de dados de treinamento e teste respectivamente. 


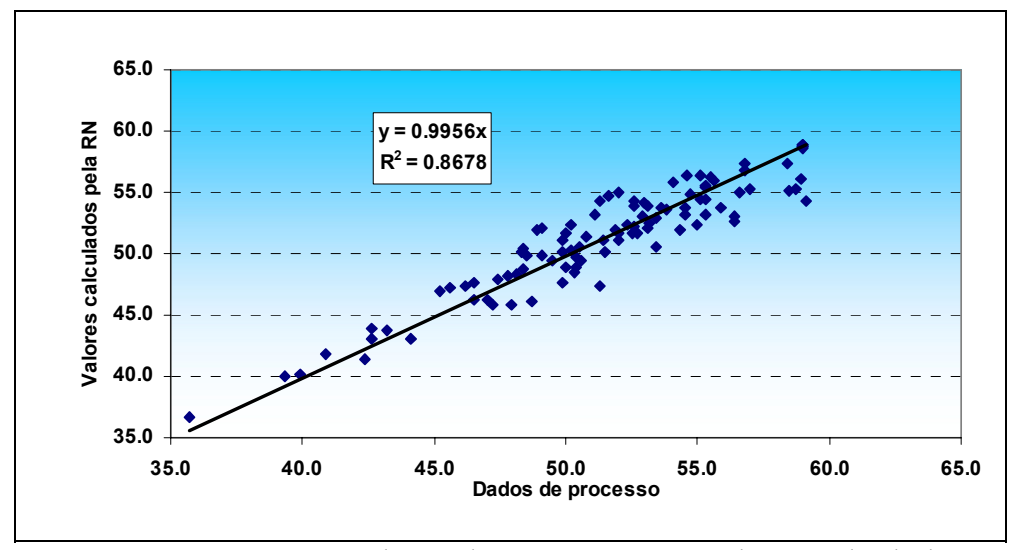

Figura 8.16 Comparação entre os valores de processo e os valores calculados pela $R N$ para dados de treinamento, evaporação, para $N H=6$.

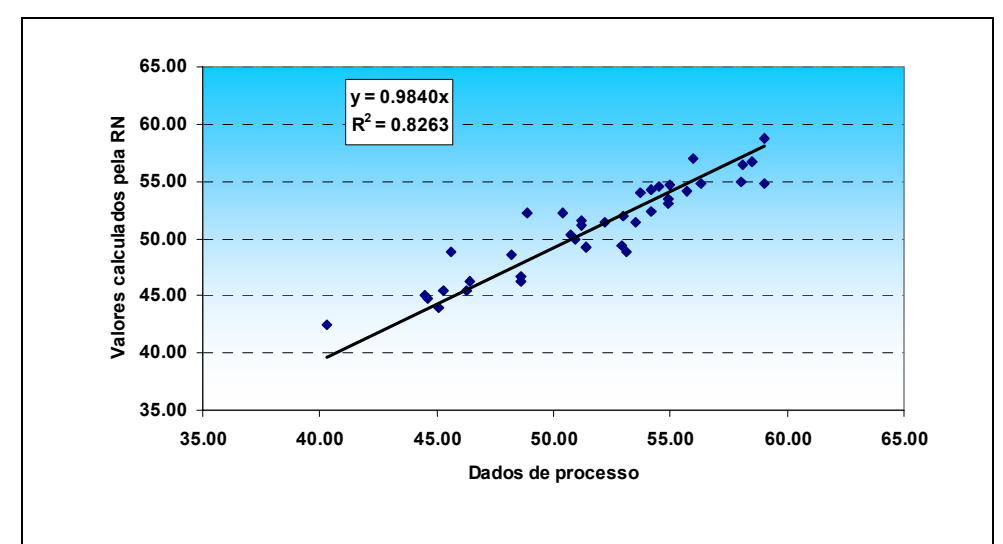

Figura 8.17 Comparação entre os valores de processo e os valores calculados pela $R N$ para dados de teste, evaporação, para $N H=6$.

A distribuição das diferenças entre valores calculados pela $\mathrm{RN}$ e dados de processo para NH igual a 6, para os conjuntos de dados de treinamento e de teste, apresentaram comportamento semelhante, indicando nos dois casos uma distribuição normal. Isto foi verificado utilizando a ferramenta do Minitab "Normality Test", com grau de incerteza de 5\%. Foram obtidos os valores de 0,29 para os dados de treinamento e 0,34 para os dados de teste, indicando curvas normais para os dois testes realizados, pois "p-value" $>0,05$, confirmando consistência no ajuste da $\mathrm{RN}$.

Na figura 8.18 são representadas a distribuição das diferenças entre os valores calculados de consumo de vapor pela $\mathrm{RN}$ e dados de processo para $\mathrm{NH}$ igual a 6 . 

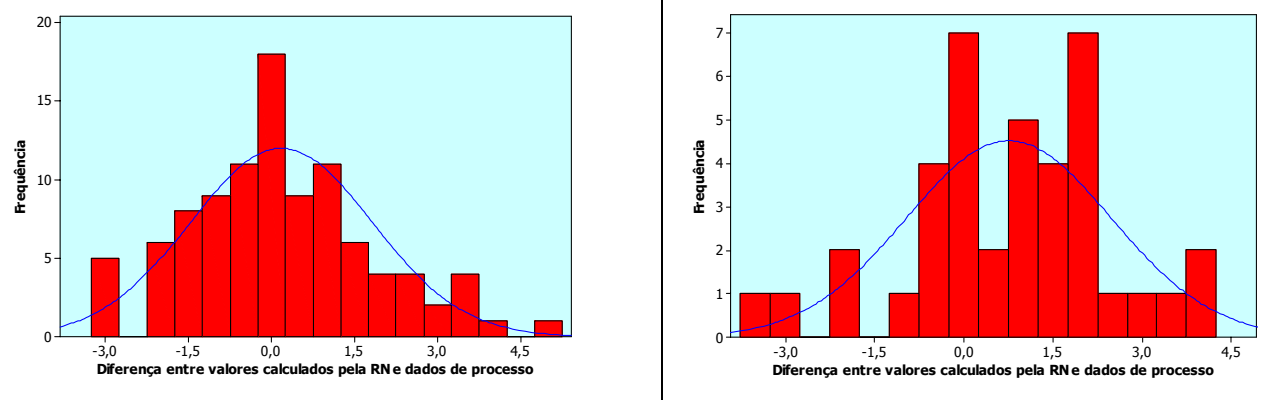

Figura 8.18 - Distribuição das diferenças entre dados de processo e valores calculados pela $\mathrm{RN}$ para os conjuntos de dados de treinamento e teste, evaporação, para $N H=6$. 


\section{SIMULAÇÃO COM OS MODELOS DE REDES NEURAIS}

\subsection{Sala de Células Diafragma}

Para os ensaios de simulação foram utilizados os três modelos de RN

ajustados para as células I, II e III com três saídas, concentração de $\mathrm{NaOH}$ no licor, eficiência de corrente e voltagem, e NH igual a 6 .

Nas simulações, apenas uma das variáveis de entrada foi alterada em cada vez, mantendo-se as demais variáveis de entrada em seus valores centrais na faixa. O critério utilizado foi analisar o efeito das variáveis de entrada que apresentem menor dependência em relação à outra, pois todas apresentam certa dependência entre si. Para as variáveis de saída concentração de $\mathrm{NaOH}$ e eficiência de corrente foi alterada a variável vazão de salmoura, enquanto que para a voltagem foi alterada a intensidade de corrente.

A seguir serão discutidas as simulações realizadas com os modelos de RN para as três variáveis de saída, sendo discutidos os resultados em relação às tendências esperadas, com base na experiência da operação da unidade industrial. Para isso, foram selecionados conjuntos de dados de operação do processo nos quais somente a variável de processo estudada apresenta maior variação, com as demais em valores próximos. Esses dados foram utilizados também como entradas dos modelos de RN. Os resultados calculados pelos modelos de RN para as variáveis de saída do modelo são então comparados com os dados de processo.

\subsubsection{Concentração de $\mathrm{NaOH}$ e eficiência de corrente}

\section{Influência da vazão de salmoura}

O resultado esperado quando há um incremento na vazão de salmoura é uma redução na concentração de $\mathrm{NaOH}$ e aumento na eficiência de corrente, pois vazões maiores na célula indicam diafragma menos obstruído e efeito menor de migração contrária de íons $\mathrm{OH}^{-}$, do catodo para o anodo, logo uma eficiência de corrente maior, conforme mencionado no item 3.1.8. Além disso, a maior vazão de salmoura 
implica menor tempo de residência nas células, o que resulta em menor quantidade de $\mathrm{NaOH}$ formada.

A representação gráfica dos dados de processo quando observadas as curvas de tendência das células I, II e III, figura 9.1, indicam redução na concentração $\mathrm{NaOH}$ com aumento na vazão de salmoura. A mesma tendência é observada quando analisamos o resultado utilizando os modelos de $\mathrm{RN}$, figura 9.2, porém indicando um intervalo maior de variação na concentração de $\mathrm{NaOH}$.

Os resultados apresentados a seguir são mostrados normalizados, de acordo com o intervalo entre o máximo e o mínimo observados na operação para as variáveis em questão.

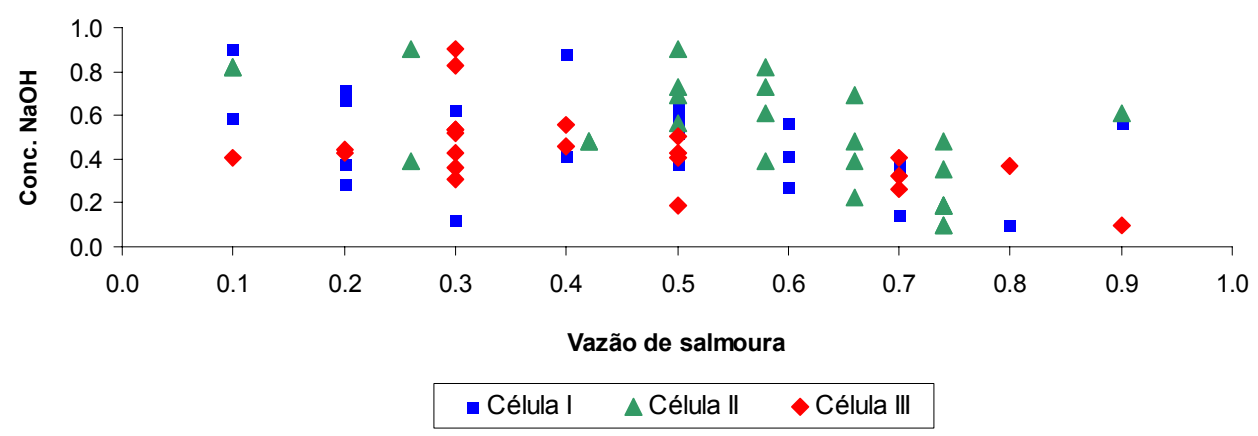

Figura 9.1. Dados de processo normalizados, concentração de $\mathrm{NaOH}$ em função da vazão de salmoura.

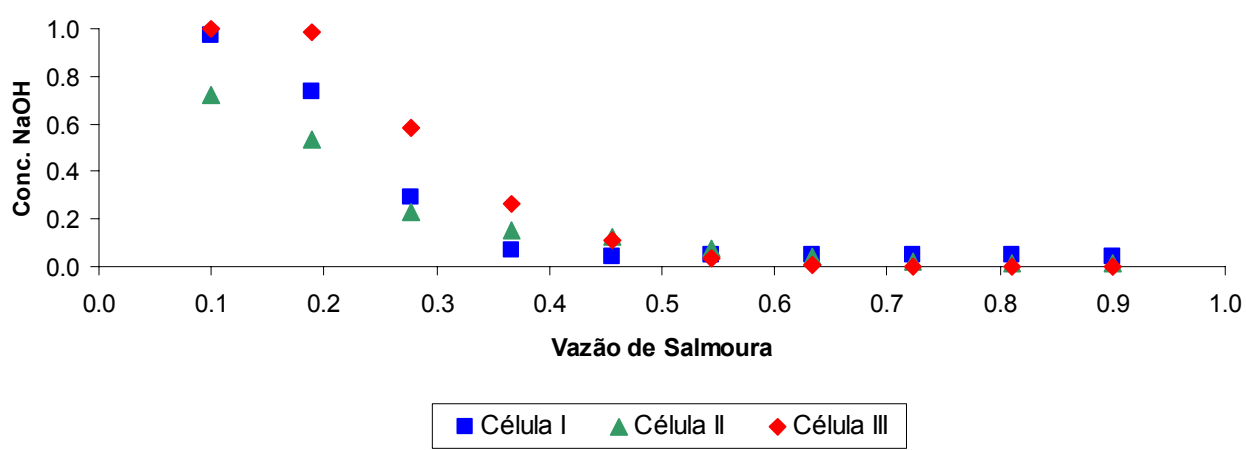

Figura 9.2. Valores calculados normalizados a partir dos modelos de $\mathrm{RN}$ com $\mathrm{NH}=6$, concentração de $\mathrm{NaOH}$ em função da vazão de salmoura.

Para a eficiência de corrente são observadas as mesmas tendências de variação nas células quando comparados os dados de processo com os resultados das 
simulações. Nas figuras 9.3 e 9.4 são representados os gráficos de variação de eficiência de corrente em função da vazão de salmoura para os dados de processo e para valores calculados pelas RN respectivamente.

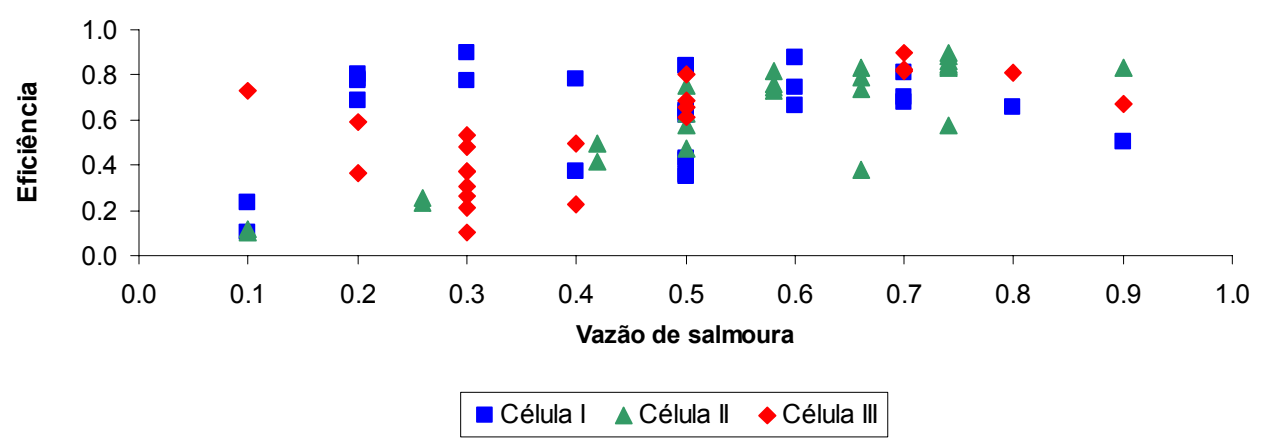

Figura 9.3 Dados de processo normalizados, eficiência de corrente em função da vazão de salmoura.

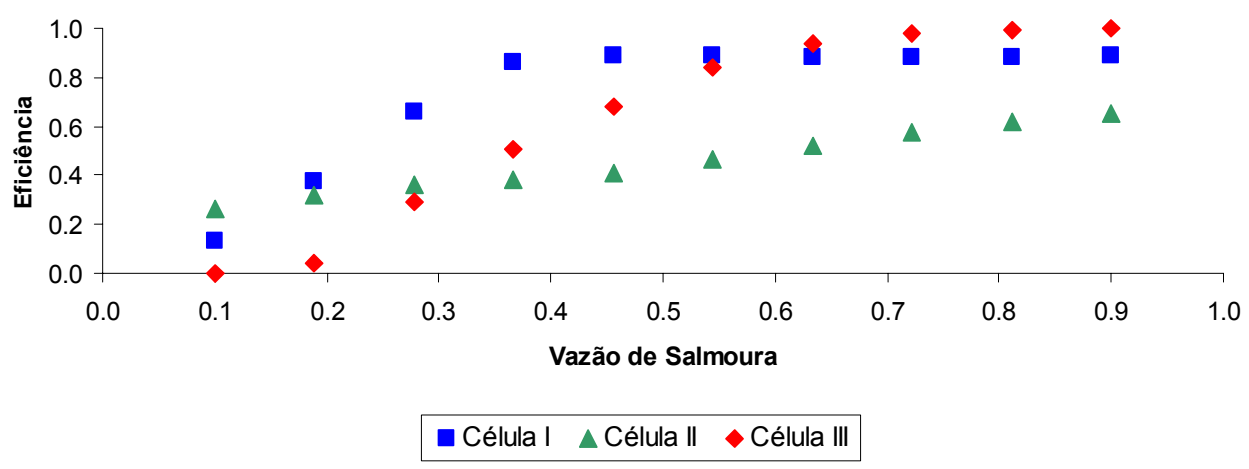

Figura 9.4. Valores calculados normalizados a partir dos modelos de $\mathrm{RN}$ com $\mathrm{NH}=6$, eficiência de corrente em função da vazão de salmoura.

\subsubsection{Voltagem}

\section{Influência da intensidade de corrente}

$\mathrm{O}$ incremento na intensidade de corrente está diretamente associado ao aumento na voltagem, conforme mencionado no item 3.1.3. Esse incremento pode ser maior ou menor de acordo com a resistência interna da célula. Outra conseqüência do aumento da intensidade de corrente é em relação a aumento da 
temperatura do licor, devido ao aumento do calor dissipado na célula, gerando aumento de temperatura. Desta forma, para minimizar os erros devido às condições operacionais distintas, as simulações foram realizadas incrementando simultaneamente a intensidade de corrente e a temperatura do licor para verificação do efeito na voltagem da célula.

Verifica-se tendência de incremento na voltagem com aumento da intensidade de corrente tanto nos dados de processo como nos valores calculados pelos modelos da RN. Paras as células I e III os dados de processo apresentam maior intensidade de variação da voltagem do que para a célula II. Para o modelo de RN, para a célula II esta característica ficou mais evidenciada. Nas figuras 9.5 e 9.6 são apresentados estes resultados.

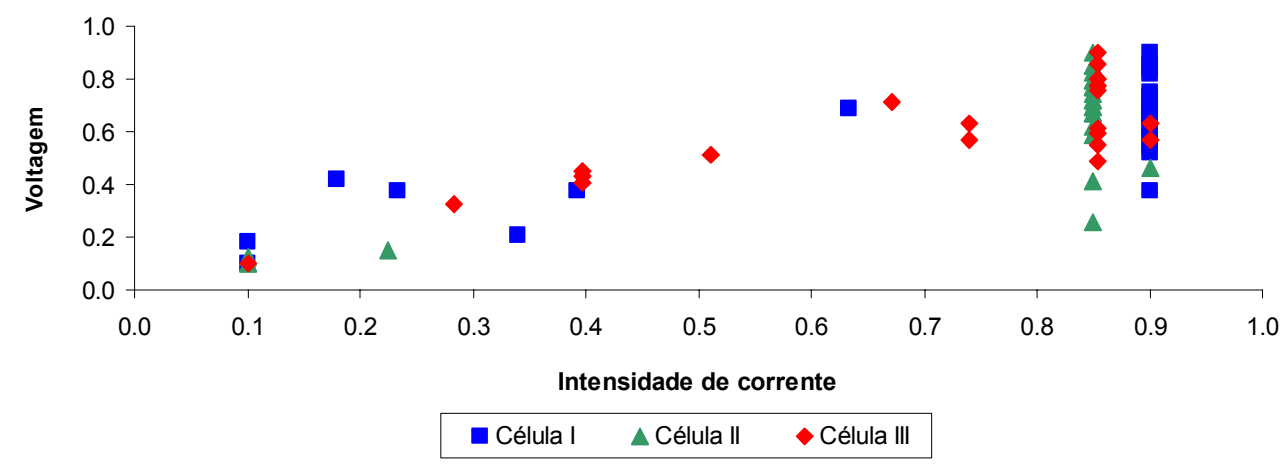

Figura 9.5. Dados de processo normalizados, voltagem em função da intensidade de corrente.

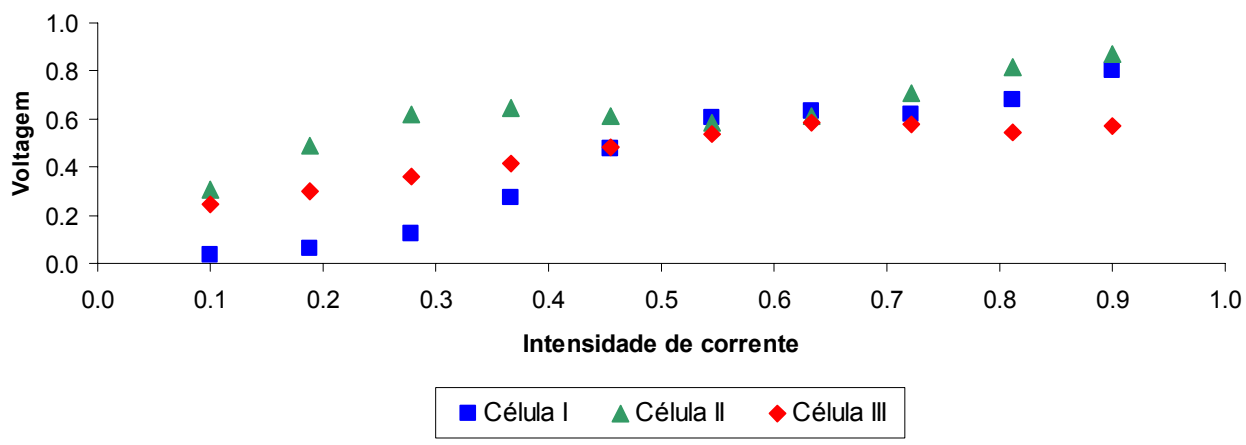

Figura 9.6. Valores calculados a partir dos modelos de $\mathrm{RN}$ com $\mathrm{NH}=6$, voltagem em função da intensidade de corrente. 
Os resultados obtidos nas simulações realizadas com os três modelos apresentaram consistência mais acentuada em alguns casos e menos em outros. Os motivos para esses desvios são descritos a seguir.

Com a relação de dependência entre si das variáveis de entrada, fica difícil verificar o efeito de uma única variável de entrada sobre qualquer variável de saída. Podem-se citar as seguintes dependências:

- vazão de salmoura e tempo de operação: células novas possuem diafragmas mais permeáveis em relação a células mais velhas, pois à medida em que aumenta o tempo de vida da célula verifica-se uma maior obstrução do diafragma, sendo necessária uma redução na vazão de salmoura, ou aumento no nível da célula.

- intensidade de corrente e temperatura de licor: aumento na intensidade de corrente ocasiona maior geração de calor na célula, produzindo aumento na temperatura de licor.

- vazão de salmoura e temperatura de licor: variação da vazão de salmoura pode gerar alteração na temperatura da célula, pois a mesma quantidade de calor dissipada passa a aquecer uma maior ou menor quantidade de solução (salmoura e licor).

Algumas condições para os ensaios de simulação não foram apresentadas para treinamento da $\mathrm{RN}$ dentro da faixa de domínio no desenvolvimento dos modelos, devido ao pequeno número de registros disponíveis no processo. Para um melhor ajuste da $\mathrm{RN}$, é necessária uma amostra com maior número de registros, possibilitando maior representatividade do modelo e a validação do mesmo.

Em função do exposto, os resultados das simulações realizadas com os modelos das três células apresentam comportamentos distintos, indicando respostas diferentes de cada um dos modelos de RN.

Dando prosseguimento ao desenvolvimento deste trabalho, os modelos aqui analisados serão utilizados no desenvolvimento do algoritmo de otimização da eletrólise diafragma e da unidade de evaporação. Entretanto, a utilização dos modelos para eletrólise deve ser vista com cuidado, tendo em vista os aspectos discutidos anteriormente. 


\subsection{Evaporação}

Utilizando o modelo obtido por RN, com NH igual a 6, para simular o consumo de vapor, foram realizadas simulações em que as variáveis de entrada, produção de $\mathrm{NaOH}$, pressão nos três efeitos, temperatura e concentração de $\mathrm{NaOH}$ no licor, são alteradas isoladamente verificando-se o efeito no consumo de vapor.

Para as simulações, uma vez escolhida a variável a ser alterada, foram utilizados dez pontos situados no intervalo de variação entre os valores mínimo e máximo dos valores obtidos a partir dos dados de operação da variável analisada, enquanto as variáveis de entrada restantes foram mantidas constantes no seu valor médio.

Os resultados das simulações, Fig. 9.7, indicam consistência nos resultados em comparação com os observados no processo. Observa-se que o aumento nas pressões dos três efeitos, ou no nível de produção, provoca aumento no consumo de vapor. Em contrapartida temperaturas e concentrações de $\mathrm{NaOH}$ mais elevadas na entrada do $3^{\circ}$ efeito resultam em menor consumo de vapor. Outro fato é a maior sensibilidade de variação no consumo de vapor quando são alterados o nível de produção ou as pressões nos efeitos.

Os resultados apresentados a seguir são mostrados normalizados, de acordo com o intervalo entre o máximo e o mínimo observados na operação para as variáveis em questão.

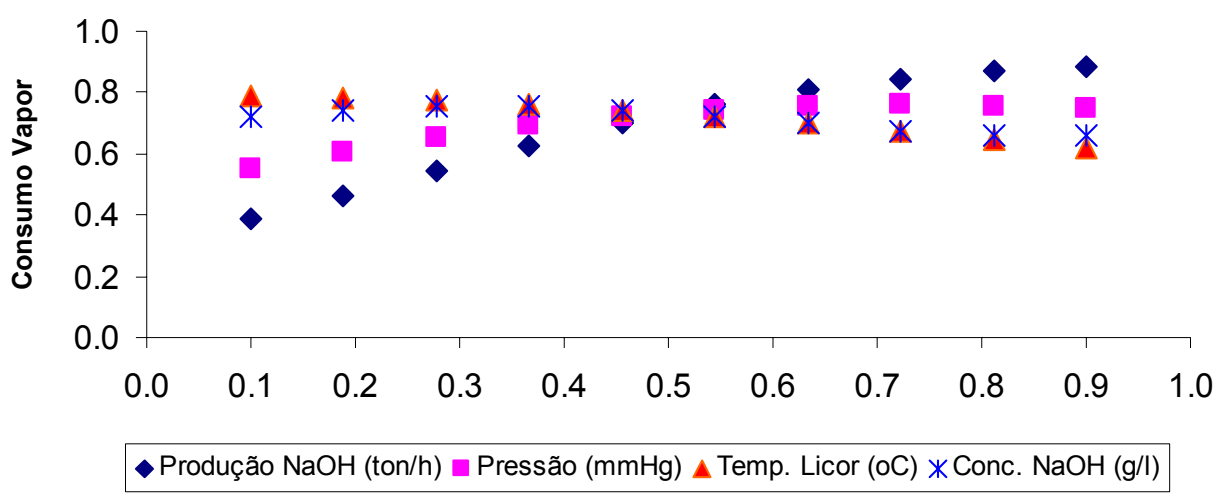

Figura 9.7 Resultados de simulações normalizados: consumo de vapor em função das variáveis de entrada para o modelo da evaporação, para $\mathrm{NH}=6$. 


\section{0 - OTIMIZAÇÃO}

Neste capítulo são apresentados resultados do estudo voltado a identificação de condições operacionais da unidade industrial que representem maximização do ganho financeiro, associando eficiência de produção e consumo de energia. São consideradas no modelo do processo apenas as etapas associadas a praticamente todo o consumo de energia, ou seja: eletrólise e evaporação. Inicialmente é apresentada a função objetivo adotada no estudo (ganho financeiro), assim como as equações do modelo do processo. Em seguida é apresentada a estratégia de otimização e, finalmente, exemplos de resultados, com discussão.

\subsection{Função objetivo}

O ganho financeiro, $G F$, em $\mathrm{R} \$$ ao longo de um período de tempo $t$, é a função objetivo a ser maximizada, sendo obtida através da seguinte equação:

$G F=G P-C F E-C V E$

Em que $G P$ é o ganho, para uma determinada taxa de produção, $C F E$ é o custo com energia elétrica na eletrólise e $C V E$ é o custo de vapor na evaporação, sendo as três variáveis expressas em $\mathrm{R} \$$.

\section{Ganho de produção}

A variável $G P$ pode ser obtida a partir da relação:

$G P=P P * t * P V$

Sendo $P P$ a taxa de produção em $\mathrm{t} / \mathrm{h}, t$ o tempo em horas e $P V$ o preço de venda em R\$. Como na eletrólise são produzidos simultaneamente o cloro, a soda e o hidrogênio a variável $G P$ é representada por

$$
G P=G P_{\mathrm{Cl}_{2}}+G P_{\mathrm{NaOH}}+G P_{\mathrm{H}_{2}}=P P_{\mathrm{Cl}_{2}} * t * P V_{\mathrm{Cl}_{2}}+P P_{\mathrm{NaOH}} * t * P V_{\mathrm{NaOH}}+P P_{\mathrm{H}_{2}} * t * P V_{\mathrm{H}_{2}}
$$


Como a taxa de produção de hidrogênio é pouco representativa quando comparada com as taxas de cloro e soda, foi desprezada sua parcela de ganho. Por estequiometria, vale a seguinte relação na eletrólise entre as taxas de produção de cloro e soda,

$$
P P_{\mathrm{NaOH}}=1,12 * P P_{\mathrm{Cl}_{2}}
$$

Logo, GP pode ser obtido da seguinte forma,

$$
G P=P P_{\mathrm{Cl}_{2}} * t *\left(P V_{\mathrm{Cl}_{2}}+1,12 * P V_{\mathrm{NaOH}}\right)
$$

A partir da equação 3-1, é estabelecida a seguinte equação para a taxa de produção horária,

$$
P P_{\mathrm{Cl}_{2}}=(I * \varepsilon) / 756
$$

Sendo $I$ a intensidade de corrente em kA e $\varepsilon$ a eficiência de corrente (em \%). Combinando as equações 10-5 e 10-6, obtem-se o ganho de produção a partir da intensidade de corrente,

$$
G P=I * \varepsilon * t *\left(P V_{\mathrm{Cl}_{2}}+1,12 * P V_{\mathrm{NaOH}}\right) / 756
$$

\section{Custo de energia elétrica}

$\mathrm{O}$ custo financeiro de energia elétrica, em $\mathrm{R} \$$, é definido como o produto do consumo de energia $C E$,em $\mathrm{MWh}$, e do preço da energia $T R$, em $\mathrm{R} \$ \mathrm{MWh}$,

$$
C F E=(C E)^{*} T R
$$

O consumo de energia pode ser obtido a partir da equação para corrente contínua

$$
C E=V^{*} I * t / 1000
$$


Em que $V$ é a voltagem da célula em volts. Combinando as equações 10-6, 10-8 e 10-9, obtem-se

$$
C F E=(756 * V * P P * t) / \varepsilon) * T R / 1000
$$

\section{Custo de vapor}

O custo de vapor, em $\mathrm{R}$, é obtido pelo produto do consumo de vapor, $W$, em toneladas, pelo seu preço unitário, $P R$, em $\mathrm{R} \$ / \mathrm{t}$,

$$
C V E=W T_{\text {vapor }} * P R
$$

\section{Modelo para otimização}

O esquema proposto para otimização entre as unidades de eletrólise e evaporação é representado a seguir, na figura 10.1. Nesse esquema, duas células são admitidas no circuito I e uma no circuito II.

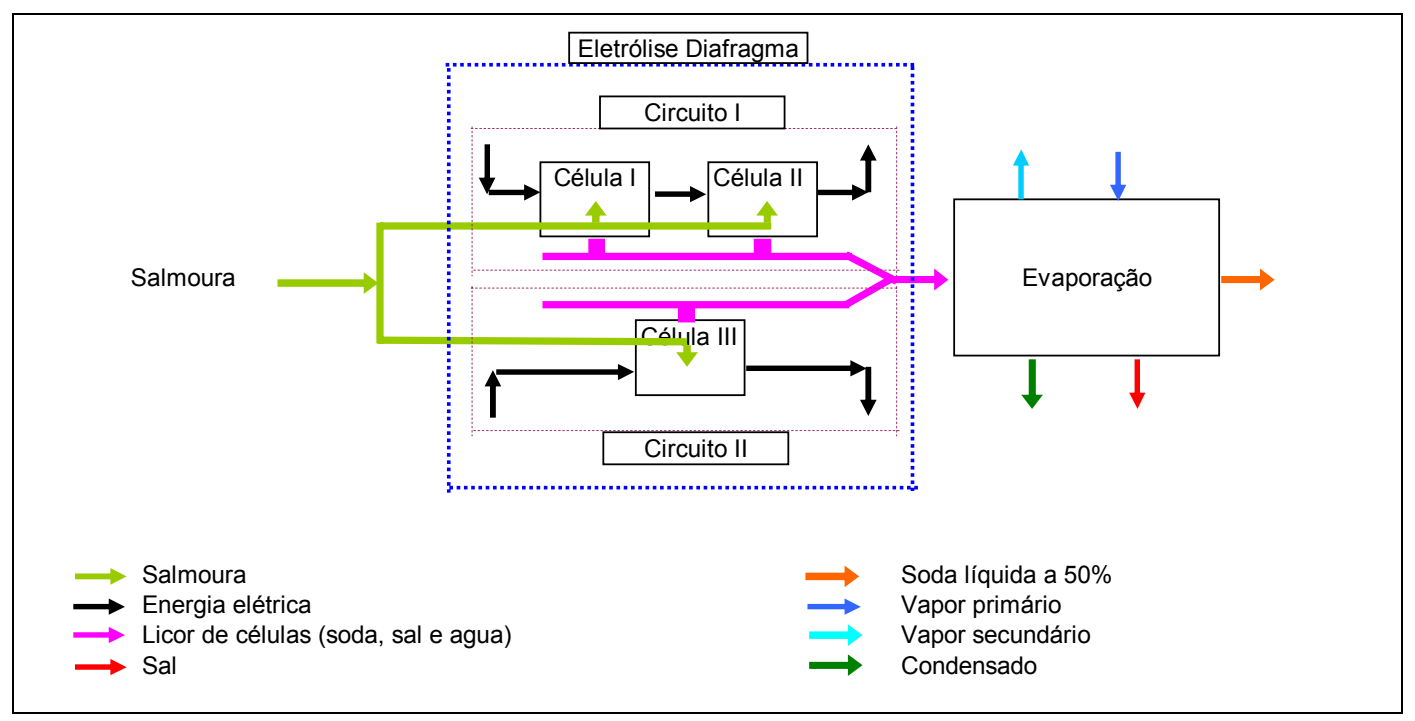

Figura 10.1 - Fluxograma proposto para otimização das unidades de eletrólise e evaporação

A produção na eletrólise é dada pela somas das produções das três células,

$$
P P=P P_{1}+P P_{2}+P P_{3}
$$


Se for admitido que, no lugar das três células, há três grupos de células, a equação 10-12 passa a ser representada por

$$
P P=N_{1} * P P_{1}+N_{2} * P P_{2}+N_{3} * P P_{3}
$$

Sendo $\mathrm{N}_{1}, \mathrm{~N}_{2}$ e $\mathrm{N}_{3}$ o número de células em cada um dos grupos.

Logo o ganho para uma taxa de produção pode ser representado em uma única equação,

$$
G P=I * t *\left(P V_{\mathrm{Cl}_{2}}+1,12 * P V_{\mathrm{NaOH}}\right) *\left(N_{1} * \varepsilon_{1}+N_{2} * \varepsilon_{2}+N_{3} * \varepsilon_{3}\right) / 756
$$

O custo de energia considerando as três células pode expresso por,

$$
C E=756 * P P * t *\left(N_{1} * V_{1} / \varepsilon_{1}+N_{2} * V_{2} / \varepsilon_{2}+N_{3} * V_{3} / \varepsilon_{3}\right) * T R / 1000
$$

Pelo esquema proposto, a mesma salmoura alimenta todas as células, então a variável concentração de $\mathrm{NaCl}$ é também igual. Quanto à intensidade de corrente, seguindo o modo de operação adotado na unidade industrial, será admitida igual para os dois circuitos, logo será também igual para todas as células.

Admitindo essas duas premissas, os modelos de RN das células I, II e III, para cálculo de voltagem, eficiência de corrente e concentração de $\mathrm{NaOH}$ no licor, podem ser representados da seguinte forma,

$$
\begin{aligned}
& V_{1}, \text { efic }_{1}, C_{\mathrm{NaOH}-1,1}=f\left(\mathrm{DOL}_{1}, Q_{1}, T_{\text {licor }, 1}, C_{\mathrm{NaCl}}, I\right) \\
& V_{2}, \text { efic }_{2}, C_{\mathrm{NaOH}-1,2}=f\left(\mathrm{DOL}_{2}, Q_{2}, T_{\text {licor }, 2}, C_{\mathrm{NaCl}}, I\right) \\
& V_{3}, \text { efic }_{3}, C_{\mathrm{NaOH}-1,3}=f\left(\mathrm{DOL}_{3}, Q_{3}, T_{\text {licor }, 3}, C_{\mathrm{NaCl}}, I\right)
\end{aligned}
$$

Sendo $D O L$ o tempo de vida, em dias, $Q$ a vazão de salmoura na célula, $\mathrm{m}^{3} / \mathrm{h}$, $T_{\text {licor }}$ a temperatura do licor na célula, ${ }^{\circ} \mathrm{C}, C_{\mathrm{NaCl}}$ a concentração de salmoura, g/L, e $I$ a intensidade de corrente, $\mathrm{kA}$.

Combinando as equações 10-14 e 10-15 com 10-16, 10-17 e 10-18 são determinados o $G P$ e $C F E$. 
Quanto ao consumo de vapor na unidade de evaporação, $\mathrm{t} / \mathrm{h}$, o modelo de RN ficou definido da seguinte forma,

$W T_{\text {vapor }}=f\left(W T_{\mathrm{NaOH}}, P_{1}, P_{2}, P_{3}, T_{\text {licor }-3}, C_{\mathrm{NaOH}-2}\right)$

Em que $W T_{\mathrm{NaOH}}$ é a taxa de produção de soda base $100 \%$ em massa, $\mathrm{t} / \mathrm{h}, P_{1}$, $P_{2}$ e $P_{3}$ são as pressões dos três efeitos, $\mathrm{mmHg}, T_{\text {licor-3 }}$ e $C_{\mathrm{NaOH}-2}$ são a temperatura, ${ }^{\circ} \mathrm{C}$, e concentração, g/L, do licor na alimentação do terceiro efeito.

As variáveis $T_{\text {licor,-3 }}$ e $\mathrm{C}_{\mathrm{NaOH}-2}$ podem ser calculadas a partir da $T_{\text {licor }}$ e $C_{\mathrm{NaOH}-\mathrm{I}}$ das três células utilizando-se $Q$ para obtenção da média ponderada,

$$
\begin{aligned}
& T_{\text {licor }-3}=\frac{N_{1} * T_{\text {licor }, 1} * Q_{1}+N_{2} * T_{\text {licor }, 2} * Q_{2}+N_{3} * T_{\text {licor }, 3} * Q_{3}}{N_{1} * Q_{1}+N_{2} * Q_{2}+N_{3} * Q_{3}}+\Delta T \\
& C_{\mathrm{NaOH}-2}=\frac{N_{1} * C_{\mathrm{NaOH}-1,1} * Q_{1}+N_{2} * C_{\mathrm{NaOH}-1,2} * Q_{2}+N_{3} * C_{\mathrm{NaOH}-1,3} * Q_{3}}{N_{1} * Q_{1}+N_{2} * Q_{2}+N_{3} * Q_{3}}
\end{aligned}
$$

Em que $\Delta T$ é a variação de temperatura no licor entre a saída da eletrólise e entrada do $3^{\circ}$ efeito, tendo um valor aproximado de $10{ }^{\circ} \mathrm{C}$.

Combinando-se as equações, 10-11, 10-19, 10-20 e 10-21 determina-se o custo de vapor $C V E$.

Conhecidos $G P, C F E$ e $C V E$ determina-se a função objetivo da otimização $G F$.

\subsection{Resultados da otimização}

Utilizando a metodologia de otimização descrita no Capítulo 5, foi elaborado um algoritmo e um programa computacional em linguagem Fortran 77 para busca do ótimo global de $G F$ e de condições operacionais que satisfazem uma dada tolerância em torno desse ótimo.

O algoritmo de otimização foi elaborado da seguinte forma: 
Primeiramente são definidos valores dos parâmetros do modelo, como preços de venda, custos, número de células em cada um dos grupos, tolerância em relação ao ótimo global, Estipulam-se níveis de operação para as variáveis controladas de acordo com as condições desejadas.

Além disso, é definido o número de passos desejados para variação de cada uma das variáveis entre os seus valores mínimos e máximos.

O procedimento de busca consiste em se calcular as equações do modelo do processo, Eqs. 10-2 a 10-21, e a função objetivo, Eq. 10-1, sendo arquivado o caso de maior ganho financeiro, ou seja, o ótimo global. Em seguida, é admitida uma tolerância em torno do ótimo global e o procedimento é repetido, sendo feita a varredura de toda a grade de valores, sendo retidos os casos em que o ganho financeiro (função objetivo) satisfizer o critério de tolerância.

Para o estudo de otimização, são consideradas seis variáveis alteradas independentemente, cinco da eletrólise (tempo de vida, vazão de salmoura, temperatura licor, concentração de $\mathrm{NaCl}$ na salmoura e intensidade de corrente) e uma da evaporação (pressão no $3^{\circ}$ efeito).

Para as variáveis de processo - intensidade de corrente, tempo de operação e concentração de NaCL - foram definidos valores com base nos critérios de operação da unidade industrial.

Intensidade de corrente (I): associada ao nível de produção desejado.

- Tempo de operação da célula $(D O L)$ : as células são substituídas individualmente de acordo com o seu rendimento, logo os tempos de vida de cada célula são diferentes, para um determinado período de operação.

Concentração de $\mathrm{NaCl}$ na salmoura $\left(C_{\mathrm{NaCl}}\right)$ : valor definido de acordo com as condições de operação da unidade de salmoura.

Para as variáveis de entrada, temperatura de licor $\left(T_{\text {licor }}\right)$ e vazão de salmoura $(Q)$ para eletrólise, e pressão do primeiro efeito $\left(P_{1}\right)$ para evaporação, foram estabelecidos critérios de acordo com os valores máximos e mínimos encontrados no processo.

As demais variáveis de entrada da unidade de evaporação são calculadas a partir dos valores das variáveis da eletrólise, taxa de produção de $\mathrm{NaOH}$ a 100\% 
$\left(W T_{\mathrm{NaOH}}\right)$, concentração $\left(C_{\mathrm{NaOH}-2}\right)$ e temperatura $\left(T_{\text {licor-3 }}\right)$ no licor. Quanto às pressões do segundo e terceiro efeitos $\left(P_{2}, P_{3}\right)$ são obtidas a partir da pressão do primeiro efeito $\left(P_{1}\right)$, pois em condição estacionária do processo de evaporação foi observada relação fixa entre essas variáveis.

Os resultados apresentados a seguir, a título de exemplo, referem-se a uma margem de tolerância em relação ao ponto ótimo global igual a $0,2 \%$, com o número de níveis para a grade das variáveis de otimização igual a 10, e o número de células de eletrólise para cada um dos tipos de célula (I, II e II) igual a 30, 30 e 32, respectivamente, totalizando 92 células.

Na prática, o número total de combinações das variáveis de otimização $\left(10^{6}\right.$ possibilidades) foi reduzido para $10^{3}$, após definidos valores para as variáveis intensidade de corrente, tempo de operação e concentração de $\mathrm{NaCl}$.

Para análise dos resultados da otimização foram escolhidos os casos em que o ganho financeiro é analisado em função das variáveis vazão de salmoura e intensidade de corrente. A vazão de salmoura tem maior influência na eficiência de corrente e na concentração de licor e a intensidade de corrente tem relação direta com a voltagem e nível de produção. Para essas simulações, as variáveis controladas foram definidas em um único valor, tempo de operação da célula em 300 dias e concentração de $\mathrm{NaCl}$ na salmoura em $320 \mathrm{~g} / \mathrm{L}$.

A primeira análise é feita para avaliação do ganho financeiro em função da vazão média de salmoura nas três células, com intensidade de corrente fixada em 145 $\mathrm{kA}$, resultando em 508 casos.

Separados os grupos por média da vazão de salmoura das três células, acrescida das restrições de igual pressão nos efeitos e temperatura de licor na evaporação entre 85 e $86{ }^{\circ} \mathrm{C}$ foram selecionados 28 casos. Ao selecionar casos de igual pressão e uma faixa restrita de temperatura o objetivo foi evitar a possibilidade do efeito dessas variáveis sobre os resultados dessa análise. Quanto à escolha do intervalo de temperatura se deu devido a maior quantidade de casos disponibilizados pelo algoritmo e situando-se próximo a média observada nos dados de operação.

A seguir são discutidos os resultados obtidos no estudo de otimização, sendo apresentados no anexo II o conjunto de valores das variáveis consideradas nesse estudo e seus respectivos ganhos financeiros. 
Verifica-se que, com o aumento da vazão de salmoura nas três células há uma tendência de aumento no ganho financeiro até a vazão de $70 \%$ da faixa, mantendo-se num mesmo patamar para vazões de 70 a $100 \%$ da faixa. $\mathrm{O}$ aumento no ganho financeiro com aumento de vazão está em concordância com o resultado esperado, pois vazões mais elevadas estão associadas a células com maior eficiência de corrente (maior taxa de produção).

Outro fato relevante é referente a ganhos diferentes em vazões de salmoura muito próximas. Isto se deve a diferenças nas vazões individuais de cada uma das células quando comparados os dois casos.

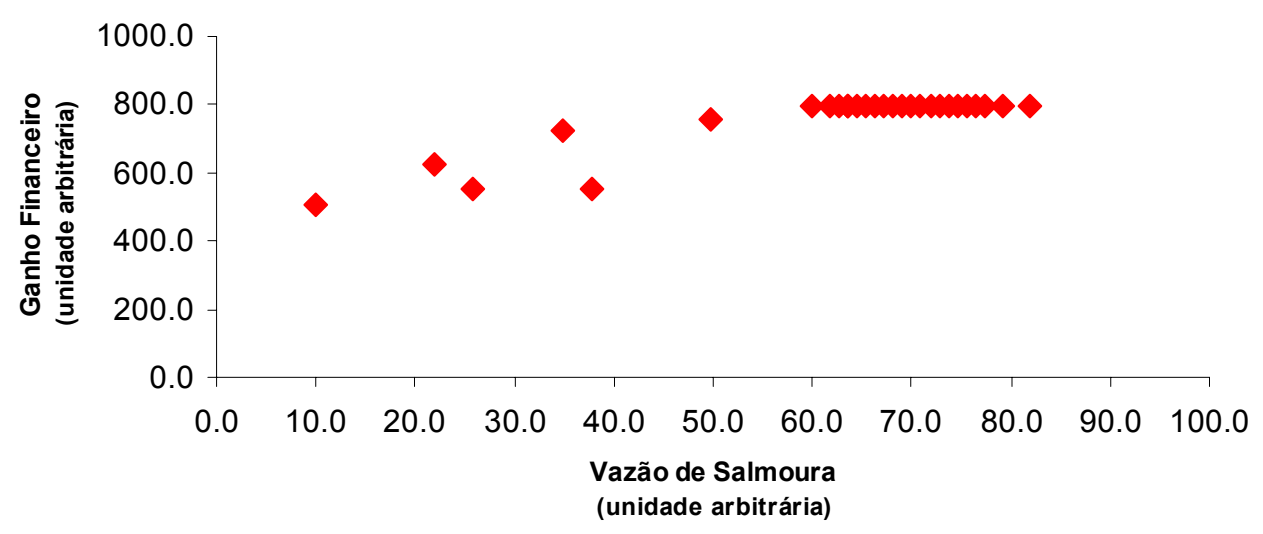

Figura 10.2 - Ganho financeiro em função da vazão média de salmoura.

Utilizando-se dos mesmos casos selecionados para a vazão de salmoura, foi calculado o ganho financeiro ótimo em para diferentes níveis da concentração de $\mathrm{NaOH}$ no licor. Observa-se concordância dos resultados com o observado na operação, figura 10.3, pois concentrações elevadas indicam baixa eficiência de corrente, ou seja, menor taxa de produção. É observada sobreposição de pontos, indicando que casos de concentração próximos mostram praticamente igual ganho financeiro. 


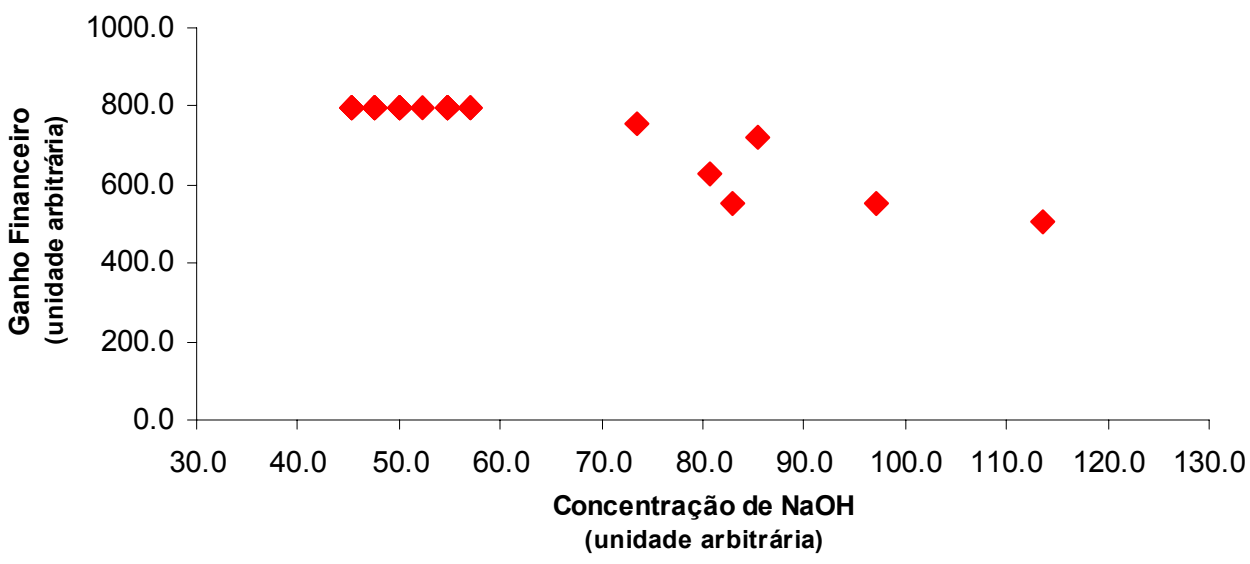

Figura 10.3 - Ganho financeiro em função da concentração de $\mathrm{NaOH}$ na evaporação.

A avaliação do efeito da intensidade de corrente sobre o ganho financeiro apresentou concordância em relação ao resultado esperado, pois esta variável está diretamente relacionada à taxa de produção.

Para esta avaliação foram utilizados os pontos ótimos de oito níveis de operação diferentes, porém mantendo-se constantes apenas as variáveis tempo de operação das células e concentração de $\mathrm{NaCl}$ na salmoura. Os pontos ótimos encontrados para o ganho financeiro indicaram incremento contínuo quando a intensidade de corrente é elevada, conforme mostrado na figura 10.4.

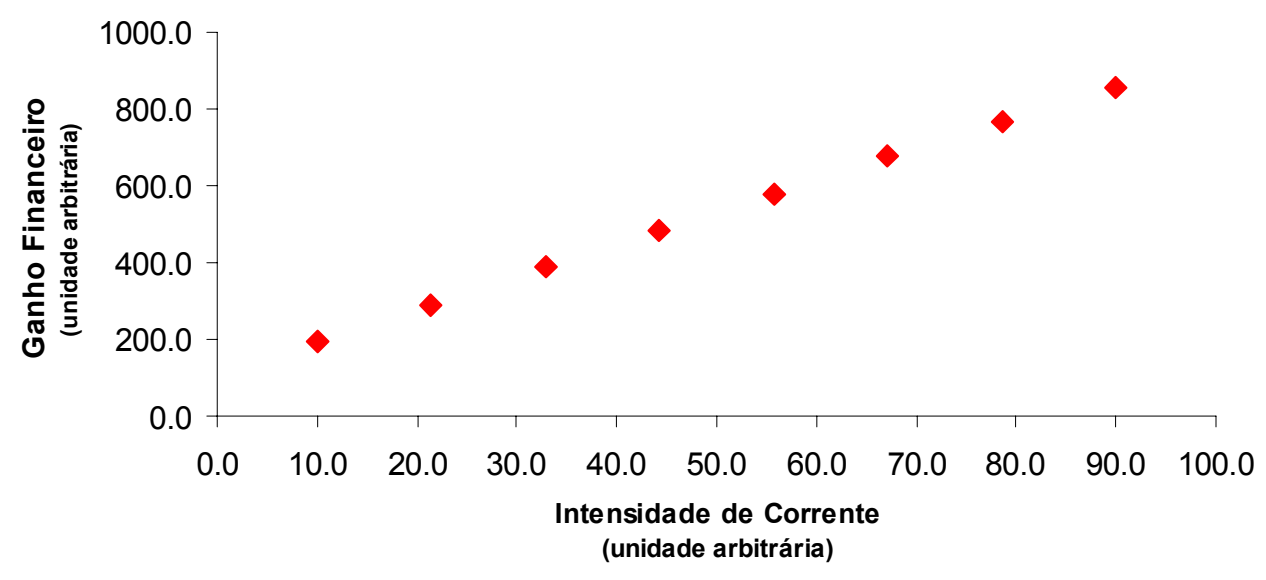

Figura 10.4 - Ganho financeiro em função da intensidade de corrente 


\section{CONCLUSÃO}

Na busca de modelos baseados em redes neurais para simulação do processo de eletrólise em diafragma verificaram-se resultados mais promissores para modelos com 6 neurônios na camada oculta, obtidos a partir dos dados de operação de uma única célula, tendo, como variáveis de saída, a eficiência de corrente, voltagem e concentração de $\mathrm{NaOH}$ no licor. Os modelos mostraram que a vazão de salmoura tem influência significativa na eficiência de corrente e na concentração de $\mathrm{NaOH}$, enquanto a intensidade de corrente tem maior impacto sobre a voltagem.

Entretanto, devido à pequena quantidade de dados de operação da unidade industrial, há necessidade de cuidados na interpretação destes resultados, pois para algumas condições de operação estes modelos não foram testados. Estes modelos podem ser melhorados se as RN forem treinadas utilizando-se um número maior de dados de operação disponíveis para cada célula.

Para os modelos de $\mathrm{RN}$ representando grupos de células não se verificou consistência nos resultados, mesmo quando testados modelos com uma única saída (eficiência de corrente ou voltagem), indicando falta de ajuste da RN. Possivelmente a falta de melhores resultados nesses casos se deve à ocorrência de sobreposição dos efeitos individuais das células, respostas divergentes para condições de operação parecidas, reduzindo sensivelmente o efeito das variáveis de entrada sobre as variáveis de saída. $\mathrm{Na}$ análise de componentes principais o mesmo problema pode ter dificultado a obtenção de componentes com maior representatividade no processo. Além disso, a ausência de mudanças significativas nas condições de operação da planta, conforme verificado na análise discriminante, quando comparados grupos de dados anuais, também pode ter influenciado no resultado.

Para a unidade de evaporação, o modelo de RN com 6 neurônios na camada oculta apresentou os melhores resultados para simular o consumo de vapor. As variáveis de entrada com maior influência foram a taxa de produção e pressão nos efeitos. Na análise de componentes principais essas três variáveis apresentaram altos coeficientes nos dois primeiros componentes principais, que apresentaram representatividade acima de $70 \%$ sobre a variância do processo. 
Na utilização da metodologia via redes neurais no estudo de otimização, tendo como função objetivo a ser maximizada o ganho financeiro envolvendo as unidades de eletrólise diafragma e evaporação, foi possível identificar um conjunto de condições operacionais próximas do mínimo global da função objetivo, expressada em termos de ganho financeiro horário na unidade.

A tendência verificada foi que, ao incrementar a vazão das células ocorre aumento no ganho financeiro, quando comparados casos para uma mesma intensidade de corrente na eletrólise e pressão nos efeitos. Desta forma, conclui-se que o ganho financeiro gerado pelo incremento na eficiência de corrente devido à elevação na vazão de salmoura se sobrepõe ao gasto adicional de energia térmica, custo de vapor, necessária para evaporar uma maior quantidade de água. Esta conclusão é importante neste tipo de processo, pois mostra que concentrações menores de $\mathrm{NaOH}$ no licor das células, devido a vazões maiores nas células, tendem a incrementar o ganho financeiro.

$\mathrm{Na}$ prática, as vazões maiores são conseguidas em células mais novas, deste modo conhecida a influência da vazão de salmoura sobre a eficiência de corrente é facilmente identificado o melhor momento para substituição da célula, bastando incluir no cálculo do ganho financeiro o custo de substituição da célula dividido pelo tempo de operação.

Como era esperado, o aumento da intensidade de corrente produz incremento no ganho financeiro, mostrando ainda que, mesmo quando há alteração de outras variáveis, esta relação de proporcionalidade não sofre influência significativa.

Resumindo, o presente trabalho mostra que a modelagem e otimização via redes neutrais de um processo de produção de cloro e soda tipo diafragma, apresentaram resultados indicando que os modelos obtidos podem simular os processos de eletrólise e evaporação, como também identificar as melhores condições de operação do ponto de vista de maximizar o ganho financeiro nas duas etapas principais do processo estudado.

Como trabalhos futuros para prosseguimento deste estudo podemos citar : - melhoria dos modelos de RN a partir de uma maior base de dados; - evoluir para um modelo fenomenológico a partir de uma célula piloto; 
- aprimorar os modelos de RN representando circuitos de células, com a inclusão de outras variáveis não contempladas neste estudo, como também partir de uma base de dados com maior precisão nas leituras. 


\section{REFERÊNCIAS BIBLIOGRÁFICAS}

ALVES, R.M.B. Otimização de um processo de produção de isopreno via redes neurais. Escola Politécnica da Universidade de São Paulo. Departamento de Engenharia Química. São Paulo, 2003. Tese de Doutorado.

ALVES, R.M.B., NASCIMENTO, C.A.O. Gross error detection of industrial data by neural network and clusters techniques. Brazilian Journal of Chemical Engineering, 19 (4): 483-489, 2002.

BHAT, N.V.; MCAVOY, T. Use of neural nets for dynamic modeling and control of chemical process systems. Computers \& Chemical Engineering, 14 (4/5), p. 573-583, 1990.

BHAT, N.V.; MINDERMAN JR, P.A.; MCAVOY, T.; WANG, N. S. Modeling chemical process systems via neural computation, IEEE Control Systems Magazine, 4 p. 24-30, 1990.

DIAMOND, S.C. Caustic Soda Handbook, USA,1973.

ELTECH SYSTEMS CORPORATION. Technical Data Manual, Ohio, 1982.

GARDINER, W.C. Electrochemical. Technology. 1, 71, 1963.

GOB, S.; OLIVEROS, E.; BOSSMAN, S.H.; BRAUN, A.M.; GUARDANI, R.; NASCIMENTO, C.A.O. Optimization of the photochemically enhaced Fenton oxidation of 2,4-dimethylaniline applying artificial neural networks. Journal Inf. Recording, 25: 447-454, 2000.

GRAY, A.; WALLACE, G.A. Principles and Practice of Eletrical Engineering, $7^{\text {a }}$ edition, Mc Graw Hill Book Company; Inc., EEUU, 1958. 
GUARDANI, R.; NASCIMENTO, C.A. O.; ONIMARU, R.S. Use of neural networks in the analysis of particle size distribution by laser diffraction: tests with different particle systems. Powder Technology, 126 (1): 42-50, 2002.

GUARDANI, R.; NASCIMENTO, C. A. O. Neural network-based study for predicting groud-level ozone concentration in large urban áreas, applied to the Metropolitan Area. Int. J. Environmental Pollution, 2003.

GUARDANI, R.; AGUIAR, J.L.; NASCIMENTO, C. A. O.; LACAVA, C.I.V; YANAGI, Y. Ground-level ozone mapping in large urban áreas using multivariate statistical analysis: application to the São Paulo Metropolitan Area. J. Air and Waste Management Association., 53: 553-559, 2003.

HINE, F.. Handbook of Chlor-Alkali Technology, Springer, New York, 2004

HINE, F.. Electrode Processes and Electrochemical Engineering, Plenum Press, New York, 1985.

HOSKINS, J. C.; HIMMELBLAU, D. M. Artificial neural network models of knowledge representation in chemical engineering, Computers \& Chemical Engineering, v. 12(9/19), p. 881-890, 1988.

HOSKINS, J. C.; HIMMELBLAU, D. M. Fault detection and diagnosis using artificial neural networks, In Artificial Intelligence in Process Engineering, (M. L. Mavrovouniots, ed.), N.Y., Academic Press, p 123-160, 1990.

HUNT, J.K.; SBARBARO, D.; ZBIKOWSKI, R.; GAWTHROP, P.J. Neural networks for control systems - A survey, Automatica, Vol. 28 (6), p 1083$1112,1992$.

JOHNSON, R.A., D.W.WICHERN. Applied Multivariate Statistical Analysis, Prentice Hall, New Jersey, 1998. 
LOPES, M.D. A importância das inovações tecnológicas e a indústria de cloro-soda. GETIQ, São Paulo, 2003. Monografia de especialização.

KERN, D. Q. Process Heat Transfer, McGraw-Hill Book Company, Inc, New York, 1950.

KNOWLTON, A.E. Standard Handbook for Electrical Engineers, $7^{\text {a }}$ edition, McGraw-Hill Book Company, Inc., New York, 1941.

MacMULLIN, R.B.; MILLS, K.L.; RUEHLEN, F.N. Journal of Electrochemistry Society.,118, 1582, 1971.

McCABE, WARREN L.; SMITH, JULIAN C., Unit Operations of Chemical Engineering, $3^{\text {a }}$ edição, McGraw-Hill Book Company, Inc., New York, 1976.

NASCIMENTO, C.A.O., GIUDICI, R., GUARDANI, R. Neural network based approach for optimization of industrial chemical processes. Computers and Chemical Engineering 24 (2000) 2303-2314.

NASCIMENTO, C.A.O., GUARDANI, R. Programas PREP e NEURO 16 B documentação LSCP - Laboratório de Simulação e Controle de Processos, EPUSP, São Paulo,2000.

NASCIMENTO, C.A.O.; GIUDICI, R.; SCHERBAKOFF, N. Modeling of industrial nylon-6,6 polymerization process in a twin-screw extruder reactor. II. Neural networks and bybrid models. Journal of Applied Polymer Science, 72: 905$912,1999 \mathrm{a}$

PERRY, John H., Chemical Engineers Handbook, $3^{\text {a }}$ edition, McGraw-Hill Book Company, Inc., New York, 1950.

PSICHOGIOS, D. C.; UNGAR, L. H. Direct and indirect model based control using artificial neural networks, Ind. Eng. Chem. Res., v. 30, p. 2564-2573, 1991. 
RUMELHART, D.; MCCLELLAND, J. Parallel distributed processing explorations in the microstruture of cognition, v. 1, cap. 8, MIT, Cambridge, Mass., 1986.

SCONCE, J.S. Chlorine - Its Manufacture, Properties And Uses, Robert E. Krieger Publishing Co., Inc., New York, 1962.

SU, H. T.; MCAVOY, T.; WERBOS, P. Long-term predictions of chemical processes using recurrent neural networks: A parallel training approach., Ind. Eng. Chem. Res., v. 31, p. 1338-1352, 1992.

TATIBANA, C.Y.; KAETSU, D.Y. Redes Neurais. Disponível em www.din.uem.br/ia/neurais. Acesso em 30.jan.2006

TOBIAS, C.W. Journal Electrochem. Soc. , 106, 833, 1959.

UNGAR, L. H.; POWELL, B. A.; KAMENS, S. N. Adaptative networks for fault diagnosis and process control, Computers \& Chemical Engineering, v. $\underline{14}(4 / 5)$, p. $651-572,1990$.

VENKATASUBRAMANIAM, V.; VAIDYANATHAN, R; YAMAMOTO, Y. Process fault detection and diagnosis using neural networks - I. Steady state process, Computers \& Chemical Engineering, v. 14(7), p. 699-712, 1990.

WATANABE, K.; MATSURA, I.; KUBOTA, M.; HIMMELBLAU, D. M.; Incipient fault diagnosis of chemical processes via artificial neural networks, Aiche Journal, v. 35(11), p. 1803-1812, 1989.

\section{BIBLIOGRÁFICAS CONSULTADAS}

DE LA RUE, R.E.; TOBIAS, C. Journal of Electrochemistry Society,106, 827, 1959. 
GLASSTONE, SAMUEL Tratado de Química Física, 2a edition, D. Van Nostrand Company, Inc., New York, 1957.

HODGMAN, C. D., Handbook of Chemistry and Physics, the Chemical Rubber Publishing CO., $4^{\mathrm{a}}$ edition, Ohio, 1962.

JOSEPH, B.; WANG, F.H.; SHIEH, D.S.S. Exploratory data analysis: a comparison of statistical methods with artificial neural networks. Computers \& Chemical Engineering, v. 16(4), p. 413-423, 1992.

KOVÁCS, Z.L. Redes Neurais Artificiais: fundamentos e aplicações. Acadêmica, São Paulo, 1996.

MOORE, W. J.; Physical Chemistry, $4^{\mathrm{a}}$ edition, Prentice-Hale Englewood Cliffs, N.J., 1963.

NELSON, M.M.; ILLINGWORTH, W.T. A Practical Guide to Neural Nets, Addison-Wesley Publishing Company, 1991.

POLLARD, J. F.; BROUSSARD, M. R.; GARRISON, D. B.; SAN, K. Y.; Process identification using neural networks, Computers \& Chemical Engineering, v. $\underline{16}(4)$, p. 253-270, 1992.

SHEREVE, R. NORRIS; BRINK JR, Joseph A. Indústria de Processos Químicos, $4^{\mathrm{a}}$ edição, McGraw-Hill, New York, 1977.

SHARMA, S.; Applied Multivariate Techniques, John Wiley \& Sons, New York, 1996. 
ANEXO I

\section{MODELO FENOMENOLÓGICO PARA UNIDADE DE EVAPORAÇÃO}

De acordo com fluxograma de processo simplificado da unidade de evaporação, figura 1, foram estabelecidas relações para determinação do consumo de vapor.

Para desenvolvimento deste estudo foram adotadas as seguintes nomenclaturas:

Massa de sal retirada no $1^{\circ}$ efeito $=S a l_{1}$

Massa de sal retirada no $2^{\circ}$ efeito $=\mathrm{Sal}_{2}$

Massa de sal retirada no $3^{\circ}$ efeito $=\mathrm{Sal}_{3}$

Massa de sal retirada no Flash $=S_{F}$

Vazão de Condensado Primário do $1^{\circ}$ efeito $=C P_{1}$

Vazão de Condensado Secundário $2^{\circ}$ efeito $=C S_{1}$

Vazão de Condensado Secundário $3^{\circ}$ efeito $=C S_{2}$

Vazão de Licor Entrada $1^{\circ}$ efeito $=L E_{1}$

Vazão de Licor Entrada $2^{\circ}$ efeito $=L E_{2}$

Vazão de Licor Entrada $3^{\circ}$ efeito $=L E_{3}$

Vazão de Soda Liquida Concentrada $=S C$

Vazão de Soda Liquida Diluída $=S$

Vazão de Vapor Primário $1^{\circ}$ efeito $=V P_{1}$

Vazão de Vapor Secundário $1^{\circ}$ efeito $=V S_{1}$

Vazão de Vapor Secundário $2^{\circ}$ efeito $=V S_{2}$

Vazão de Vapor Secundário $3^{\circ}$ efeito $=V S_{3}$ 
Vazão de Vapor Secundário efeito Flash $=V S_{F}$

A equação de balanço de massa global para o licor é definida por:

$L E_{3}=V S_{3}+C S_{1}+C S_{2}+S C+S a l_{1}+S a l_{2}+S a l_{3}+S a l_{F}$

como

$C S_{1}=V S_{1}$ e $C S_{2}=V S_{2}$

tem-se,

$L E_{3}=V S_{3}+V S_{1}+V S_{2}+V S_{F}+S C+S a l_{1}+S a l_{2}+S a l_{3}+S a l_{F}$

Balanço de massa global para o vapor:

$V P_{1}=C P_{1}$

Com o balanço de energia global licor-vapor define-se a equação para o consumo de vapor primário,

$$
\begin{aligned}
V P_{1}= & \left(V S_{3} * H_{V S_{3}}+V S_{F} * H_{V S_{F}}+V S_{2} * H_{C S_{3}}+V S_{1} * H_{C S_{2}}+S C * H_{S C}+S a l_{1} * H_{S a l_{1}}+\right. \\
& \left.+S a l_{2} * H_{S a l_{2}}+S a l_{3} * H_{S a l_{3}}+S a l_{F} * H_{S a l_{F}}-L E_{3} * H_{L E_{3}}+P\right) /\left(H_{V P_{1}}-H_{C P_{1}}\right)
\end{aligned}
$$

Em que $H$ é a entalpia do componente ou solução nas diversas correntes do sistema. Por exemplo, $H_{V S_{3}}$ é a entalpia do vapor secundário do evaporador do $3^{\circ}$ efeito, $H_{S}$ é a entalpia do licor na saída do evaporador do $1^{\circ}$ efeito, e assim por diante. O termo $P$ é a quantidade de energia perdida pelo sistema em forma de calor.

Das variáveis que compõem a equação, têm seus valores conhecidos pelo processo direta ou indiretamente apenas as variáveis $S C$ e $L E_{3}$.

Realizando o balanço de massa global e por componente para cada um dos evaporadores contemplados no sistema licor, obtemos as seguintes relações: 


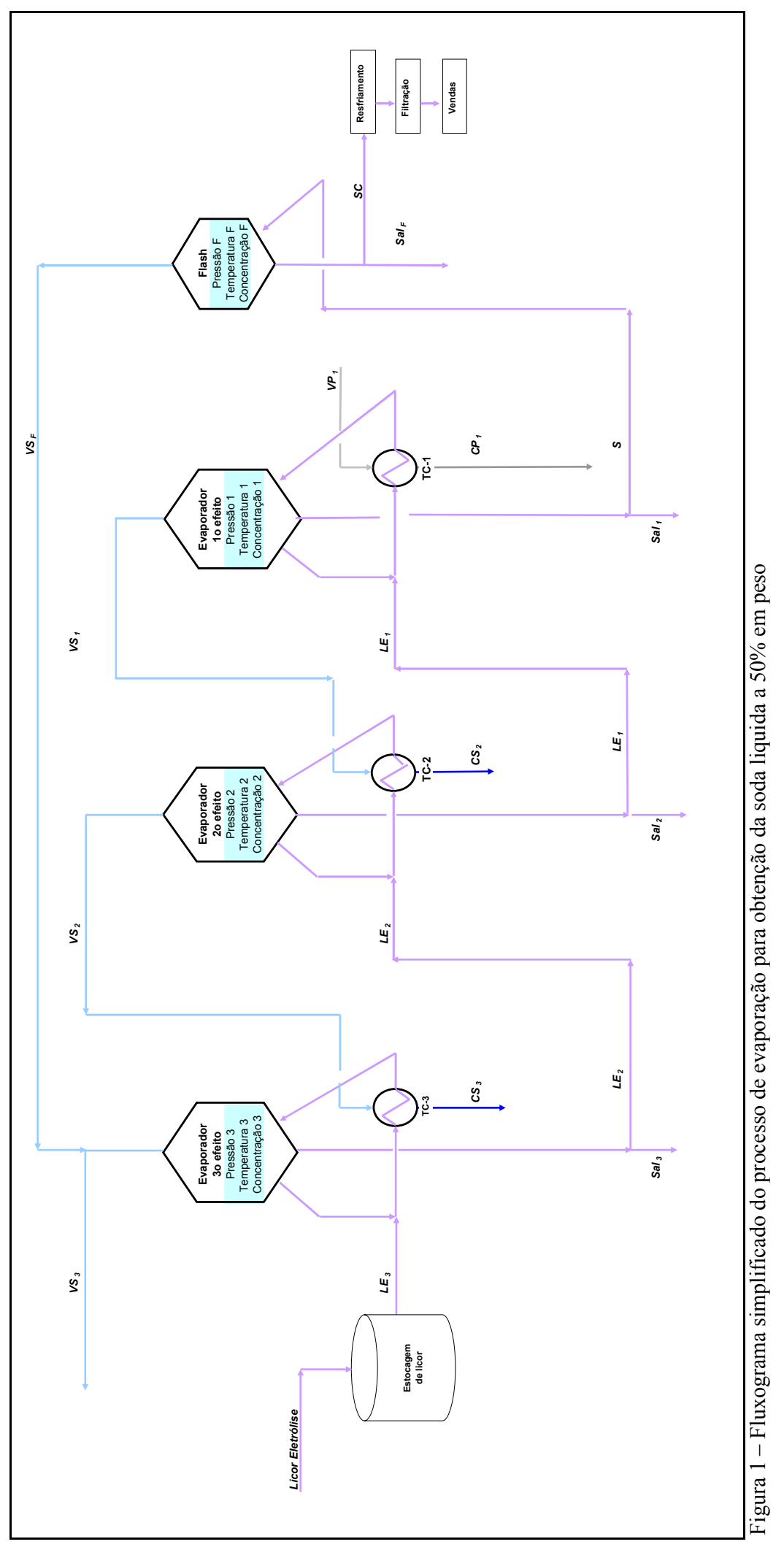


Flash

Balanço de massa para água:

$\mathrm{S} * \% \mathrm{H}_{2} \mathrm{O}_{S}=\mathrm{VS}_{\mathrm{F}}+\mathrm{Sal}_{\mathrm{F}} * \% \mathrm{H}_{2} \mathrm{O}_{S l_{F}}+\mathrm{SC} * 0 \mathrm{H}_{2} \mathrm{O}_{S \mathrm{C}}$

As variáveis porcentuais referem-se à fração porcentual de um dado componente em uma determinada corrente do processo. Por exemplo, $\% \mathrm{H}_{2} \mathrm{O}_{\mathrm{S}}$ corresponde à fração porcentual da água na corrente $\mathrm{S}, \mathrm{H}_{2} \mathrm{O}_{L E_{1}}$ corresponde à fração porcentual da água na corrente $L E_{1}$, e assim por diante.

Balanço de massa para a soda:

$S * \% \mathrm{NaOH}_{S}=\mathrm{Sal}_{F} * \% \mathrm{NaOH}_{S a l_{F}}+\mathrm{SC} * \% \mathrm{NaOH}_{S C}$

Balanço de massa para o sal:

$S * \% \mathrm{NaCl}_{S}=S a l_{F} * \% \mathrm{NaCl}_{\mathrm{Sal}_{F}}+S C * \% N a C l_{S C}$

As relações obtidas das equações para o efeito Flash são as seguintes:

$$
\begin{aligned}
& S a l_{F}= \frac{S C *\left(\% \mathrm{NaOH}_{S} * \% \mathrm{NaCl}_{S C}-\% \mathrm{NaOH}_{S C} * \% \mathrm{NaCl}_{S}\right)}{\left(\% \mathrm{NaOH}_{\mathrm{Sal}_{F}} * \% \mathrm{NaCl}_{S}-\% \mathrm{NaOH}_{S} * \% \mathrm{NaCl}_{S a l_{F}}\right)} \\
& S=\left(\left(\frac{S C *\left(\% \mathrm{NaOH}_{S} * \% \mathrm{NaCl}_{S C}-\% \mathrm{NaOH}_{S C} * \% N a C l_{S}\right.}{\% \mathrm{NaOH}_{\mathrm{Sal}_{F}} * \% N a C l_{S}-\% \mathrm{NaOH}_{S} * \% N a C l_{S a l_{F}}}\right) *\right. \\
&\left.* \% \mathrm{NaCl}_{S a l_{F}}+S \mathrm{SC} \% \mathrm{NaCl} l_{S C}\right) /\left(\% \mathrm{NaCl}_{S}\right)
\end{aligned}
$$

Utilizando o balanço de massa licor no efeito Flash define-se $V S_{\mathrm{F}}$ em função das variáveis já calculadas $S_{a l}$ e $\mathrm{S}$, equações 9 e 10 respectivamente: 
$V S_{F}=S-S a l_{F}-S C$

$1^{\mathrm{o}}$ efeito

Balanço de massa para a água:

$L E_{1} * \% H_{2} O_{L E_{1}}=V S_{1}+S a l_{1} * \% H_{2} O_{S a l_{1}}+S * \% H_{2} O_{S}$

Balanço de massa para a soda:

$L E_{1} * \% \mathrm{NaOH}_{L E_{1}}=\mathrm{Sal}_{1} * \% \mathrm{NaOH} \mathrm{Sal}_{1}+\mathrm{S} * \% \mathrm{NaOH}_{S}$

Balanço de massa para o sal:

$L E_{1} * \% \mathrm{NaCl}_{L E_{1}}=S a l_{1} * \% \mathrm{NaCl}_{S a l_{1}}+\mathrm{S} * \% \mathrm{NaCl} l_{S}$

As relações obtidas das equações para o evaporador do $1^{\circ}$ efeito são as seguintes:

$$
\begin{aligned}
S a l_{1} & =\frac{S *\left(\% N a O H_{L E_{1}} * \% N a C l_{S}-\% N a O H_{S} * \% N a C l_{L E_{1}}\right)}{\left(\% N a O H_{S a l_{1}} * \% N a C l_{L E_{1}}-\% N a O H_{L E_{1}} * \% N a C l_{S a l_{1}}\right)} \\
L E_{1} & =\left(\left(\frac{S *\left(\% N a O H_{L E_{1}} * \% N a C l_{S}-\% N a O H_{S} * \% N a C l_{L E_{1}}\right.}{\% N a O H_{S a l_{1}} * \% N a C l_{L E_{1}}-\% N a O H_{L E_{1}} * \% N a C l_{S a l_{1}}}\right) *\right. \\
& \left.* \% N a C l_{S a l_{1}}+S * \% N a C l_{S}\right) /\left(\% S a l_{L E_{1}}\right)
\end{aligned}
$$

Em que $S$ é conhecida quando do balanço do efeito flash, equação 8-10.

Utilizando o balanço de massa licor neste evaporador define-se $V S_{1}$ em função das variáveis já calculadas $S a l_{1}$ e $L E_{1}$, equações 15 e 16 respectivamente: 
$V S_{1}=L E_{1}-S a l_{1}-S$

$2^{\circ}$ efeito

Balanço de massa para a água:

$L E_{2} * \% H_{2} O_{L E_{2}}=V S_{2}+S a l_{2} * \% H_{2} O_{S a l_{2}}+L E_{1} * \% H_{2} O_{L E_{1}}$

Balanço de massa para a soda:

$L E_{2} * \% \mathrm{NaOH}_{\mathrm{LE}_{2}}=\mathrm{Sal}_{2} * \% \mathrm{NaOH} \mathrm{Sal}_{2}+\mathrm{LE}_{1} * \% \mathrm{NaOH} \mathrm{LE}_{1}$

Balanço de massa para o sal:

$L E_{2} * \% \mathrm{NaCl}_{\mathrm{LE}_{2}}=\mathrm{Sal}_{2} * \% \mathrm{NaCl} \mathrm{Sal}_{2}+L E_{1} * \% \mathrm{NaCl} l_{L E_{1}}$

As variáveis $L E_{1}$ e $S a l_{2}$ são obtidas pelas expressões

$\mathrm{Sal}_{2}=\frac{L E_{1} *\left(\% \mathrm{NaOH}_{L E_{2}} * \% \mathrm{NaCl}_{L E_{1}}-\% \mathrm{NaOH}_{L E_{1}} * \% \mathrm{NaCl}_{L E_{2}}\right)}{\left(\% \mathrm{NaOH} \mathrm{Sal}_{2} * \% \mathrm{NaCl}_{L E_{2}}-\% \mathrm{NaOH}_{L E_{2}} * \% \mathrm{NaCl}_{S a l_{2}}\right)}$

e

$\begin{aligned} L E_{2} & =\left(\left(\frac{L E_{1} *\left(\% \mathrm{NaOH}_{L E_{2}} * \% \mathrm{NaCl}_{L E_{1}}-\% \mathrm{NaOH}_{L E_{1}} * \% \mathrm{NaCl}_{L E_{2}}\right)}{\left(\% \mathrm{NaOH}_{\mathrm{Sal}_{2}} * \% \mathrm{NaCl}_{L E_{2}}-\% \mathrm{NaOH}_{L E_{2}} * \% \mathrm{NaCl}_{\mathrm{Sal}_{2}}\right)}\right) *\right. \\ & \left.* \% \mathrm{NaCl} l_{S l_{2}}+L E_{1} * \% \mathrm{NaCl}_{L E_{1}}\right) /\left(\% \mathrm{Sal}_{L E_{2}}\right)\end{aligned}$ $\left.* \% \mathrm{NaCl}_{S a l_{2}}+L E_{1} * \% \mathrm{NaCl} l_{L E_{1}}\right) /\left(\% \mathrm{Sal}_{L E_{2}}\right)$

Em que $L E_{1}$ é conhecida pelo balanço do evaporador do $1^{\circ}$ efeito, equação 14 .

Pelo balanço de massa no licor calcula-se a variável $V S_{2}$ em função das variáveis já conhecidas $L E_{1}, S a l_{2}, L E_{2}$, equações 16,21 e 22 respectivamente. 
$V S_{2}=L E_{2}-S a l_{2}-L E_{1}$

$3^{\circ}$ efeito

Balanço de massa para a água:

$L E_{3} * \% \mathrm{H}_{2} \mathrm{O}_{L E_{3}}=\mathrm{VS}_{3}+\mathrm{Sal}_{3} * \% \mathrm{H}_{2} \mathrm{O}_{\mathrm{Sal}_{3}}+\mathrm{LE}_{2} * \% \mathrm{H}_{2} \mathrm{O}_{L E_{2}}$

Balanço de massa para a soda:

$L E_{3} * \% \mathrm{NaOH}_{\mathrm{LE}_{3}}=\mathrm{Sal}_{3} * \% \mathrm{NaOH}_{\mathrm{Sal}_{3}}+\mathrm{LE}_{2} * \% \mathrm{NaOH} \mathrm{LE}_{2}$

Balanço de massa para o sal:

$L E_{3} * \% \mathrm{NaCl}_{\mathrm{LE}_{3}}=\mathrm{Sal}_{3} * \% \mathrm{NaCl}_{\mathrm{Sal}_{3}}+L E_{2} * \% \mathrm{NaCl}_{L E_{2}}$

As variáveis $L E_{1}$ e $S a l_{2}$ são obtidas pelas expressões

$\mathrm{Sal}_{3}=\frac{\mathrm{LE}_{2} *\left(\% \mathrm{NaOH}_{\mathrm{LE}_{3}} * \% \mathrm{NaCl}_{\mathrm{LE}_{2}}-\% \mathrm{NaOH}_{\mathrm{LE}_{2}} * \% \mathrm{NaCl}_{\mathrm{LE}_{3}}\right)}{\left(\% \mathrm{NaOH}_{\mathrm{Sal}_{3}} * \% \mathrm{NaCl}_{\mathrm{LE}_{3}}-\% \mathrm{NaOH}_{L E_{3}} * \% \mathrm{NaCl}_{\mathrm{Sal}_{3}}\right)}$

e

$$
\begin{aligned}
L E_{3}= & \left(\left(\frac{\mathrm{LE}_{2} *\left(\% \mathrm{NaOH}_{\mathrm{LE}_{3}} * \% \mathrm{NaCl}_{\mathrm{LE}_{2}}-\% \mathrm{NaOH}_{L E_{2}} * \% \mathrm{NaCl}_{\mathrm{LE}_{3}}\right)}{\left(\% \mathrm{NaOH}_{\mathrm{Sal}_{3}} * \% \mathrm{NaCl}_{\mathrm{LE}_{3}}-\% \mathrm{NaOH}_{L E_{3}} * \% \mathrm{NaCl}_{\mathrm{Sal}_{3}}\right)}\right) *\right. \\
& \left.* \% \mathrm{NaCl}_{\mathrm{Sal}_{3}}+\mathrm{LE}_{2} * \% \mathrm{NaCl}_{L E_{2}}\right) /\left(\% \mathrm{Sal}_{L E_{3}}\right)
\end{aligned}
$$

Em que $L E_{2}$ é conhecida quando do balanço do evaporador do $2^{\circ}$ efeito, equação 22 .

Pelo balanço de massa do licor calcula-se $V S_{3}$ em função das variáveis já conhecidas $L E_{2}, \mathrm{Sal}_{3} e L E_{3}$, e equações 22,27 e 28 respectivamente. 
$V S_{3}=L E_{3}-S a l_{3}-L E_{2}$

Desta forma, as variáveis $\mathrm{Sal}_{1}, \mathrm{Sal}_{2}, \mathrm{Sal}_{3}, \mathrm{Sal}_{\mathrm{F}}, V S_{1}, V S_{2}, V S_{3}$ e $V S_{\mathrm{F}}$ são calculadas a partir da corrente " $S C$ " e dos porcentuais de cada componente nas diversas correntes do processo. Logo para o consumo de vapor $V P_{1}$, equação 5 , fica dependendo apenas determinar o valor de perda de calor na unidade,$P$.

Para calcular a variável $P$, utiliza-se valores obtidos no processo a partir das variáveis medidas, como $V P_{1}$ e $S C$, e de valores tabelados de entalpia nas várias correntes.

Entretanto, os valores de entalpia dependem da composição de cada uma das correntes do processo, cujas composições não são conhecidas, mas que podem ser obtidas através de consultas em tabelas relativas a propriedades físicas de solução de $\mathrm{NaOH}$ saturada em sal, Diamond (1973).

Uma vez determinado o valor de perda de calor, $P$, definimos a função objetivo para determinação do consumo de vapor,equação 5 , admitindo que a quantidade de perda de calor é constante no processo. 

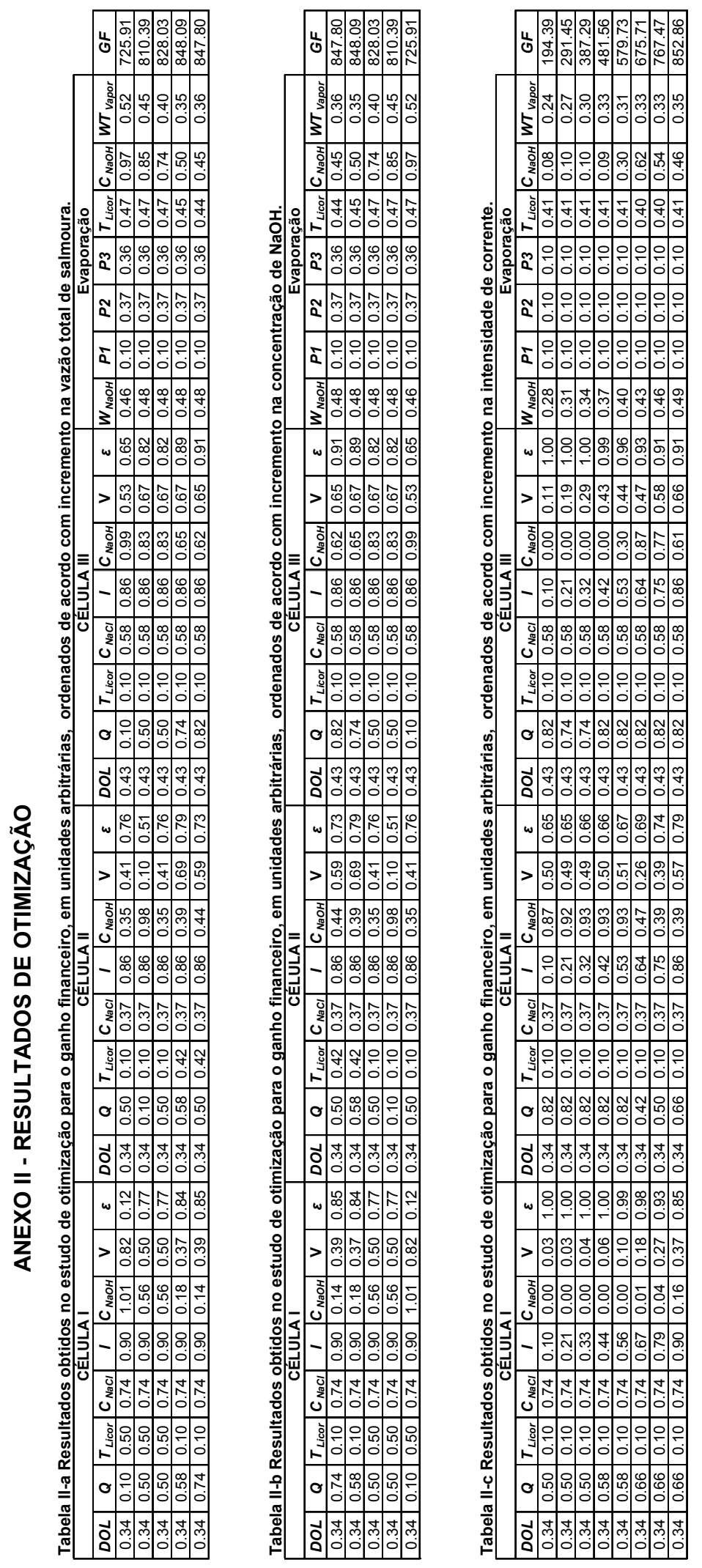